Aus der Poliklinik für Prothetik

(Komm. Leiter: PD. Dr. med. dent. N. Gersdorff)

im Zentrum Zahn-, Mund- und Kieferheilkunde

der Medizinischen Fakultät der Universität Göttingen

\title{
Replikation, Differenzierbarkeit und Proteinausstattung von Klonen chondrogener Progenitorzelllinien
}

\author{
INAUGURAL - DISSERTATION \\ zur Erlangung des Doktorgrades für Zahnheilkunde \\ der Medizinischen Fakultät \\ der Georg-August-Universität zu Göttingen
}

vorgelegt von

Tolga Raoul Kizildere

aus

Wolfenbüttel

Göttingen 2013 
Dekan:

Prof. Dr. rer. nat. H. K. Kroemer

I. Berichterstatter: Prof. Dr. med. N. Miosge

II. Berichterstatter/in: $\quad$ Prof. Dr. med. Dr. med. dent. K. G. Wiese

III. Berichterstatter/in:

Tag der mündlichen Prüfung: 10.02.2014 


\section{Inhaltsverzeichnis}

Abbildungsverzeichnis V

Tabellenverzeichnis VI

Abkürzungsverzeichnis VII

1. Einleitung 1

1.1 Osteoarthrose: Ätiologie und Pathogenese 2

1.2 Der Gelenkknorpel

1.2.1 Aufbau des hyalinen Gelenkknorpels

1.2.2 Osteoarthrotische Veränderungen des Gelenkknorpels

1.2.3 Knorpelregeneration 3 3

1.3 Stammzellen

1.3.1 Embryonale Stammzellen

1.3.2 Adulte mesenchymale Stammzellen

1.3.3 Stammzellen und ihre „Nische“

1.3.3.1 Nische der hämatopoetischen Stammzellen

1.3.3.2 Nische der mesenchymalen Stammzellen

1.3.4 Plastizität von Stammzellen: Symmetrische und asymmetrische Teilung

1.3.4.1 Plastizität und Trans-Differenzierung

1.3.5 Migrierende chondrogene Progenitorzellen 5

1.4 Ziel der Arbeit 9

\section{Material und}

2.1 Material

$\begin{array}{lr}\text { 2.1.1 Chemikalien } & 22 \\ \text { 2.1.2 Reagenzien } & 23 \\ \text { 2.1.3 Medien und Lösungen } & 28 \\ \text { 2.1.4 Verbrauchsmaterialien_räte } & 29 \\ \text { 2.1.5 Geräte } & 30\end{array}$

2.2 Methoden 30

2.2.1 Probenmaterial _ 30

2.2.1.1 Osteoarthrotischer Knorpel __ 30

2.2.1.2 Aufarbeitung des Knorpelgewebes __ 31

2.2.1.3 Zellkultur

2.2.2. Immortalisierung __ 33

2.2.3. Klonierung___ 33

2.2.4 Replikationsassay __ 34

2.2.5 Zelldifferenzierung __ 34

2.2.5.1 Adipogene Differenzierung___ 34

2.2.5.2 Osteogene Differenzierung ___ 35

2.2.5.3 Kontrollpopulation___ 35

2.2.6 Oil-Red-Färbung ___ 36

2.2.7 Alkalische-Phosphatase-Färbung ___ 36

2.2.8 Immunfluoreszenzzytochemie ___ 37

$\begin{array}{lr}\text { 2.2.8.1 Zur Methode } & 37 \\ \text { 2.2.8.2 Primäre Antikörper } & 38 \\ \text { 2.2.8.3 Sekundäre Antikörper } & 38 \\ \text { 2.2.8.4 Durchführung } & 39\end{array}$


2.2.9 Western-Blot 39

2.2.9.1 Zur Methode 39

2.2.9.2 Probenaufbereitung 2.2.9.3 SDS-PAGE

2.2.9.4 Coomassie-Brilliant-Blau-Färbung

2.2.9.5 Western-Blot

2.2.9.6 Immunreaktion auf PVDF-Membran

2.2.9.6.1 Primäre Antikörper

2.2.9.6.2 Sekundäre Antikörper

2.2.9.6.3 Durchführung

3. Ergebnisse

3.1 Klone in 2D-Flaschenkultur 46

3.2 Ergebnisse des Replikationsassays

3.3 Ergebnisse der Differenzierung

3.3.1 Klon-IF-8

3.3.2 Klon-IIB-6

3.3.3 Klon-IID-4

50

52

3.4 Oil-Red-Färbung 53

3.5 Alkalische-Phosphatase 54

3.6 Immunfluoreszenzzytochemie

3.6.1 Klon-IF-8

56

3.6.2 Klon-IIB-6 57

3.6.3 Klon-IID-4 58 59

3.7 Western-Blot 61

3.7.1 Runx-2

3.7.2 Sox-9

4. Diskussion

4.1 Diskussion zur Methode

64

4.1.1 Proliferationsassay

4.1.2 Zelldifferenzierung

4.1.3 Immunfluoreszenzzytochemie 64

4.1.4 Western-Blot

66

4.2 Diskussion der Ergebnisse

67

4.2.1 Phänotypen

4.2.2 Proliferationsassay und Differenzierungsnachweis 68

4.2.3 Western-Blot

4.2.4 Charakteristika migrierender CPCs

68

70

70

71

5. Zusammenfassung 74

6. Literaturverzeichnis 76 


\section{Abbildungsverzeichnis}

Abbildung 1: Osteoarthrose am Condylus des Femur 2

Abbildung 2: Zonen des Gelenkknorpels 4

Abbildung 3: Schema der Hämatopoese 13

Abbildung 4: Teilungsmuster der Stammzellen 16

Abbildung 5: Theorie über die Plastizität der Stammzellen 18

Abbildung 6: Klon-IF-8

Abbildung 7: Klon-IIB-6 47

Abbildung 8: Klon-IID-4 47

Abbildung 9: Wachstumsdiagramm 49

Abbildung 10: Klon-IF-8: $1 \times 10^{3}$-adipogen Abbildung 12: Klon-IF-8: $1 \times 10^{3}$-osteogen Abbildung 14: Klon-IIB-6: $1 \times 10^{3}$-adipogen Abbildung 16: Klon-IIB-6: $1 \times 10^{3}$-osteogen Abbildung 18: Klon-II-4: $1 \times 10^{3}$-adipogen Abbildung 20: Klon-IID-4: $1 \times 10^{3}$-osteogen Abbildung 22: Klon-IF-8: Oil-Red

Abbildung 24: Klon-IIB-6: Oil-Red Abbildung 26: Klon-IID-4: Oil-Red Abbildung 28: Klon-IF-8: AP-Färbung Abbildung 30: Klon-IIB-6: AP-Färbung Abbildung 32: Klon-IID-4: AP-Färbung Abbildung 34: IF-8-LPL Abbildung 36: IF-8-PPAR $\gamma$ Abbildung 38: IF-8-Osteocalcin Abbildung 40: IF-8-runx-2 Abbildung 42: IIB-6-LPL Abbildung 44: IIB-6-PPAR $\gamma$ Abbildung 46: IIB-6-Osteocalcin Abbildung 48: IIB-6-runx-2 Abbildung 50: IID-4-LPL Abbildung 52: IID-4-PPAR $\gamma$ Abbildung 54: IID-4-Osteocalcin Abbildung 56: IID-4-runx-2 Abbildung 11: Klon-IF-8: $3 \times 10^{3}$-adipogen__ 50 Abbildung 13: Klon-IF-8: $1 \times 10^{3}$-osteogen__ 50 Abbildung 15: Klon-IIB-6: $3 \times 10^{3}$-adipogen _ 51 Abbildung 17: Klon-IIB-6: $3 \times 10^{3}$-osteogen _ 51 Abbildung 19: Klon-IID-4: $3 \times 10^{3}$-adipogen _ 52 Abbildung 21: Klon-IID-4: $3 \times 10^{3}$-osteogen _ 53 Abbildung 23: Klon-IF-8: Oil-Red-Kontrolle _ 53 Abbildung 25: Klon-IIB-6: Oil-Red-Kontrolle _ 54 Abbildung 27: Klon-IID-4: Oil-Red-Kontrolle_ 54 Abbildung 29: Klon-IF-8: AP-Kontrolle 55

Abbildung 31: Klon-IIB-6: AP-Kontrolle___ 55

Abbildung 33: Klon-IID-4 AP-Kontrolle __ 56

Abbildung 35: IF-8-LPL-Kontrolle ___ 57

Abbildung 37: IF-8-PPAR $\gamma$-Kontrolle __ 57

Abbildung 39: IF-8-Osteocalcin-Kontrolle___ 57

Abbildung 41: IF-8-runx-2-Kontrolle __ 58

Abbildung 43: IIB-6-LPL-Kontrolle __ 58

Abbildung 45: IIB-6-PPAR $\gamma$-Kontrolle ___ 58

Abbildung 47: IIB-6-Osteocalcin-Kontrolle _ 59

Abbildung 49: IIB-6-runx-2-Kontrolle _ 59

Abbildung 51: IID-4-LPL-Kontrolle _ 59

Abbildung 53: IID-4-PPAR $\gamma$-Kontrolle __ 60

Abbildung 55: IID-4-Osteocalcin-Kontrolle _ 60

Abbildung 57: IID-4-runx-2-Kontrolle __ 60

Abbildung 58: Western-Blot: runx-2 __ 61

Abbildung 59: Western-Blot: sox-9 _ 62 


\section{Tabellenverzeichnis}

Tabelle 1: Chemikalien __ 22

Tabelle 2: Verbrauchsmaterialien ___ 29

Tabelle 3: Geräte __ 30

Tabelle 4: Probenaufbereitung für SDS-PAGE ___ 41

Tabelle 5: Zusammensetzung der Gele für SDS-PAGE ___ 42 


\section{Abkürzungsverzeichnis}

\begin{tabular}{|c|c|}
\hline Abb. & Abbildung \\
\hline AK & Antikörper \\
\hline AMPD & 2-Amino-2-methyl-1,3-propandiol \\
\hline AP & Alkalische-Phosphatase \\
\hline APS & Ammoniumperoxidsulfat \\
\hline aqua dest. & aqua destillata \\
\hline ARCs & Adventitial reticular cells \\
\hline BMP & bone morphogenetic protein \\
\hline BSA & bovine serum albumin \\
\hline bzw. & beziehungsweise \\
\hline${ }^{\circ} \mathrm{C}$ & Grad Celsius \\
\hline ca. & circa \\
\hline C/EBP & CCAAT/enhancer-binding-proteine \\
\hline CD & cluster of differentiation \\
\hline CFU-F & colony forming unit-fibroblast \\
\hline $\mathrm{cm}$ & Zentimeter \\
\hline $\mathrm{cm}^{2}$ & Quadratzentimeter \\
\hline $\mathrm{CO}_{2}$ & Kohlendioxid \\
\hline CPCs & chondrogene Progenitorzellen \\
\hline CXCL12 & CXC-Motiv-Chemokin 12 \\
\hline $2 \mathrm{D}$ & zweidimensional \\
\hline DAPI & 4,6-Diamidin-2-phenylindol \\
\hline $\mathrm{DE}$ & Deutschland \\
\hline $\mathrm{DG}$ & Deckglas \\
\hline DMEM & Dulbecco's Modified Eagle Medium \\
\hline DMSO & Dimethylsulfoxid \\
\hline DNS & Desoxyribonukleinsäure \\
\hline
\end{tabular}




\begin{tabular}{|c|c|}
\hline EdU & 5-Ethynyl-2-desoxyuridin \\
\hline engl. & englisch \\
\hline ESCs & embryonale Stammzelle \\
\hline et al. & und andere \\
\hline EZM & extrazelluläre Matrix \\
\hline FBS & fetal bovine serum \\
\hline 9 & Zentrifugalkraft \\
\hline 9 & Gramm \\
\hline $\mathrm{HCl}$ & Salzsäure \\
\hline HR-Peroxidase & horseradish-peroxidase \\
\hline hrsg. v. & herausgegeben von \\
\hline HSCs & hämatopoetische Stammzellen \\
\hline hTERT & $\begin{array}{l}\text { humane-Telomerase-Reverse- } \\
\text { Transkriptase }\end{array}$ \\
\hline ICM & Inner cell mass \\
\hline $\lg G$ & Immunglobulin G \\
\hline $\lg M$ & Immunglobulin M \\
\hline IL & Interleukin \\
\hline iPSC & induced pluripotent stemm cells \\
\hline k.A. & keine Angabe \\
\hline Kap. & Kapitel \\
\hline $\mathrm{KCl}$ & Kaliumchlorid \\
\hline $\mathrm{kDa}$ & Kilodalton \\
\hline $\mathrm{KH}_{2} \mathrm{PO}_{4}$ & Kaliumdihydrogenphosphat \\
\hline KIf4 & Krueppel-like factor 4 \\
\hline I & Liter \\
\hline LPL & Lipoproteinlipase \\
\hline LT-HSC & long term haematopoietic stem cells \\
\hline $\bar{M}$ & Molar \\
\hline
\end{tabular}




\begin{tabular}{|c|c|}
\hline$\mu g$ & Mikrogramm \\
\hline$\mu l$ & Mikroliter \\
\hline$\mu \mathrm{m}$ & Mikrometer \\
\hline $\mathrm{mA}$ & Milliampere \\
\hline MAPCs & multipotent adult progenitor cells \\
\hline $\mathrm{mg}$ & Milligramm \\
\hline MIAMI & $\begin{array}{l}\text { marrow-isolated adult multilineage } \\
\text { inducible cells }\end{array}$ \\
\hline $\min$ & Minute \\
\hline $\mathrm{ml}$ & Milliliter \\
\hline $\mathrm{mM}$ & Millimolar \\
\hline $\mathrm{mm}$ & Millimeter \\
\hline $\mathrm{mm}^{2}$ & Quadratmillimeter \\
\hline MMP & Matrix-Metalloprotease \\
\hline MPCs & mesenchymale Progenitorzellen \\
\hline mRNA & messenger Ribonukleinsäure \\
\hline MSCs & mesenchymale Stammzellen \\
\hline $\mathrm{NaCl}$ & Natriumchlorid \\
\hline $\mathrm{Na}_{2} \mathrm{HPO}_{4}$ & Dinatriumhydrogenphosphat \\
\hline NSC & neuronale Stammzelle \\
\hline $\mathrm{OA}$ & Osteoarthrose \\
\hline Oct4 & octamer-binding transcription factor 4 \\
\hline OT & Objektträger \\
\hline PAGE & polyacrylamide gel electrophoresis \\
\hline PBS & phosphate buffered saline \\
\hline PPAR $\gamma$ & $\begin{array}{l}\text { peroxisomal } \\
\text { proliferators-activated receptor } \mathrm{y}\end{array}$ \\
\hline PVDF & Polyvinylidenfluorid \\
\hline $\mathrm{RS} 1 / 2$ & recycling stemm cells \\
\hline
\end{tabular}




\begin{tabular}{|l|l|}
\hline RT & Raumtemperatur \\
\hline RT-PCR & $\begin{array}{l}\text { Reverse-Transkriptase-Polymerase- } \\
\text { Kettenreaktion }\end{array}$ \\
\hline Runx-2 & runt-related transcription factor-2 \\
\hline S. & Seite \\
\hline S. & siehe \\
\hline SDS & sodium dodecyl sulfate \\
\hline Sec & Sekunde \\
\hline Sox-2 & sex determining region Y-box-2 \\
\hline Sox-9 & sex determining region Y-box-9 \\
\hline ST-HSC & short-term haematopoietic stem cells \\
\hline Std. & Stunde \\
\hline Tab. & Tabelle \\
\hline TBS-T & Tris buffered saline+Tween \\
\hline TGF- $\beta$ & transforming growth factor-beta \\
\hline TNF- $\alpha$ & Tumornekrosefaktor-alpha \\
\hline Tris & Tris(hydroxymethyl)-aminomethan \\
\hline Tween & Polyoxyethylen(20)-sorbitan-monolaurat \\
\hline U & Unit \\
\hline UK & United Kingdom \\
\hline USA & United States of America \\
\hline vgl. & vergleiche \\
\hline z.T. & zum Teil \\
\hline
\end{tabular}




\section{Einleitung}

Die Prävalenz der Osteoarthrose (OA) nimmt bei über 60-Jährigen stark zu, wobei Frauen fast doppelt so häufig betroffen sind wie Männer (Felson 1990). Aufgrund des demografischen Wandels und der immer älter werdenden Weltbevölkerung wird die OA vermutlich im Jahre 2020 einer der häufigsten Gründe für Invalidität sein (Woolf und Pfleger 2003).

Die therapeutischen Maßnahmen bei leichter Gonarthrose sind unter anderem die autologe Chondrozytenimplantation zur symptomatischen Behandlung von Knorpeldefekten (Bartlett et al. 2005) sowie die kurative Therapie mittels Knietotalendoprothese (Hamel et al. 2008). Der hieraus entstehende Nachteil ist eine sich eventuell entwickelnde Immunogenität gegen das autologe Transplantat bzw. eine Lockerung des alloplastischen Implantats. Neuere Forschungsansätze gehen dazu über, mittels mesenchymaler Stammzellen (MSCs), die unter anderem aus dem Knochenmark entnommen werden können (Bruder et al. 1994), autogene Transplantate zu erstellen, die ex vivo generiert und später in das defekte Gewebe implantiert werden können (Caplan 2007, Schaefer et al. 2000). Die Vorzüge dieser Stammzellen ergeben sich aus ihrer hohen Selbsterneuerungsrate und ihrer Multipotenz; sie lassen sich in alle Zelltypen des Mesoderms differenzieren und sogar in Zellinien des Ektoderms (Drost et al. 2009, Gong et al. 2009, Kokai et al. 2005, Mackay et al. 1998, Oswald et al. 2004, Pittenger et al. 1999). Studien haben auch gezeigt, dass MSCs die Angiogenese positiv beeinflussen und entscheidend an der Differenzierung und Entwicklung anderer Zellen mitwirken (Goldberg 2012). Mittlerweile wurde publiziert, dass sich MSCs in mehreren Gewebsarten des Menschen nachweisen lassen (Crisan et al. 2008). Diese Stammzellen sind ebenfalls multipotent wie MSCs aus dem Knochenmark, allerdings aufgrund ihrer Gewebespezifität und weiteren Differenzierung werden sie auch als mesenchymale Progenitorzellen (MPCs) bezeichnet. Auch im Knorpelgewebe der Gelenke lassen sich solche Progenitorzellen nachweisen, die im gesunden sowie im osteoarthrotisch veränderten Knorpel vorkommen (Alsalameh et al. 2004).

Vor Kurzem wurde eine Zellpopulation in den späten Stadien der Gonarthrose beschrieben, die sich im Reparaturgewebe - angrenzendes Gebiet zum Hauptdefekt der Gonarthrose - des ostheoarthrotisch veränderten Gelenkknorpels befindet und durch die Tidemark des Knorpels in die Interterritorialmatrix migriert. Diese Zellen 
werden chondrogene Progenitorzellen (CPCs) genannt und zeigen ebenfalls Stammzelleigenschaften (Koelling et al 2009). Aufgrund ihres hohen chondrogenen Potenzials und ihrer Migrationsfähigkeit könnten diese Zelllinien in Zukunft eine neue Möglichkeit für eine zellbasierende Therapie der OA bieten (Koelling und Miosge 2009, Muhammad et al. 2013).

\subsection{Osteoarthrose: Ätiologie und Pathogenese}

Als $O A$ wird eine langsam fortschreitende, degenerative und primär nicht inflammatorische Erkrankung der Gelenkoberflächen bezeichnet, die zunächst mit einer Degeneration der hyalinen Knorpeloberfläche einhergeht und in einem fortgeschrittenen Stadium auch die subchondralen Knochenanteile befallen kann (s. Abb. 1), sowie Anteile der Gelenkkapsel und des Bandapparates (Ahmed und Hincke 2010). Durch den Abbau der für die Gelenkfunktion wichtigen Gewebeanteile kann es zu chronischen Gelenkschmerzen kommen, wobei nach jahrelanger Progredienz dieser muskuloskelettalen Erkrankung auch eine Einschränkung in der Beweglichkeit folgen kann, bis hin zum völligen Verlust der Gelenkfunktion (Felson 2006).

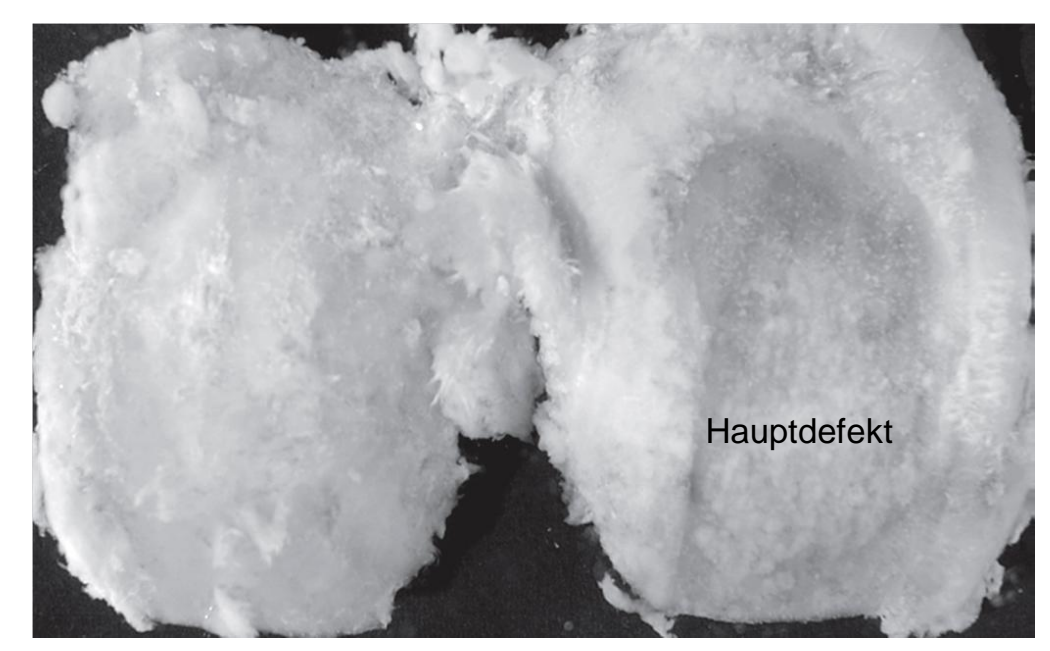

Abbildung 1: Osteoarthrose am Condylus des Femur; im Bereich des Hauptdefektes liegt die Knochenoberfläche frei

(aus Koelling und Miosge 2009, S. 1400)

Bei der OA handelt es sich um eine multifaktorielle Erkrankung, wobei mechanische Einflüsse, altersbedingte Veränderungen der Knorpelmatrix und genetische Faktoren die größte Gewichtung haben (Felson 2004). Daneben sind aber auch Adipositas 
und die dadurch über ein physiologisches $M a ß$ hinausgehende Belastung der Gelenke, rezidivierende Gelenkverletzungen und Gelenkfehlstellungen, Faktoren, die eine Arthrose begünstigen (Goldring MB und Goldring SR 2007).

Ätiologisch unterscheidet man eine primäre bzw. ideopathische $O A$, bei der die Ursachen nicht bekannt sind, von der sekundären $O A$, die in einem direkten kausalen Zusammenhang steht (Altman et al. 1986). Die Manifestation dieser Gelenkserkrankung ist häufig auf ein oder zwei Gelenke begrenzt, sie tritt aber auch generalisiert auf (Egloff et al. 2012, Poole AR et al. 2001). Überwiegend sind die Gelenke der unteren Extremitäten betroffen, sodass neben den arthrotischen Veränderungen in den Händen und der Wirbelsäule die Coxarthrose und Gonarthrose besonders häufig vorkommen (Flouzat-Lachaniette 2012, Goldring MB und Goldring SR 2006).

\subsection{Der Gelenkknorpel}

Der hyaline Knorpel entwickelt sich ursprünglich aus dem Mesoderm des Keimblattes und besteht aus Chondrozyten und extrazellulärer Matrix (EZM) (Muir 1995).

\subsubsection{Aufbau des hyalinen Gelenkknorpels}

Beim hyalinen Gelenkknorpel liegen die Knorpelzellen in isolierten Komplexen zusammen, die auch als isogene Gruppen bezeichnet werden, da sie alle aus derselben Vorläuferzelle durch mitotische Teilung entstanden sind. Die Zellen liegen in einer Knorpelhöhle zusammen, die durch die Knorpelkapsel und den Knorpelhof von der EZM abgegrenzt ist. Dieser gesamte Zellkomplex wird auch als Territorium bzw. Chondron bezeichnet, das im Durchschnitt aus ca. zwei bis sechs Chondrozyten besteht (Poole CA et al. 1992). Die von innen exprimierte EZM wird auch als Interterritorialmatrix bezeichnet und besteht überwiegend aus kollagenen Fibrillen des Typs II, Hyaluronsäure und dem Proteoglykan Aggrecan (Aigner und McKenna 2002, Ahmed und Hincke 2010). Die Proteoglycan-Aggregate besitzen eine große Wasserbindungskapazität und sorgen so für eine hohe Druckelastizität. Zusammen mit der Synovialflüssigkeit sorgt das Knorpelgewebe für ein reibungsfreies Gleiten der Gelenkflächen aufeinander (Buckwalter et al. 2005).

Der Gelenkknorpel lässt sich in vier Zonen einteilen (s. Abb. 2), die sich je nach Lage zur Knorpeloberfläche durch den Verlauf der kollagenen Fibrillen, der Morphologie 
und Anzahl der Chondrozyten sowie der biochemischen Zusammensetzung der EZM unterscheiden (Umlauf et al. 2010). Die Dicke dieser Zonen variiert zwischen einzelnen Gelenken und sie lassen sich mikroskopisch auch nicht genau voneinander trennen (Buckwalter et al. 1988, Aydelotte et al. 1996).

\section{Superfizialzone \\ Transitionalzone}

Radiärzone

Tidemark

Kalzifizierende Zone

Subchondraler Knochen

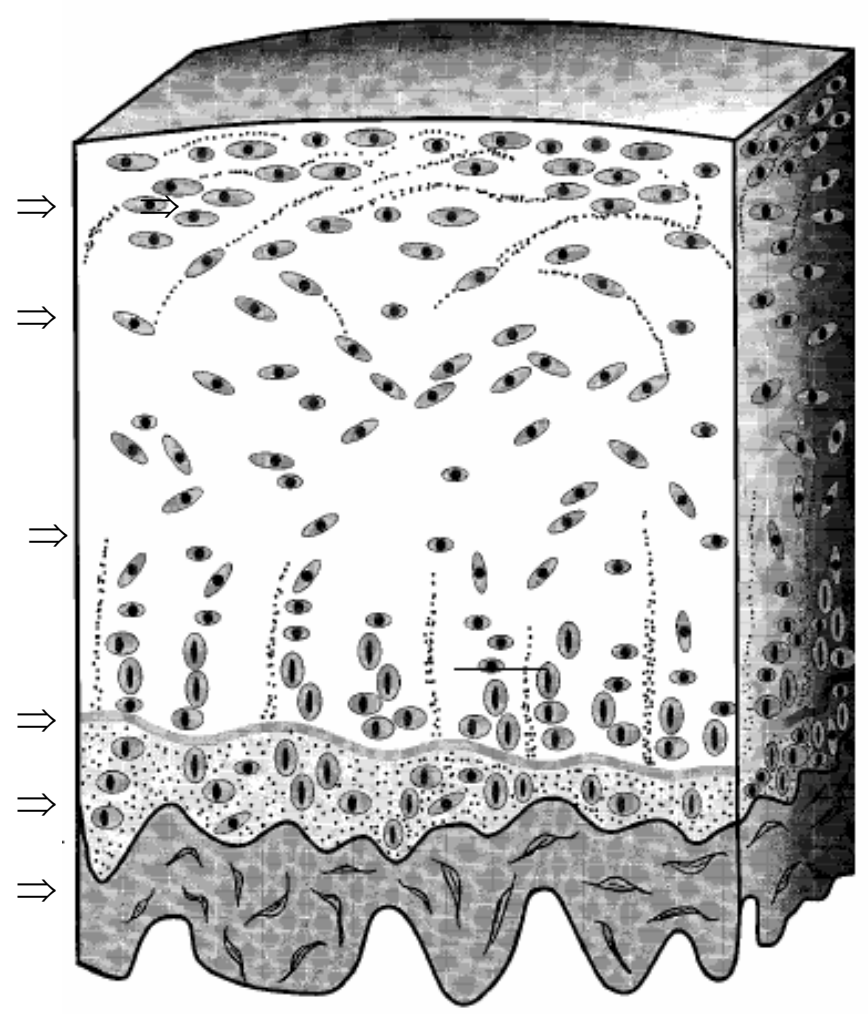

Abbildung 2: Zonen des Gelenkknorpels

(aus Rudert und Wirth 1998, S.311; modifiziert nach Buckwalter et al. 2005)

Die Superfizialzone teilt sich auf in zwei feinere Schichten, wobei die Gelenkoberfläche von einer azellulären Schicht überzogen ist, in der sehr feine Kollagenfibrillen liegen, die parallel zur Oberfläche angeordnet sind. Unterhalb dieser Schicht, die auch Lamina splendens genannt wird, liegen spindelförmige, ebenfalls parallel ausgerichtete Chondrozyten, die eine kollagen- und wasserreiche EZM exprimieren. Daran anschließend folgt die Transitionalzone, in der die Chondrozyten eher eine ovale bis rundliche Gestalt besitzen und willkürlich angeordnet sind. Die von innen synthetisierte EZM enthält weniger Wasser und Kollagen als die der Superfizialzone, allerdings ist im Gegensatz dazu der Durchmesser der Kollagenfibrillen etwas dicker und der Gehalt an Proteoglykanen höher (Kuettner 
1992). Die Chondrozyten der Radiärzone sind säulenförmig angeordnet und haben eine ovale Form. Diese Zone enthält die dicksten Kollagenfibrillen und den höchsten Proteoglykananteil. Die Abgrenzung zwischen hyalinem Knorpel und dem subchondralen Knochen bildet die kalzifizierende Zone (Hoemann et al. 2012). In ihr sind die Chondrozyten sehr klein und von kalzifizierter Knorpelmatrix umgeben. Das endoplasmatische Retikulum und der Golgi-Apparat sind schlecht entwickelt und die Chondrozyten sind kaum metabolisch aktiv (Buckwalter et al. 2005, Umlauf et al. 2010).

\subsubsection{Osteoarthrotische Veränderungen des Gelenkknorpels}

In jedem Gewebe des Körpers kommt es im Laufe der Zeit zu normalen altersbedingten Veränderungen. Es besteht zwar ein enger Zusammenhang zwischen Lebensalter und OA (Goldring MB und Goldring SR 2007), dennoch unterscheiden sich die Veränderungen im Gelenkknorpel deutlich voneinander. Während des physiologischen Alterungsprozesses des Knorpels kommt es zu Veränderungen in der Zusammensetzung und Struktur der EZM; die Chondrozytenzahl und ihr Metabolismus verringern sich. Die von den Chondrozyten synthetisierten Proteoglycan-Moleküle sind kleiner (Hidaka und Goldring MB 2008), was mit einer verringerten Bindungskapazität von Wasser einhergeht. Das Kollagen der Interterritorialmatrix ist stärker vernetzt, die Festigkeit des Knorpels nimmt aber ab. Die Gelenkoberfläche bleibt dennoch weitestgehend frei von Fibrillationen (Horton et al. 2006).

Der genaue Mechanismus, wie es zur primären Arthrose kommt, ist noch nicht komplett verstanden. Die Progression der Erkrankung verläuft jedoch in typischen Stadien, die sich zur altersbedingten Knorpelveränderung dadurch unterscheiden, dass Chondrozyten proliferieren, in eine erhöhte anabole Stoffwechsellage übergehen und im fortgeschrittenen Stadium ihren Phänotyp wechseln (Sandell und Aigner 2001, Horton et al. 2006).

$\mathrm{Zu}$ Beginn der primären Arthrose kommt es in der Superfizialzone zur Knorpeldegeneration mit der für OA typischen Fibrillation (Aigner und McKenna 2002). Diese Faserung der Kollagenfibrillen beruht auf einer verringerten Synthese von EZM-Komponenten, zu denen auch die Link-Proteine gehören. Diese verbinden 
einzelne Kollagenfibrillen miteinander und stabilisieren so die Matrix (Kuettner 1992). Im weiteren Verlauf kommt es zu tiefen Fissuren in der Knorpelmatrix (Koelling et al. 2009), die die Homöostase der EZM negativ beeinflussen. Durch die Fissuren eindringende Wachstumsfaktoren und Veränderungen der Osmolarität werden die Chondrozyten zur Proliferation angeregt, dadurch soll der Verlust an Matrixkomponenten und abgestorbenen Zellen kompensiert werden (Mankin et al. 1971). Durch diese Zellvermehrung bilden sich die für die OA typischen Zell-Cluster bzw. Zell-Klone (Sandell und Aigner 2001).

Die proliferierten Chondrozyten gehen im zweiten Stadium in einen anabolen Zustand über und synthetisieren eine neue Matrix aus Kollagen II und Aggrecan um sich herum. Aufgrund eines gestörten Zell-Matrix Gleichgewichts oder direkt durch Mediatoren, setzen die Chondrozyten den Entzündungsmediator Interleukin-1 (IL-1) frei. Dadurch werden Matrix-Metalloproteasen (MMPs) aktiviert, die für einen weiteren Abbau der Knorpelmatrix verantwortlich sind. Es wird überwiegend Kollagen IX und XI abgebaut, wodurch das Kollagen-II-Netzwerk destabilisiert wird (Buckwalter et al. 2005). Das IL-1 bewirkt ebenfalls eine Dedifferenzierung der Chondrozyten zu fibroblastenartigen Zellen und damit auch eine Veränderung ihres Genexpressionsmusters. Die fibroblastenartigen Chondrozyten exprimieren jetzt überwiegend Kollagen I, III und V (Benya et al. 1978, Miosge et al. 2004), wodurch defekte Matrixterritorien mit einem fibrokartilaginären Ersatzgewebe ausgefüllt werden. Aus dem subchondralen Knochen durchbrechen Blutgefäße die Tidemark und dringen in das Knorpelgewebe ein (Koelling et al. 2009). Die Aufrechterhaltung der Knorpelfunktion kann aufgrund des "Reparaturgewebes“ über Jahre stabil gehalten werden (Aigner und McKenna 2002, Tesche und Miosge 2005).

Im dritten Stadium der $O A$ versagt das fibrokartilaginäre Ersatzgewebe aufgrund fehlender biomechanischer Resistenz und es kommt zum Zusammenbruch der EZM mit komplettem Verlust der Knorpelschicht. Die subchondralen Bereiche sklerosieren und werden dicker, darin bilden sich kleine Lakunen. Auf der Knochenoberfläche ist regenerierter Knorpel und fibröses Gewebe aufgelagert, am Rand bilden sich Osteophyten. Der Verlust von Knorpel geht nun mit den typischen klinischen Anzeichen einer OA einher (Felson 2004, Sun 2010). 


\subsubsection{Knorpelregeneration}

MPCs in anderen Bindegeweben wie Muskeln oder Knochen, können Gewebsdefekte nach Verletzungen im Sinne einer "Restitutio ad integrum" vollständig ausgleichen. Die Progenitorzellen im Knorpel hingegen decken Gewebsdefekte im Sinne einer „Reparatio“, die den biomechanischen Ansprüchen der Gelenke nicht genügen kann.

Der Gelenkknorpel ist ein avaskuläres, nicht innerviertes und lymphgefäßfreies Bindegewebe. Die hochdifferenzierten Chondrozyten sind der einzige Zelltyp und machen ca. 5\% der Knorpelmasse aus. Es handelt sich hierbei um ausdifferenzierte Chondrozyten, die sich im gesunden Knorpel nicht mehr teilen. Der restliche Anteil des Knorpelgewebes wird von der selbstexprimierten EZM gebildet (Muir 1995). Da ein vaskularisiertes Perichondrium fehlt, erfolgt die Nährstoffversorgung der oberflächlich liegenden Chondrozyten über Diffusion aus der Synovia, die der tiefer liegenden Zellschichten durch die Gefäße des subchondralen Knochens. Dadurch bedingt ist ihre Umgebung relativ sauerstoffarm und damit ihr Metabolismus sehr gering (Goldring MB und Goldring SR 2007). Dennoch kann ein Teil der Chondrozyten, wie oben beschrieben, in den ersten Stadien der OA in eine anabole Stoffwechsellage übergehen. Sie können sich erneut teilen und Klone bilden, die sich in Clustern zusammenfinden, die die ursprünglichen Matrixkomponenten wie Kollagen Typ II, VI, IX, XI und Proteoglykane synthetisieren, um degenerierte Knorpelanteile zu kompensieren (Koelling et al. 2009, Poole AR 1999). Erst in den späteren Stadien der OA erfolgt bei einem Teil der Chondrozyten ein Übergang in einen fibroblastenartigen Phänotyp und damit einhergehend ein anderes Genexpressionsmuster von EZM-Komponenten. Die restlichen gewebsständigen Chondrozyten verändern sich gar nicht oder gehen in die Apoptose über; neuer Knochen wird ebenfalls gebildet (Sandell und Aigner 2001).

MPCs sind mittlerweile auch in der EZM des Gelenkknorpels nachgewiesen worden, sowohl im gesunden als auch im arthrotisch veränderten Knorpel. Es scheint der Fall zu sein, dass MPCs an den Regenerationsprozessen der EZM bei OA eine wichtige Rolle einnehmen (Koelling et al. 2009). Alsalameh et al. beschrieben 2004 als Erste die Charakterisierung von MPCs im gesunden sowie im osteoarthrotisch veränderten Knorpel des Knies. Mit Hilfe des Stammzellmarkers CD105, der MSCs aus dem Knochenmark charakterisiert, wurde festgestellt, dass im erkrankten Knorpel ca. 95\% 
der Zellen CD105-positiv waren, im gesunden lediglich ca. 3,5\%. Die positiven Zellen ließen sich auch zu Adipozyten, Osteozyten und Chondrozyten differenzieren, was die Multipotenz dieser Zellen nachweist. Undifferenzierte MPCs wiesen jedoch keine Expression von Kollagen Typ II auf. Es konnte auch nicht nachgewiesen werden, ob die erhöhte Anzahl an Progenitorzellen durch Proliferation ortsständiger Stammzellen erfolgte oder ob sie aus umgebenden Geweben eingewandert waren und sich erst später differenzierten. Es lassen sich in den verschiedenen Zonen des Knorpels noch weitere Progenitorzellen nachweisen, die sich bezüglich ihrer Differenzierbarkeit, Expressionsmuster der Proteine und ihres Phänotyps unterscheiden (Dowthwaite et al. 2004, Fickert et al. 2004).

MPCs sind definiert als klonale Subpopulation einer mesenchymalen Stammzelllinie. Aus ursprünglichen MSCs entwickeln sich durch Teilung und Differenzierungsschritte verschiedene Phänotypen, bis sie schließlich im ausdifferenzierten Zustand in die Bildung von Bindegeweben eingebunden sind und ihr Teilungspotenzial verlieren. Diese Entwicklung geschieht auf Basis von extrinsischen und intrinsischen Faktoren (Caplan 1991). Diese Entwicklungsbahn impliziert, dass sich Zellen einer Gewebspopulation auf verschiedenen Differenzierungsebenen befinden müssen, bzw. Progenitorzellen in verschiedenen Geweben vorgehalten werden (Lepperdinger 2011, da Silva Meirelles et al. 2006). Diese Differenzierungsschritte gehen nicht nur in Richtung ausdifferenzierter Zellen, sondern auch von ausdifferenzierten in Richtung proliferierender Zellen. Wie oben beschrieben, können nicht mehr teilungsfähige Chondrozyten dedifferenzieren und klonal proliferieren. Solch eine Dedifferenzierung ist besonders deutlich in der Monolayer-Kultur von Chondrozyten zu beobachten. Die Chondrozyten ändern dabei nicht nur ihren Phänotyp, sondern auch ihr Expressionsmuster an spezifisch chondrogenen Proteinen (Benya und Shaffer 1982).

Für das Verständnis von den Vorgängen der Differenzierung bei MSCs bzw. MPCs werden in den folgenden Kapiteln die Grundlagen und Ursachen der Stammzelldifferenzierung dargestellt. 


\subsection{Stammzellen}

Als Stammzellen werden undifferenzierte Zellen bezeichnet, die noch keinem endgültigen Zelltyp zugeordnet werden können. Aufgrund ihres Vorkommens und Differenzierungspotenzials unterscheidet man embryonale von adulten Stammzellen.

\subsubsection{Embryonale Stammzellen}

Nach dem 4.-5 Tag der Befruchtung entsteht die Blastozyste. Ihre innere Zellmasse, der Embryoblast, enthält totipotente Stammzellen, die sich in alle Zelltypen des menschlichen Organismus differenzieren können und eine uneingeschränkte Teilungsfähigkeit besitzen (Evans und Kaufman 1981, Martin 1981). Diese Totipotenz behält der Embryoblast bis zum 8-Zellstadium, darüber hinaus bleibt das Potenzial auf die Pluripotenz begrenzt. 1998 gelang es Thomson et al. zum ersten Mal, humane pluripotente Stammzellen aus der Blastozyste zu isolieren und in Kultur zu nehmen. Man sah darin eine neue Möglichkeit in der Erstellung neuer Organe oder in der Heilung von Gendefekten.

Der Gedanke an geklonte Menschen und die Schädigung des Embryos brachte die Stammzellforschung sehr schnell in die Kontroverse, sodass die Politik die Forschung an embryonalen Stammzellen sehr stark einschränkte. Takahashi et al. entwickelten 2007 das Modell einer induzierten embryonalen Stammzelle (iPSCs engl. ,induced pluripotent stemm cells"), indem ein adulter, somatischer Zellkern in eine Blastozyste transplantiert wurde. Dadurch wurden embryonale Gene wieder aktiviert und es entstand eine pluripotente Stammzelle (French et al. 2008, Takahashi et al. 2007). An diesem Modell kann man erkennen, dass ausdifferenzierte Zellen auch wieder dedifferenzieren können, das sog. „Reprogrammieren“. Dazu müssen nur wenige (drei bis vier) Transkriptionsfaktoren aktiviert werden, so zum Beispiel die Faktoren c-Myc, Klf4, Oct4, Sox-2 (Bonfanti et al. 2012, Brunt et al. 2012).

\subsubsection{Adulte mesenchymale Stammzellen}

Der Ursprung der adulten MSCs liegt in der Umformung der zweiblättrigen Keimscheibe in eine dreiblättrige Keimscheibe in der dritten Woche nach der Befruchtung. Nach der als Gastrulation bezeichneten Bildung des dritten Keimblattes liegen nun Ektoderm, Endoderm und das Mesoderm mit den MSCs vor. Aus innen gehen alle Binde- und Stützgewebe des Organismus hervor, sowie die Stammzellen der hämatopoetischen Zelllinien (Burton 2008, Méndez-Ferrer et al. 2010). Dadurch 
können MSCs in hämatopoetische und nicht-hämatopoetische Stammzellen eingeteilt werden.

A.J. Friedenstein fand vor über 40 Jahren als Erster heraus, dass das Knochenmark von erwachsenen Individuen nicht-hämatogene MSCs enthält. Er isolierte aus dem Knochenmark eine adhärente, koloniebildende, fibroblastenähnliche Zelllinie (CFU-F, engl. „colony forming unit-fibroblast"), die in vitro eine hohe Replikationsrate aufwies und multipotente Eigenschaften bezüglich der Differenzierung in Chondrozyten, Osteozyten und Adipozyten besaß (Friedenstein 1980, Friedenstein et al. 1966, 1968, 1970, 1974, 1987). Die CFU-Fs wurden später unter dem Namen mesenchymale Stammzellen weitergeführt (Bianco et al. 2008). MSCs lassen sich heutzutage nicht nur aus dem Knochenmark isolieren, sondern aus vielen verschiedenen Geweben und Organen wie Fettgewebe, Knorpel, Pankreas und dem Periost (Dowthwaite et al. 2004, Kokai et al. 2005, Kruse et al. 2006, Alsalameh et al. 2004). Es wird mittlerweile davon ausgegangen, dass MSCs in jedem Gewebe vorkommen, um dort abgestorbene Zellen zu ersetzen oder Gewebsdefekte zu kompensieren (Lepperdinger 2011, da Silva Meirelles et al. 2006). Die klassischen Kriterien, um sie als Stammzellen zu charakterisieren, sind die Möglichkeit der Klonierung, uneingeschränktes Teilungspotenzial und die Differenzierbarkeit in alle mesenchymalen Zelltypen. Basierend auf ihrer Differenzierbarkeit werden die MSCs oft als multipotent beschrieben, was nach heutigen Forschungserkenntnissen nur eingeschränkt gültig sein kann, denn einige MSCs besitzen auch pluripotente Differenzierbarkeit. Nach der aktuellen Nomenklatur beschreibt die Multipotenz die Fähigkeit, sich in einen anderen Zelltyp der gleichen Zelllinie zu differenzieren. Mittlerweile konnte aber gezeigt werden, dass sich MSCs auch in neuronenähnliche Zellen differenzieren lassen, die bei der embryonalen Entwicklung jedoch aus dem Ektoderm hervorgehen und somit einer anderen Zelllinie angehören (Kokai et al. 2005). Die Fähigkeiten multipotenter/pluripotenter Zellen, sich innerhalb ihrer Zelllinie und darüber hinaus zu differenzieren, wird Plastizität genannt. Die Plastizität von Zellen wird im weiteren Verlauf genauer beschrieben (s. Kap. 1.3.4, S. 15).

Aufgrund neuerer Methoden zur Kultivierung und Charakterisierung von MSCs wurden immer mehr MSC-ähnliche Zellen aus Geweben und Organen isoliert, die sich allerdings nicht eindeutig einem Entwicklungsstadium zuordnen lassen bzw. es noch nicht bekannt ist, welchen Platz sie in der Hierarchie der MSCs einnehmen. Es 
wurden Zelltypen wie MAPCs (engl. „multipotent adult progenitor cells“), MIAMIZellen (engl. "marrow-isolated adult multilineage inducible cells“) und RS-1/RS-2 (engl. „recycling stem cells“) beschrieben (Colter et al. 2000, D'lppolito et al. 2004, Reyes et al. 2001).

Daraus lässt sich ableiten, dass MSCs eine sehr hohe Plastizität in ihren Genexpressionsmustern besitzen. Es konnte bis heute auch noch kein Oberflächenmarker gefunden werden, der, alleine angewendet, MSCs eindeutig charakterisieren kann. Mafi et al. hatten in einer Studie aus dem Jahr 2011 die am meisten verwendeten Oberflächenmarker verglichen, die zur Charakterisierung von MSCs benutzt wurden. Meistens handelte es sich dabei um CD105, CD90, CD44, CD73, CD29 und STRO-1. Das Ergebnis der Studie zeigte, dass die Oberflächenmarker je nach Gewebetyp und Entwicklungsstadium voneinander abwichen. Einige MSCs aus dem Knochenmark und Fettgewebe waren auch positiv für Oberflächenmarker wie CD34 und CD45, die Stammzellen der hämatopoetischen Reihe charakterisieren. Das ist damit zu begründen, dass MSCs und ihre osteoblastenähnlichen Nachkommen im Knochenmarkstroma, die „Nische“ der hämatopoetischen Stammzellen (HSCs) im Knochenmark bilden (Ho und Wagner 2007).

\subsubsection{Stammzellen und ihre „Nische“}

Der Körper besitzt eine große Vielfalt unterschiedlichster Zelltypen, die in den Geweben und Organen spezielle Aufgaben übernehmen. Diese Zellen unterliegen jedoch der normalen Umsatzrate der Gewebe und sterben nach einer gewissen Zeit ab bzw. können durch Traumata geschädigt werden. Um die Homöostase von Zellabbau und -aufbau dennoch aufrecht zu erhalten, besitzen viele Gewebe ein Reservoir von adulten Stammzellen/Progenitorzellen in ihrem Stroma, die ein Leben lang die Fähigkeit besitzen, sich erneut zu teilen, und sich dann gewebsspezifisch ausdifferenzieren (Fuchs et al. 2004). Die adulten Stammzellen stehen dabei mit vielen verschiedenen Stromazellen in Kontakt, die zusammen in ihrer EZM eingebettet sind. Die Aktivierung der Stammzellen und Regulation der Differenzierungsprozesse sind hoch komplex und müssen exakt auf das Gewebe abgestimmt sein, daraus entwickelte sich die Bezeichnung "Mikroumgebung“ bzw. "Nische“ der Stammzellen. In dieser Mikroumgebung erfolgt die Regulation der Homöostase nicht durch die Stammzellen alleine, sondern es ist ein Zusammenspiel 
aller Oberflächenrezeptoren, Mediatoren, Matrixproteine, Zellkontakte und intrinsischen Faktoren aller Zellen dieser Nische, die die Teilung und Genexpressionsmuster der ortsansässigen Stammzellen beinflussen (Lee und Kim 2012).

Besonders deutlich zeigt sich der Einfluss der Umgebung auf die Zelle bei einem Experiment mit embryonalen Stammzellen (ESCs). Dabei wurden pluripotente Stammzellen aus der Blastozyste isoliert und in Kultur genommen; die Zellen blieben dabei undifferenziert und behielten ihre pluripotenten Eigenschaften (Shamblott et al. 1998, Thomson et al. 1998). Werden solche ESCs hingegen von der Blastozyste in fremdes Gewebe in vivo implantiert, dann entwickeln sich Teratome, gutartige Geschwulste, die Gewebeanteile aller drei Keimblätter enthalten. Implantiert man solche Stammzellen allerdings wieder in eine Blastozyste, ihre natürliche Nische, so erlangen sie wieder ihre normalen Eigenschaften zurück. Die genauen Mechanismen sind bis heute nicht verstanden, aber es zeigt sich, dass ein Zusammenspiel der extrinsischen Faktoren ihrer Umgebung die intrinsischen Faktoren der Stammzellen beeinflussen und so ihr Differenzierungspotenzial und die Autoregulation steuern (Fuchs et al. 2004).

\subsubsection{Nische der hämatopoetischen Stammzellen}

Die Zellen des Blutes haben alle nur eine begrenzte Lebensdauer und müssen fortlaufend erneuert werden. Die dafür nötigen HSCs sitzen beim Erwachsenen im roten blutbildenden Knochenmark. Die Blutzellen sind die am Besten charakterisierten Stammzellen des Menschen, da die einzelnen Differenzierungsstadien und die dazugehörigen Mediatoren durch Oberflächenmarker sehr genau definiert werden konnten. Alle Blutzellen stammen von einer gemeinsamen pluripotenten Stammzelle ab, die sich zunächst in eine myeloische und eine lymphatische Progenitorzelle teilt. Aus diesen beiden multipotenten Zelllinien gehen alle anderen Zellen des Blutes hervor (s. Abb. 3, S. 13). 


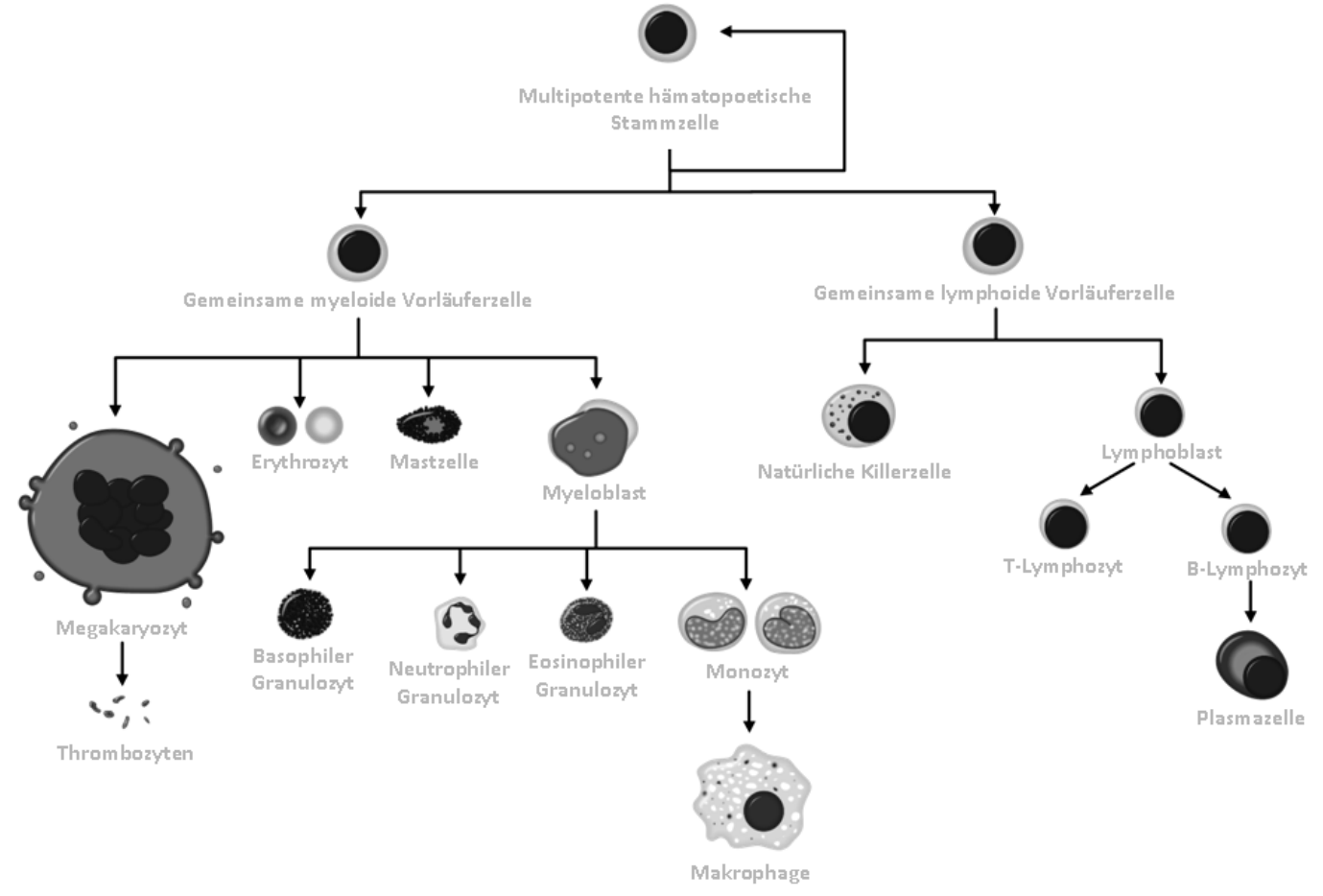

Abbildung 3: Schema der Hämatopoese

(Differenzierungsschritte nicht vollständig)

(Quelle: www.doktor-schubert.net, 2011)

Das Knochenmark enthält CFU-Fs, ARCs (engl. "adventitial reticular cells"), Adipozyten, Osteoblasten und HSCs, dabei spielen die ARCs die wichtigste Rolle in der Organisation der Nische (Bianco 2011). Auf die Adventitia sind die ARCs aufgelagert, die sich dort auch aus den MSCs entwickelt haben (Weiss 1976). Diese Zellen sind Vorläufer von Osteoblasten und Adipozyten, können neue ARCs bilden und sich wieder zu CFU-Fs dedifferenzieren (Bianco et al. 1988, Sacchetti et al. 2007, Song et al. 2010, Tavassoli 1976). Die osteogenen Progenitorzellen spielen bei der Heilung von Frakturen eine wichtige Rolle.

In der Nische der HSCs treffen auch die Nischen der Osteoprogenitorzellen und CFU-Fs des Knochenmarks zusammen, die einer gegenseitigen Regulation über die ARCs unterliegen. Die Lage der ARCs auf der Adventitia ist quasi das Bindeglied zwischen der Hämatopoese und der Homöostase des Knochenmarkstromas, da sie über die Blutbahn zirkulierende Chemotaxine erleichtert aufnehmen können und über Cadherine mit den Osteoblasten in direktem Zellkontakt stehen (Bianco 2011, Zhang et al. 2003). 


\subsubsection{Nische der mesenchymalen Stammzellen}

Die Nische der MSCs, die nicht in Verbindung mit der Hämatopoese steht, ist bisweilen noch weniger verstanden bzw. es konnte noch kein eng umschriebenes Areal definiert werden. Da MSCs und ihre Nachkommen nicht in der Blutbahn vorkommen, aber in fast sämtlichen Geweben und Organen charakterisiert werden konnten, wird die Nische der MSCs dynamisch verwendet, d.h. sie kann nur mit gewebsspezifschen Merkmalen beschrieben werden. Hierbei gibt es aber in Bezug auf Signalproteine in den verschiedenen Geweben Parallelen. So induziert zum Beispiel BMP (engl. „bone morphogenetic protein“), ein Zytokin der TGF-ßSuperfamilie (engl. „transforming growth factor- $\aleph^{\prime \prime)}$ ), die chondrogene Differenzierung in vitro (Schaefer et al. 2000) und hat auch Einfluss auf die Blutbildung. Ebenso spielt der Ligand Wnt, der den gleichnamigen Signaltransduktionsweg aktiviert, bei der Entwicklung des Embryos eine wichtige Rolle, aber auch bei der Proliferation und Ausdifferenzierung von Stammzellen des Erwachsenen (Alonso und Fuchs 2003). Bei Verletzungen der quergestreiften Muskulatur aktiviert Wnt lokale Stammzellen während der Regeneration und regt auch HSCs in vitro zur Proliferation an (Polesskaya et al. 2003, Reya et al. 2003, Willert et al. 2003).

In Bezug auf die Nische der HSCs konnten Crisan et al. (2008) nachweisen, dass es in mehreren Organen perivaskulär Zellen gibt, die mesenchymale Stammzelleigenschaften besitzen und der Ursprung bzw. die Nische der MSCs sein könnten. Diese „Perizyten“ wurden mittels Oberflächenmarker an Gefäßen der Skelettmuskulatur, des Pankreas, des Fettgewebes und der Plazenta charakterisiert. Diese Zellen wiesen keine Oberflächenmarker der hämatopoetischen und endothelialen Zelllinien auf, konnten in Adipozyten, Osteoblasten und Chondrozyten differenziert werden und besaßen migrierende Fähigkeiten.

Die Annahme, dass es sich dabei um die Nische der MSCs handeln könnte, beruht auf mehreren Forschungsarbeiten, in denen ebenfalls Perizyten als Vorläuferzellen von verschiedenen Zelltypen vermutet wurden. So konnte nachgewiesen werden, dass sich retinale Perizyten in Chondrozyten und Adipozyten differenzieren lassen (Farrington-Rock et al. 2004). In Bezug auf ihr osteogenes Potenzial wird vermutet, dass sie bei der Sklerosierung der Blutgefäße beteiligt sind und damit eine wichtige Rolle bei kardiovaskulären Erkrankungen haben (Collett und Canfield 2005). Auch bei den dentinbildenden Odontoblasten des Zahnes nimmt man an, dass sie aus 
Zellen der Gefäßwand der Pulpa entstehen (Alliott-Licht et al. 2005). Gronthos et al. konnten 2001 Ähnlichkeiten von Perizyten des gut vaskularisierten Fettgewebes mit Zellen des ebenfalls gut vaskularisierten Knochenmarkstromas nachweisen.

Ob die Gefäßwand der verschiedenen Gewebe als Nische der MSCs bezeichnet werden darf, bleibt abzuwarten. Ein direkter Zusammenhang zwischen MSCs und Blutgefäßen ist jedoch erkennbar. Alle Zellen, die am Aufbau von Gefäßen beteiligt sind, haben das Potenzial zur Angiogenese, und überall wo Angiogenese stattfindet, finden sich auch MSCs bzw. gewebsspezifische Progenitorzellen (Bianco 2011, Crisan et al. 2008).

\subsubsection{Plastizität von Stammzellen: Symmetrische und asymmetrische Teilung}

Bei Stammzellen handelt es sich um nicht ausdifferenzierte Zellen. Sie zeichnen sich durch Reduplizierung und Differenzierung in verschiedene Zelltypen aus. Einerseits müssen sie ihren eigenen Pool durch Reproduktion aufrechterhalten, andererseits müssen für jegliche Arten von Geweben bestimmte Zelltypen generiert werden. Um dieser Aufgabe gerecht zu werden, können sich Stammzellen symmetrisch oder asymmetrisch teilen. Dient die Reproduktion nur zur Erhaltung des Stammzellenpools, erfolgt eine symmetrische Teilung. Wird ein bestimmter Zelltyp benötigt, entsteht durch asymmetrische Teilung eine Tochterzelle der ursprünglichen Stammzelle sowie eine Progenitorzelle, die als Vorläuferzelle zur determinierten Differenzierung vorgesehen ist (s. Abb. 4, S. 16) (Knoblich 2001). 


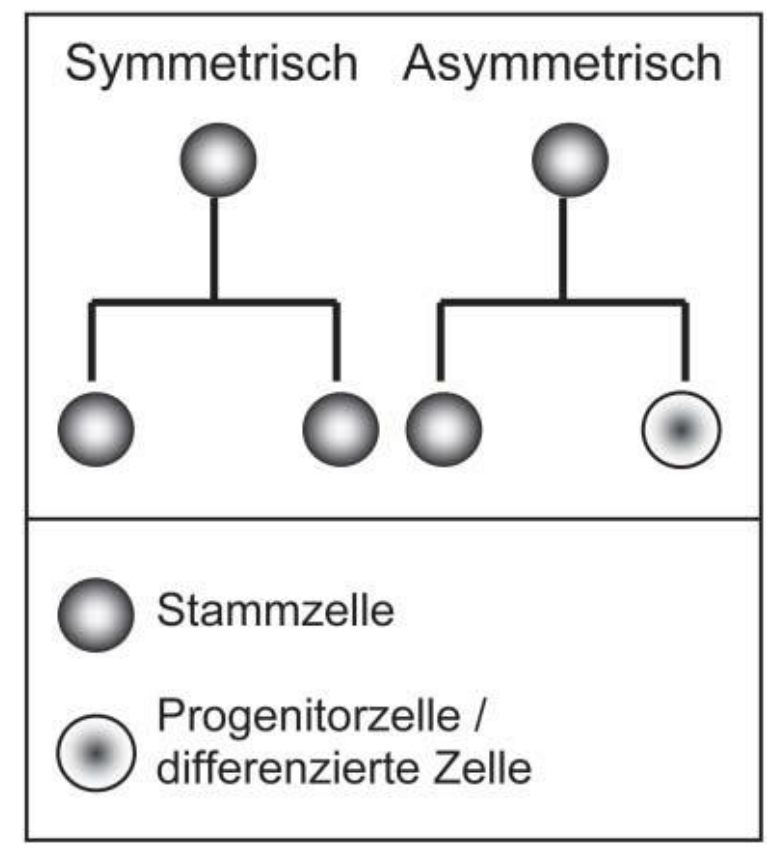

Abbildung 4: Teilungsmuster der Stammzellen

(aus Koestenbauer et al. 2006, S. 324)

Dabei können theoretisch vier verschiedene Mechanismen beschrieben werden ( $\mathrm{Ho}$ und Wagner 2007):

1. Die Tochterzellen sind aufgrund intrinsischer Faktoren direkt nach der Teilung der Stammzelle unterschiedlich.

2. Aufgrund extrinsischer Faktoren aus der Umgebung erfolgt eine Polarisation der Zelle vor der Mitose, die in einer asymmetrischen Teilung mündet.

3. Eine Tochterzelle wird nach der Teilung durch Zell-Zell Kommunikation mit ihrer Nische durch diese determiniert.

4. Die Tochterzellen teilen sich symmetrisch und die Differenzierung folgt einem stochastischen Verlauf durch intrinsische Faktoren.

Da der eigentliche Mechanismus noch nicht verstanden ist, nimmt man an, dass es sich bei dem Prinzip um die Einwirkung mehrerer dieser Faktoren handelt. Bekannt ist aber der Zusammenhang zwischen Potenz und Entwicklungsstadium der Zelle. Die völlig undifferenzierten, totipotenten Stammzellen der Blastozyste können alle Gewebe des Körpers generieren. Mit zunehmendem Entwicklungsstadium nimmt die Potenz über pluri- und multipotente Stammzellen ab, bis schließlich Progenitorzellen 
in den Geweben zu finden sind, die teils nur noch bi- oder unipotent sind (Schaefer et al. 2000).

\subsubsection{Plastizität und Trans-Differenzierung}

Den oben beschriebenen Differenzierungsprozess innerhalb der eigenen Zellinie nennt man Plastizität. Sie nimmt mit dem Entwicklungsstadium der Zelle ab. So gehen bei der Hämatopoese die Stammzellen für die myeloische und lymphatische Reihe aus derselben pluripotenten Stammzelle hervor. Aus dem pluripotenten myeloischen Progenitor gehen dann zum Beispiel die weiteren Vorläufer der Erythrozyten und Thrombozyten hervor, die keinerlei Plastizität mehr besitzen. Die Plastizität einer Zelle ist die Ursache dafür, dass Zellen schwer zu identifizieren und isolieren sind. Je nach Entwicklungsstadium und EZM ergeben sich andere Oberflächenmarker, Genexpressionsmuster und Phänotypen (Koestenbauer et al. 2006).

Mittlerweile wurde mehrfach beschrieben, dass sich Stammzellen aus bestimmten Geweben nicht nur gewebsspezifisch differenzieren, sondern sich auch in Zellinien anderer Gewebe differenzieren lassen. Diese Eigenschaft einer Stammzelle wird als Trans-Differenzierung bezeichnet und kann innerhalb der Zelllinien eines Keimblattes stattfinden oder über die Grenzen der Keimblätter hinaus (Drost et al. 2009, Kokai et al. 2005, Oswald et al. 2004). Oft stellte sich aber heraus, dass die vermeintliche Trans-Differenzierung ein Artefakt der Zellkultur ist und es sich um eine Zellfusion handelte, wie sie bei der Befruchtung stattfindet (Terada et al. 2002, Ying et al. 2002). Die Probleme, dass diese beiden Phänomene in vitro nicht direkt auseinander gehalten werden können und es immer wieder zu Missinterpretationen kommt, liegen häufig in der Verwendung von heterogenen Zellpopulationen. So wurde beschrieben, dass der skelettale Muskel Blutzellen bilden könne. In Wirklichkeit war die Zellkultur der Muskelzellen mit HSCs aus dem Muskel selbst durchmischt (Jackson et al. 1999)

Ein weiterer Grund für die Plastizität von Zellen liegt in der De-Differenzierung von Progenitorzellen. Hier geht man davon aus, dass eine weit ausdifferenzierte Zelle erst wieder durch Zwischenschritte zu naiveren Zellen eine Trans-Differenzierung vollziehen kann, da sich keine Zelle direkt in eine andere umwandelt (Koestenbauer et al. 2006). 


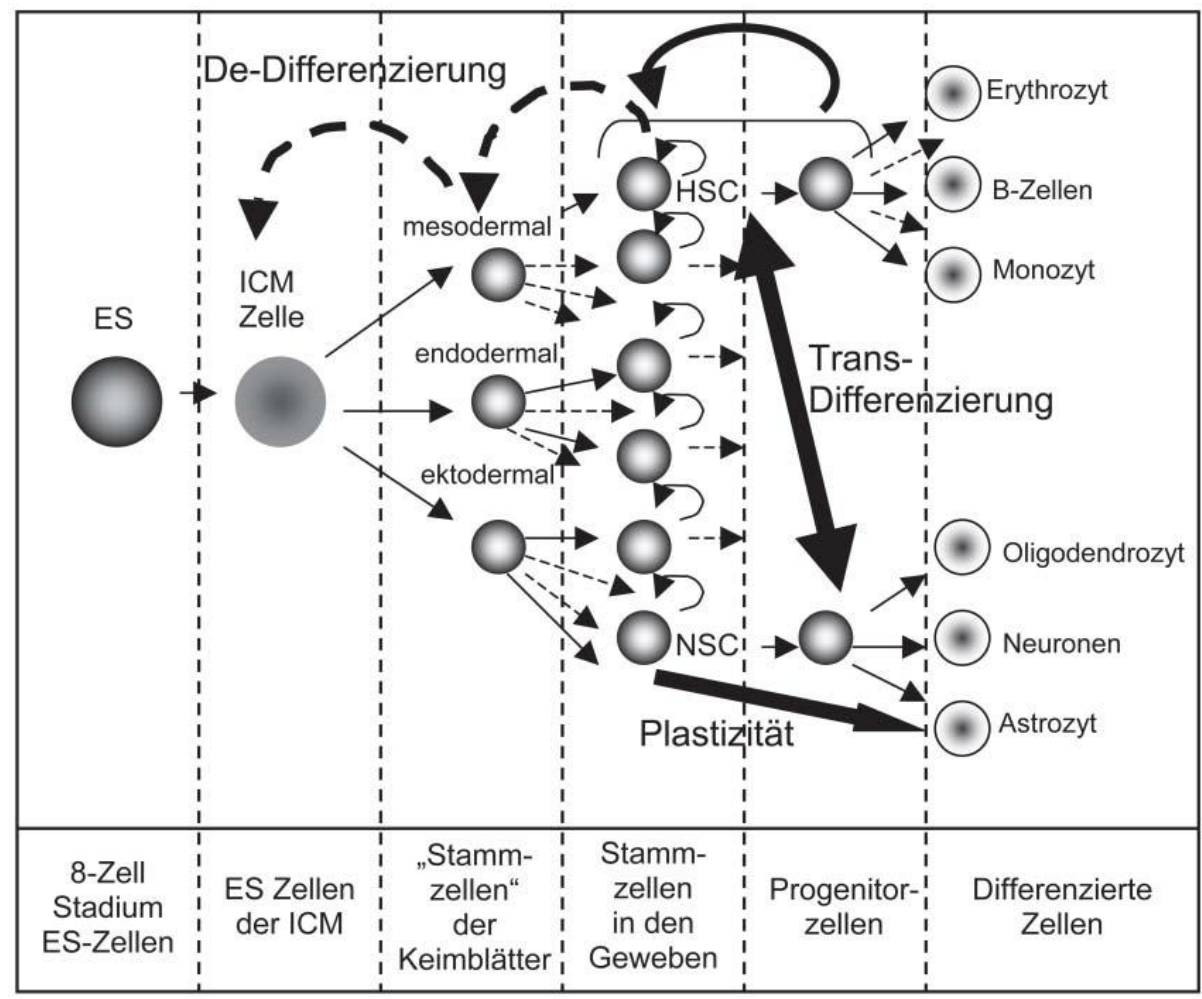

Legende:

$\mathrm{ES}=$ Embryonale

Stammzelle

$\mathrm{ICM}=$ Innere Zellmasse

$\mathrm{HSC}=$ Hämatopoetische

Stammzellen

$\mathrm{NSC}=$ Neuronale

Stammzellen

Abbildung 5: Theorie über die Plastizität der Satmmzellen

(aus Koestenbauer et al. 2006, S. 326)

Die De-Differenzierung kann bisher am deutlichsten veranschaulicht werden, wenn adulte Stammzellen wieder in eine Blastozyste injiziert werden und diese dann die Pluripotenz von embryonalen Stammzellen erreichen, ähnlich wie die iPSCs, die von Takahashi et al. (2007) beschrieben wurden. Die adulten Zellen gehen unter dem Einfluss der Blastozyste in einen naiveren Zustand über, indem sie sich in die innere Zellmasse integrieren und durch sie beeinflusst werden. Die Einwirkung von der Umgebung auf das Entwicklungsstadium beschrieben Benya und Shaffer (1982), indem sie fibroblastenähnliche Zellen durch Kultivierung in Agarosegel in Chondrozyten überführten. Ähnliches zeigt sich bei den CPCs in Agarosegel, die aufgrund ihrer Umgebung das Genexpressionsmuster wechseln (Koelling et al. 2009), sie bilden vermehrt Kollagen II.

\subsubsection{Migrierende chondrogene Progenitorzellen}

Die von Koelling et al. (2009) beschriebenen migrierenden CPCs kommen im degenerierten Knorpel der OA vor. Sie können durch die Tidemark in die EZM des Knorpels einwandern und finden sich dort im Regenerationsgewebe. Es gibt zwar Anzeichen dafür, dass sie zu einer mesenchymalen Stammzellinie des 
Knochenmarks gehören, es kann aber auch nicht ausgeschlossen werden, dass es sich um transdifferenzierte Chondrozyten handelt. Die CPCs weisen alle Eigenschaften von MSCs auf. Sie lassen sich in verschiedene Zelltypen des Mesenchyms differenzieren, wie Chondrozyten, Adipozyten und Osteozyten. Nach der Differenzierung expremieren diese auch die für die verschiedenen Zelllinien typischen Proteine. Es konnte mittels der Immunfluoreszenzhistochemie gezeigt werden, dass adipogen differenzierte CPCs die Lipoproteinlipase (LPL) und den adipogenen Transkriptionsfaktor PPARY (engl. „peroxisomal proliferator-activated receptor $\gamma^{\prime \prime}$ ) bilden. Die osteogen differenzierten Zellen waren positiv auf Osteocalcin. Des Weiteren besitzen sie ein Selbsterneuerungspotenzial und lassen sich klonen. Die Zellen können mittels Immunhistochemie positiv auf die Stammzellmarker STRO-1, CD29, CD44, CD73, CD90 und CD105 (Mafi et al. 2011) getestet werden. Negativ reagieren sie hingegen auf den Leukozytenmarker CD45, sodass eine Mischpopulation mit hämatopoetischen Zelllinien ausgeschlossen werden kann.

Das Genexpressionsmuster nach normaler Flaschenkultur zeigt im Vergleich zu Chondrozyten, dass in den CPCs die osteogenen Transkriptionsfaktoren runx-2 (engl. „runt-related transcription factor 2") und Kollagen I stärker aktiviert sind als die chondrogenen Transkriptionsfaktoren Kollagen II und sox-9 (SRY engl. „sex determining region Y-box 9"), so wie es bei normalen Chondrozyten der Fall ist. Nach dreiwöchiger Kultur in Alginatkugeln zeigen die CPCs ein ähnliches Expressionsmuster der oben genannten Transkriptionsfaktoren wie Chondrozyten aus gesundem Knorpel. Durch einen Knockdown des Transkriptionsfaktors runx-2 und die Kultivierung in Alginatkugeln, senkte sich die Expression von runx-2 um 92\%, während der chondrogene Transkriptionsfaktor sox-9 um über $100 \%$ anstieg. Ebenso stieg die Expression von Kollagen II und Aggrecan an. Ein weiterer Einfluss der EZM auf die CPCs zeigt sich in der Expression von den Stammzellmarkern CD29 und CD73, die nach Kultivierung auf einer Basalmembranmatrix anstiegen. Dadurch konnte nachgewiesen werden, dass die EZM-Komponenten auf die CPCs Einfluss nehmen und dass die Herunterregulation von runx-2 ihr chondrogenes Potenzial massiv verstärkt. Ihr großes chondrogenes Potenzial, was bisher noch bei keiner anderen chondrogenen Progenitorzelle nachgewiesen wurde, macht sie sehr interessant für neue Therapieansätze degenerativer Gelenkserkrankungen (Koelling et al. 2009). 


\subsection{Ziel der Arbeit}

Der physiologische Reparaturmechanismus des hyalinen Knorpels bei OA ist sehr begrenzt wirksam. Es entsteht ein fibrokartilaginäres Reparaturgewebe, das sehr viel Kollagen I besitzt anstatt des sonst vorhandenen Kollagens II und dadurch den biomechanischen Ansprüchen des Knies nicht gerecht werden kann. Für Patienten in fortgeschrittenen Stadien der OA ist deshalb die einzige wirksame Therapieform oft nur die Knietotalendoprothese (Hamel et al. 2008). In Zukunft sollen osteoarthrotische Knorpeldefekte mit autogenen Transplantaten gedeckt werden können, basierend auf einer ex-vivo-Knorpelneubildung mittels MSCs durch Tissue engineering und einer auf die Chondrozyten abgestimmten Gentherapie. Dadurch sollen autogene Transplantate erstellt werden können, die ein hohes Regenerationspotenzial besitzen und einen geringen Spenderdefekt hinterlassen (Schaefer et al. 2000). Die von Koelling et al. 2009 beschriebenen CPCs besitzen Eigenschaften, die sie als MSCs charakterisieren. Sie sind multipotent, haben migrierende Eigenschaften und sind klonal. Zudem haben sie ein hohes chondrogenes Potenzial und könnten sich deshalb für zellbasierende Therapieformen der OA eignen.

Barbero et al. zeigten 2003 an verschiedenen Klonen von dedifferenzierten Chondrozyten aus humanen Gelenken, die z.T. mit Wachstumsfaktoren behandelt wurden, dass sich zwischen diesen Populationen Unterschiede in ihrer Replikationsrate und der Differenzierbarkeit in andere Zelllinien ergaben. Nicht alle Klone zeigten die Multipotenz von MSCs und ließen sich adipogen bzw. osteogen differenzieren, sondern redifferenzierten sich nur in Chondrozyten oder ließen sich gar nicht differenzieren. Vor allem zeigten überwiegend langsam wachsende Zellen ein besseres osteogenes und adipogenes Potenzial. Auch Mareddy et al. 2007 konnten anhand von MSC-Klonen aus dem Knochenmark osteoarthrotisch erkrankter Menschen Unterschiede in der Proliferationsrate und der Differenzierbarkeit feststellen. Während schnell wachsende Zellen multipotent waren, verringerte sich ihre Differenzierbarkeit mit abnehmender Proliferationsrate und veränderter Zellmorphologie. Die Zellen der CPCs besitzen von Natur aus ein osteogenes und chondrogenes Potenzial aufgrund der von innen dauerhaft exprimierten Transkriptionsfaktoren runx-2 und sox-9, allerdings sind sie nachweislich auch multipotent (Koelling et al. 2009). Um den Zusammenhang zwischen Replikationsrate und Differenzierbarkeit bei den migrierenden CPCs zu untersuchen, wurden für diese 
Arbeit drei Klone einer humanen chondrogenen Progenitorzelllinie aus osteoarthrotisch verändertem Knorpel bei Gonarthrose verglichen. Ausgehend von einer genetischen Gleichheit der Klone wurde ihre Proliferationsrate miteinander verglichen und diese in Zusammenhang mit ihrer Differenzierbarkeit und ihrem osteochondrogenen Expressionsmuster gebracht. Es wird vermutet, dass sich langsam wachsende Klone der CPCs schlechter in andere Zelllinien des Mesenchyms differenzieren lassen als schnell wachsende, da dieses Verhalten auch schon bei anderen Zelllinien beobachtet werden konnte. Ebenso wurden ihr Phänotyp und ihr Wachstumsverhalten in Kolonie beobachtet, da sich häufig auch in diesem Zusammenhang Unterschiede in der Morphologie ergeben (Barbero et al. 2003, Mareddy et al. 2007). Die Klone wurden osteogen und adipogen differenziert und mittels Alkalischer-Phosphatase-Reaktion (AP) und Oil-Red-Färbung die Differenzierbarkeit nachgewiesen. An dem Vergleich der adipogenen und osteogenen Differenzierung sollte sich zeigen, ob Zellen, die wie die CPCs genetisch eher ein osteogenes Expressionsmuster in Monolayer-Kultur aufweisen, sich erschwert adipogen differenzieren lassen. Die Expression von typischen Proteinen und Transkriptionsfaktoren für Osteoblasten und Adipozyten wurde quantitativ bestimmt. Für die Osteoblasten wurden Antikörper gegen den osteogenen Transkriptionsfaktor runx-2 und das Knochenprotein Osteocalcin verwendet, für die Adipozyten AK gegen die Lipoproteinlipase (LPL) und den adipogenen Transkriptionsfaktor PPAR $\gamma$. Abschließend wurden mittels Western-Blot quantitativ die Transkriptionsfaktoren runx-2 und sox-9 der Klone bestimmt, um Auskunft über ihr osteogenes bzw. chondrogenes Potenzial zu erhalten. 


\section{Material und Methoden}

\subsection{Material}

\subsubsection{Chemikalien}

Acrylamid Rotiphorese ${ }^{\circledR}$ Gel 30

Ammoniumperoxidsulfat (APS)

Bromphenol-Blau

BSA

$\beta$-Mercaptoethanol

Coomassie-Brilliant-Blau-R250

Dimethylsulfoxid (DMSO)

\section{Essigsäure}

Ethanol p.a.

Formaldehyd

Glycerin

Glycin

Kaliumchlorid (KCl)

$\mathrm{KH}_{2} \mathrm{PO}_{4}$

Magermilchpulver

Methanol

$\mathrm{Na}_{2} \mathrm{HPO}_{4}$

Natriumchlorid $(\mathrm{NaCl})$

Oil Red O

Paraformaldehyd

PBS-Pellets

2-Propanol

Salzsäure $(\mathrm{HCl})$

SDS-Pellets

TEMED

Tris

Triton ${ }^{\circledR} \mathrm{X}-100$

Tween $^{\circledR}$
Carl Roth GmbH \& Co KG

Carl Roth GmbH \& Co KG

Carl Roth GmbH \& Co KG

Sigma-Aldrich Chemie GmbH

Sigma-Aldrich Chemie GmbH

Carl Roth $\mathrm{GmbH}$ \& Co KG

Sigma-Aldrich Chemie GmbH

AppliChem GmbH

AppliChem GmbH

Carl Roth GmbH \& Co KG

Carl Roth $\mathrm{GmbH} \&$ Co KG

AppliChem GmbH

Merck Millipore

Merck Millipore

AppliChem GmbH

Carl Roth GmbH \& Co KG

Sigma-Aldrich Chemie GmbH

AppliChem GmbH

Sigma-Aldrich Chemie GmbH

Carl Roth GmbH \& Co KG

Sigma-Aldrich Chemie GmbH

Carl Roth GmbH \& Co KG

Carl Roth $\mathrm{GmbH}$ \& Co KG

Carl Roth $\mathrm{GmbH}$ \& Co KG

Carl Roth GmbH \& Co KG

Carl Roth GmbH \& Co KG

Sigma-Aldrich Chemie GmbH

Sigma-Aldrich Chemie GmbH
Karlsruhe, DE

Karlsruhe, DE

Karlsruhe, DE

Steinheim, DE

Steinheim, DE

Karlsruhe, DE

Steinheim, DE

Darmstadt, DE

Darmstadt, DE

Karlsruhe, DE

Karlsruhe, DE

Darmstadt, DE

Darmstadt, DE

Darmstadt, DE

Darmstadt, DE

Karlsruhe, DE

Steinheim, DE

Darmstadt, DE

Steinheim, DE

Karlsruhe, DE

Steinheim, DE

Karlsruhe, DE

Karlsruhe, DE

Karlsruhe, DE

Karlsruhe, DE

Karlsruhe, DE

Steinheim, DE

Steinheim, DE

Tabelle 1: Chemikalien 


\title{
2.1.2 Reagenzien
}

Alkalische-Phosphatase-Kit (Sigma-Aldrich Chemie GmbH, Steinheim, DE)

\section{Alkalifarbstoffgemisch}

$0,1 \mathrm{ml}$ Natriumnitritlösung $(0,1 \mathrm{~mol} / \mathrm{l})$

0,1 ml FBB-Alkalilösung (Fast Blue BB-Standardlösung, $5 \mathrm{mg} / \mathrm{ml}$, in 0,4 mol/l

Salzsäure, mit Stabilisatoren)

2 min bei RT stehenlassen

$4,5 \mathrm{ml}$ aqua dest.

0,1 ml Naphthol As-BI-Alkali-Lösung (Naphthol AS-BI Phosphat, 4 mg/ml, in AMPD-Puffer, 2 mol/l, $\mathrm{pH} 9,5)$

\section{Amersham ECL Prime Western Blotting Detection Reagent (GE Healthcare, Buckinghamshire, UK)}

Lösung A: $100 \mathrm{ml}$ ECL Plus Substrat in Tris-Puffer

Lösung B: $\quad$ 2,5 ml Acridiniumester in Dioxan und Ethanol als Lösungsmittel

\section{$10 \%$ Ammoniumperoxidsulfat}

$1 \mathrm{~g}$ Ammoniumperoxidsulfat in

$10 \mathrm{ml}$ aqua dest. lösen

\author{
$5 \%$ Blocklösung \\ $0,5 \mathrm{~g}$ Milchpulver in \\ $10 \mathrm{ml}$ TBS-T lösen
}




\section{1 \% BSA-Lösung}

$0,5 \mathrm{~g}$ BSA in

$50 \mathrm{ml}$ PBS lösen und steril filtrieren

\section{Coomassie-Brilliant-Blau-Färbelösung}

0,75 g Brilliant-Blau-R250

$250 \mathrm{ml} \quad$ Methanol

$50 \mathrm{ml} \quad$ Essigsäure

mit aqua dest. auf $500 \mathrm{ml}$ bei RT auffüllen

\section{Entfärbelösung 1}

$500 \mathrm{ml} \quad$ Methanol

$100 \mathrm{ml} \quad$ Essigsäure

mit aqua dest. auf $1000 \mathrm{ml}$ bei RT auffüllen

\section{Entfärbelösung 2}

$100 \mathrm{ml} \quad$ Methanol $90 \%$

$5 \mathrm{ml} \quad$ Essigsäure $10 \%$

mit aqua dest. auf $1000 \mathrm{ml}$ bei RT auffüllen

\section{Entwickler- und Fixiererlösung}

Kodak, Rochester, USA 
Faramount Aqueous Mounting Medium

DAKO GmbH, Hamburg, DE

\section{Laufpuffer $5 \mathrm{x}$}

$30,3 \mathrm{~g} \quad$ Tris $(0,25 \mathrm{M})$

$142,6 \mathrm{~g} \quad$ Glycin (1,9 M)

$50 \mathrm{ml} \quad$ SDS (10\%)

mit aqua dest. auf $1000 \mathrm{ml}$ auffüllen

\section{Neutral-Red}

Sigma-Aldrich Chemie GmbH, Steinheim, DE

\section{Oil-Red-O-Färbelösung}

\section{Stammlösung}

0,35 g Oil-Red-O in

$100 \mathrm{ml} \quad 100 \%$ 2-Propanol lösen

über Nacht rühren

\section{Gebrauchslösung Oil-Red-O}

$6 \mathrm{ml}$ Stammlösung

$4 \mathrm{ml}$ aqua dest.

über Nacht bei RT ruhen lassen

durch 0,2 $\mu \mathrm{m}$ Filter filtrieren 


\section{$2 \%$ Paraformaldehyd}

0,5 g Paraformaldehyd in

$25 \mathrm{ml}$ PBS in einem $50 \mathrm{ml}$ Falcon Tube mischen

bei $70^{\circ} \mathrm{C}$ im Wasserbad lösen

\section{PBS $10 \%$}

$\begin{array}{ll}81,8 \mathrm{~g} & \mathrm{NaCl} \\ 2,0 \mathrm{~g} & \mathrm{KCl} \\ 16,0 \mathrm{~g} & \mathrm{Na}_{2} \mathrm{HPO}_{4} \\ 2,0 \mathrm{~g} & \mathrm{KH}_{2} \mathrm{PO}_{4} \\ & \text { mit aqua dest. auf } 1000 \mathrm{ml} \text { auffüllen } \\ & \mathrm{pH} 7,4\end{array}$

\section{Sammelgelpuffer}

$15,1 \mathrm{~g} \quad$ Tris $(0,5 \mathrm{M})$

$250 \mathrm{ml} \quad$ aqua dest.

mit $\mathrm{HCl}$ auf $\mathrm{pH}$ 6,8 einstellen

$10 \%$ SDS

$100 \mathrm{~g} \quad$ SDS in

$1000 \mathrm{ml}$ aqua dest. lösen 


\section{SDS-Probenpuffer $3 \mathrm{x}$}

$3,6 \mathrm{~g}$ Tris $(0,25 \mathrm{M})$

$9 \mathrm{~g} \operatorname{SDS}(9 \%)$

$22,5 \mathrm{~g}$ Glycerin $(22,5 \%)$

Spatelspitze Bromphenol-Blau

vor SDS Zugabe mit HCl auf ph 6,7 und $100 \mathrm{ml}$ aqua dest. bei RT zugeben

\section{TBS $10 x$}

24,2 g Tris (200 mM)

$87,6 \mathrm{~g} \mathrm{NaCl}(1,5 \mathrm{M})$

mit aqua dest. auf $1000 \mathrm{ml}$ bei RT auffüllen

\section{TBS-T}

$100 \mathrm{ml} \quad$ TBS $10 \mathrm{x}$

0,5 g Tween $20(0,05 \%)$

mit aqua dest. auf 1000 ml bei RT auffüllen

\section{Transferpuffer}

$6,05 \mathrm{~g} \quad$ Tris $(25 \mathrm{mM})$

28,8 g Glycin (192 mM)

$400 \mathrm{ml} \quad$ Methanol (20\%)

mit aqua dest. auf 2000 ml auffüllen

$\mathrm{pH} 8,3$ 
Trenngelpuffer

$45,4 \mathrm{~g} \quad 1,5 \mathrm{M}$ Tris

$250 \mathrm{ml} \quad$ aqua dest.

mit $\mathrm{HCl}$ auf $\mathrm{pH}$ 8,9 einstellen

1 x Trypsin-Lösung (Enzym Trypsin, Gibco ${ }^{\circledR}$, Life Technologies GmbH, Darmstadt, DE)

$1 \mathrm{ml}$ Trypsin-Lösung $(10 \mathrm{x})$

$9 \mathrm{ml}$ PBS (10\%)

$0,25 \%$ Triton $^{\circledR} \mathrm{X}-100$

$0,125 \mathrm{~g} \quad \operatorname{Triton}^{\circledR} \mathrm{X}-100 \mathrm{in}$

$50 \mathrm{ml} \quad$ PBS lösen

Vectashield $^{\circledR}$ Mounting Medium with DAPI

Vector Laboratories, Kalifornien, USA

\subsubsection{Medien und Lösungen}

Dulbecco's Modified Eagle Medium (DMEM+GlutaMAX ${ }^{\mathrm{TM}}$, Gibco ${ }^{\circledR}$, Life Technologies GmbH, Darmstadt, DE)

$500 \mathrm{ml} \quad$ DMEM

$10 \% \quad$ FBS

50.000 U Penicillin

$50 \mathrm{mg} \quad$ Streptomycin 
MSC Adipogenic Differentation Medium C-28011 (ready to use)

PromoCell GmbH, Heidelberg, DE

MSC Osteogenic Differentation Medium C-39813 (ready to use)

PromoCell GmbH, Heidelberg, DE

\section{Fötales Rinderserum (FBS)}

Gibco $^{\circledR}$, Life Technologies GmbH, Darmstadt, DE

\subsubsection{Verbrauchsmaterialien}

\begin{tabular}{|l|l|l|}
\hline Amersham Hyperfilm ECL & GE Healthcare & Buckinghamshire, UK \\
Cell Scraper & Sarstedt AG \& Co & Nümbrecht, DE \\
Feckgläser (12 mm, rund) & Gerhard Menzel GmbH & Braunschweig, DE \\
Falcon Tube (10/50 ml) & Sarstedt AG \& Co & Nümbrecht, DE \\
Filtropur S plus $0.2 \mu \mathrm{m}$ & Sarstedt AG \& Co & Nümbrecht, DE \\
Nunc Cryo Tubes Vials & Thermo Scientific & Langenselbold, DE \\
Objektträger (76 $\times 26 \mathrm{~mm})$ & Knittel Glasbearbeitungs GmbH & Braunschweig, DE \\
Parafilm ${ }^{\circledR} \mathrm{M}$ & Brand GmbH \& Co KG & Wertheim, DE \\
PVDF-Membran & Merck Millipore & Darmstadt, DE \\
Safe Lock Tubes $(1,5 / 2 \mathrm{~mm})$ & Eppendorf AG & Hamburg, DE \\
Zellkulturflaschen Cellstar & Greiner BioOne GmbH & Frickenhausen, DE \\
Well-Platten (96/6 Well) & Sarstedt AG \& Co & Nümbrecht, DE \\
Zählkammer (SD100 Slides) & Nexcelom Bioscience LLC & Lawrence, USA \\
\hline
\end{tabular}

Tabelle 2: Verbrauchsmaterialien 


\subsubsection{Geräte}

\begin{tabular}{|l|l|l|}
\hline Cellometer ${ }^{\text {TM }}$ AutoT4 & Nexcelom Bioscience LLC & Lawrence, USA \\
Centrifuge 5810 & Eppendorf AG & Eppendorf, DE \\
Elektrophoresekammer & Eppendorf AG & Eppendorf, DE \\
Herafreeze -80 ${ }^{\circ} \mathrm{C}$ & Nachbau & Thermo Scientific \\
Inkubator Labotect C200 & Labotect GmbH & Langenselbold, DE \\
Kamera Nikon D90 & Nikon GmbH & Göttingen, DE \\
Mikroskop Axiovert 40CFL & Carl Zeiss AG & Düsseldorf, DE \\
Nalgene ${ }^{\circledR}$ Freezing Container & Thermo Scientific & Oberkochen, DE \\
Objektiv EC Plan-Neofluar & Carl Zeiss AG & Langenselbold, DE \\
PureLab Ultra & Elga LabWater & Oberkochen, DE \\
Scanner Scanjet G4050 & Hewlett-Packard GmbH & Celle, DE \\
Sterilwerkbank HeraSafe & Heraeus Holding GmbH & Göblingen, DE \\
Thermocycler comfort & Eppendorf AG & Eartorius AG \\
Waage & & \\
\hline
\end{tabular}

Tabelle 3: Geräte

\subsection{Methoden}

\subsubsection{Probenmaterial}

Die Methodenteile 2.2.1.1-2.2.3 sind vollständigkeitshalber hier mit aufgeführt, wurden aber nicht für diese Arbeit explizit durchgeführt. Sie sind in der Originalpublikation von Koelling et al. (2009) nachzulesen.

\subsubsection{Osteoarthrotischer Knorpel}

Das Knorpelgewebe zur Gewinnung der hier verwendeten CPCs stammt von einer Patientin, die aufgrund einer fortgeschrittenen Gonarthrose eine Knietotalendoprothese bekam. Die Diagnose wurde anhand der Kriterien des „American College of Rheumatology“ verifiziert, die Altman et al. (1986) zur Klassifikation der Osteoarthrose des Knies aufstellten. Die histopathologische Bestimmung einer OA erfolgte nach der von Pritzker et al. (2006) erstellten Graduierung. Die Patientin wurde im 
Rahmen der Richtlinien der Ethikkommission der Georg-August-Universität Göttingen über die Probenentnahme aufgeklärt und gab dafür ihr schriftliches Einverständnis. Der Ethikantrag ist unter der Nummer 25/12/10 zu finden.

\subsubsection{Aufarbeitung des Knorpelgewebes}

Das intraoperativ abgetrennte Plateau des Femurkondylus wurde bis zur weiteren Aufarbeitung in mit Nährmedium (s.u.) befüllten, sterilen Sammelbehältern aufbewahrt. Unter einer Sterilwerkbank (HeraSafe, Heraeus, Hanau) wurde der Femurkondylus in eine sterile Petrischale überführt, um dort die weitere Aufbereitung durchzuführen. Mit einem Skalpell wurden etwa $4 \mathrm{~mm}^{2}$ große Chips aus dem fibrokartilaginären Randbereich des Hauptdefektes geschnitten und etwa zwei bis drei Skalpellklingenspitzen voll in eine $75-\mathrm{cm}^{2}$-Zellkulturflasche (Cellstar ${ }^{\circledR}$, Greiner Bio-One, Frickenhausen) mit $10 \mathrm{ml}$ Nährmedium gegeben. Als Zellkulturmedium wurde Dulbecco's Modified Eagle Medium (DMEM+GlutaMAX ${ }^{\top M}$, Gibco ${ }^{\circledR}$, Life Technologies, Darmstadt) mit $10 \%$ fötalem Rinderserum (FBS, engl. „fetal bovine serum", Gibco ${ }^{\circledR}$, Life Technologies $\mathrm{GmbH}$, Darmstadt) versetzt. Des Weiteren kamen noch $50.000 \cup$ Penicillin und $50 \mathrm{mg}$ Streptomycin dazu. Die so befüllten Zellkulturflaschen kamen für 10 Tage bei $37{ }^{\circ} \mathrm{C}$ und $5 \% \mathrm{CO}_{2}$ in den Inkubator (Labotect C200, Labotect, Göttingen). Die CPCs sind während dieser Zeit selbstständig aus den Chips migriert und setzten sich auf dem Flaschenboden ab. Zu dicht gewachsene Zellen im Bereich der Knorpelchips wurden mittels Schaber gelöst, um so eine gleichmäßige Konfluenz der Zellen zu garantieren. Nach Ablauf der 10 Tage wurden die Knorpelchips verworfen und das Nährmedium zum ersten Mal gewechselt. Die so erhaltene Zellpopulation wurde zur weiteren Vermehrung in den normalen Ablauf der Zellkultur eingebunden.

\subsubsection{Zellkultur}

Die Zellkultur - zur Vermehrung der Zellpopulation - wurde in $75-\mathrm{cm}^{2}$-Zellkulturflaschen (Cellstar ${ }^{\circledR}$, Greiner Bio-One, Frickenhausen) angelegt. Die Zellen wurden bei $37{ }^{\circ} \mathrm{C}$ und $5 \% \mathrm{CO}_{2}$ im Inkubator (Labotect C200, Labotect, Göttingen) gelagert. Als Nährmedium wurde das bereits oben beschriebene DMEM mit den selben Zusätzen verwendet, mit jeweils $10 \mathrm{ml}$ pro Flasche. Alle zwei bis drei Tage wurde das Medium in den Zellkulturflaschen gewechselt. Unter einer Sterilwerkbank wurde dazu das verbrauchte Medium aus den Flaschen dekantiert und jeweils $10 \mathrm{ml}$, auf $37^{\circ} \mathrm{C}$ vorgewärmtes Medium, neu einpipettiert. 
Nach einer Konfluenz von ca. $90 \%$ wurden die Zellen passagiert. Dazu wurde das Medium abgegossen und die Flasche zweimal mit 10 \% PBS (engl. „phosphate buffered saline“, Sigma-Aldrich, Steinheim) gespült. Anschließend wurde $1 \mathrm{ml}$ des Verdauungsenzyms Trypsin in die Zellkulturflasche pipettiert um die adhärenten Zellen vom Boden zu lösen. Das Trypsin lag in einer einfachen Konzentration vor, da zuvor 10 x konzentriertes Trypsin mit $10 \%$ PBS verdünnt wurde. Durch ein Mikroskop (Axiovert 40CFL, Carl Zeiss, Oberkochen) wurde der Fortschritt des Lösens beobachtet und durch Klopfen auf die Flasche beschleunigt. Die gelösten Zellen wurden in ein $50 \mathrm{ml}$ Falcon Tube (Sarstedt, Nümbrecht) geschüttet und die Flasche mit $5 \mathrm{ml}$ Nährmedium gespült, um alle Zellen aus der Flasche zu bekommen und die Wirkung des Trypsins zu inhibieren. Die $5 \mathrm{ml}$ wurden ebenfalls zu den restlichen Zellen in das Falcon Tube gegeben. Die Zellsuspension wurde dann bei $200 \mathrm{~g}$ für $10 \mathrm{~min}$ zentrifugiert (centrifuge 5810, Eppendorf, Hamburg), um ein konzentriertes Zellpellet am Boden des Zentrifugenröhrchens zu erhalten. Der Überstand wurde verworfen und das Zellpellet in $1 \mathrm{ml}$ Nährmedium resuspendiert. $20 \mu \mathrm{l}$ dieser Zellsuspension wurden in eine Zählkammer (SD100 Slides, Nexcelom Bioscience LLC, Lawrence-USA) einpipettiert und die Zellen mittels Zellometer (Cellometer ${ }^{\mathrm{TM}}$ AutoT4, Nexcelom Bioscience LLC, Lawrence-USA) automatisch ausgezählt. Die $980 \mu \mathrm{l}$ wurden daraufhin auf so viele $75-\mathrm{cm}^{2}$-Zellkulturflaschen verteilt, dass sich pro Flasche eine Zellzahl von ca. 75.000 Zellen ergab. Die Flaschen wurden mit der fortlaufenden Passagennummer gekennzeichnet und wieder in den Inkubator gelegt.

Für das Einfrieren von Zellen oder die Erstellung eines Zellpellets für den WesternBlot wurde das Medium aus der Flasche verworfen und die Zellkulturflasche zweimal mit $10 \mathrm{ml} 10 \%$ PBS gespült, um Zelltrümmer vollständig zu entfernen. Danach folgte, wie oben beschrieben, das Lösen der Zellen mittels Trypsin, Nachspülen mit 5 $\mathrm{ml}$ Nährmedium und das Zentrifugieren bei $200 \mathrm{~g}$ für $10 \mathrm{~min}$. Das so entstandene Pellet konnte, nach Abgießen des Überstandes, für spätere Versuche (z.B. WesternBlot) bei $-80^{\circ} \mathrm{C}$ weggefroren werden.

Für die Einlagerung in flüssigem Stickstoff wurde ein spezielles Einfriermedium erstellt, für das $8 \mathrm{ml}$ gebrauchsfertigem DMEM noch zusätzlich $1 \mathrm{ml} \mathrm{FBS} \mathrm{und} 1 \mathrm{ml}$ Dimethylsulfoxid (DMSO) zugesetzt wurden. Nach dem Abzentrifugieren der Zellen wurden diese in $1 \mathrm{ml}$ Einfriermedium resuspendiert und mittels Zellometer deren 
Anzahl bestimmt. Die Zellsuspension wurde daraufhin mit dem Einfriermedium so verdünnt, dass sich ca. 500.000 Zellen/ml ergaben. Spezielle Cryo Tubes (Nunc CryoTubes Vials, Thermo Scientific, Langenselbold) wurden mit $1 \mathrm{ml}$ dieser Suspension befüllt und in Gefrierbehältern (Nalgene ${ }^{\circledR}$ Mr. Frosty, Freezing Container, Rochester-USA) über Nacht bei $-80{ }^{\circ} \mathrm{C}$ im Gefrierschrank (Herafreeze, Thermo Scientific, Langenselbold) gelagert. Am folgenden Tag konnten dann die Cryo Tubes in flüssigem Stickstoff eingelagert werden.

\subsubsection{Immortalisierung}

Die Immortalisierung wurde von Wolfgang Böcker an der Ludwig-MaximilianUniversität in München mittels eines lentiviralen Plasmids für die HumaneTelomerase-Reverse-Transkriptase (hTERT) durchgeführt. Der Plasmid pLenti6/v5hTERT wurde mit den Helferplasmiden pLP1, pLP2 und pLP/VSVG in 293FT-Zellen kotransfiziert (ViraPower ${ }^{\mathrm{TM}}$ Lentiviral Expression System, Invitrogen ${ }^{\mathrm{TM}}$, Karlsruhe). Nach 48 Stunden wurde der Überstand mit den rekombinanten Viren geerntet und die CPCs damit infiziert. Der Plasmid enthielt als Selektionsmaker ein BlasticidinResistenzgen, dadurch konnten unter Verwendung von $1 \mu \mathrm{g} / \mathrm{ml}$ Blasticidin die infizierten CPCs innerhalb einer Woche selektiert werden.

\subsubsection{Klonierung}

Die Klonierung erfolgte für die Arbeit von Koelling et al. (2009) mittels serieller Verdünnung einer CPC-Zellpopulation. Wie oben beschrieben, wurden die Zellen geerntet und gezählt. Nach der Bestimmung der Zellzahl wurde die Zellsuspension auf 400 Zellen/ $\mu$ verdünnt. Die Zellen sollten auf vier 96 -Well-Mikrotestplatten (Sarstedt, Nümbrecht) verteilt werden, wobei zur leichteren Rechnung eine Mikrotestplatte mit 100 Wells berechnet wurde. Pro Well sollten $100 \mu \mathrm{l}$ Nährmedium verwendet werden. $1 \mu \mathrm{l}$ der Zellsuspension wurde auf $40 \mathrm{ml}$ verdünnt, sodass rechnerisch jedes Well mit $100 \mu \mathrm{l}$ Medium und genau einer Zelle befüllt werden konnte. Wells, die nach lichtmikroskopischer Kontrolle genau eine Zelle enthielten, wurden markiert und daraus die Klone generiert. Als Nährmedium wurde wieder DMEM mit $10 \%$ FBS und den oben beschriebenen Antibiotika verwendet. Die Platten wurden mit den römischen Ziffern I, II, III und IV durchnummeriert. Die Bezeichnung der einzelnen Wells erfolgte quer zur Platte durch die Buchstaben A-L und längs durch die arabischen Ziffern 1-8, sodass die Kennzeichnung jedes Klons aus drei Teilen bestand (z.B. IIE-5). Für diese Arbeit wurden die Klone IF-8, IIB-6 und 
IID-4 verwendet. Nach mehreren Replikationsphasen wurden sie zunächst in 6-WellPlatten (Sarstedt, Nümbrecht) passagiert, danach in $25-\mathrm{cm}^{2}$-Zellkulturflaschen $\left(\right.$ Cellstar $^{\circledast}$, Greiner Bio-One, Frickenhausen) und anschließend in $75-\mathrm{cm}^{2}$-Flaschen, um ausreichend Zellen für die verschiedenen Versuchsreihen zur Verfügung zu haben.

\subsubsection{Replikationsassay}

Zum Vergleich der Replikationsraten der Klone wurde ein Replikationsassay durchgeführt. Die Messung erfolgte über einen Zeitraum von sieben Tagen, wobei für jeden Klon drei Wachstumskurven erstellt wurden aus denen ein Mittelwert errechnet wurde. Die Zellen wurden dafür in 6-Well-Platten ausgesät, wobei pro Klon und Tag jeweils zwei Wells genutzt wurden mit einer Anfangskonzentration von $10 \times 10^{3}$ Zellen pro Well. Als Nährmedium wurde wieder DMEM mit $10 \%$ FBS und dem Zusatz von Penicillin und Streptomycin verwendet, mit einem Volumen von 2 ml/Well.

Jeden Tag wurden jeweils zwei Wells einer Platte geerntet, wozu das Nährmedium abgesaugt und anschließend die Wells mit je $500 \mu \mathrm{l} 10 \%$ PBS gespült wurden. Das PBS zur Spülung wurde ebenfalls abgesaugt und danach erneut $500 \mu 10 \%$ PBS in die Wells pipettiert, in dem dann die Zellen mittels Schaber gelöst wurden. Die Zellsuspension beider Wells wurde in ein E-Cup (Eppendorf, Hamburg) überführt und die Wells nochmals mit $250 \mu \mathrm{l}$ PBS nachgespült und ebenfalls in das E-Cup einpipettiert, das dann mit $300 \mathrm{~g}$ für 10 min zentrifugiert wurde (Eppendorf Zentrifuge Modell 5415 R, Eppendorf, Hamburg). Der Überstand wurde verworfen und die Zellen in frischen $100 \mu \mathrm{l} 10 \%$ PBS resuspendiert. $20 \mu \mathrm{l}$ dieser Suspension wurden in eine Zählkammer pipettiert und mittels Zellometer gezählt.

\subsubsection{Zelldifferenzierung}

\subsubsection{Adipogene Differenzierung}

Die adipogene Differenzierung, zum Nachweis der Multipotenz und die quantitative Auswertung, wurde wie folgt vorgenommen. Auf den Boden einer 6-Well-Platte wurden vier runde Deckgläser (Gerhard Menzel, Braunschweig) mit einem Durchmesser von $12 \mathrm{~mm}$ gelegt und 2,5 ml DMEM pro Well einpipettiert. Das Aussäen der Zellen auf Deckgläser (DG) diente zur leichteren Handhabung bei verschiedenen Versuchsreihen. Zum Vergleich, ob es zu Unterschieden in der Differenzierbarkeit bei unterschiedlicher Zelldichte kommen würde, wurde für jeden 
Versuch mit zwei unterschiedlichen Anfangskonzentrationen bezüglich der Zellzahl gearbeitet. Es wurden pro Klon jeweils einmal $1 \times 10^{3}$ und $3 \times 10^{3}$ Zellen/Well ausgesät. Die Zellzahl wurde zuvor mittels Zellometer bestimmt. Die so bestückten Platten kamen für $24 \mathrm{Std}$. bei $37{ }^{\circ} \mathrm{C}$ und $5 \% \mathrm{CO}_{2}$ in den Inkubator. Laut Herstellerangaben mussten die Zellen über $24 \mathrm{Std}$. mit normalem Medium inkubiert werden, bevor die Differenzierung beginnen konnte. Das DMEM wurde am folgenden Tag abgesaugt und die Wells jeweils mit $500 \mu \mathrm{l} 10 \%$ PBS gespült. Danach kamen 2,5 ml MSC Adipogenic Differentation Medium (PromoCell, Heidelberg) in die Wells und die Zellen wurden unter Standardbedingungen weiter inkubiert. Das hier verwendete Differenzierungsmedium enthält alle Wachstumsfaktoren und Nährstoffe, die zur adipogenen Differenzierung notwendig sind. Alle zwei bis drei Tage wurde das Medium gewechselt und unter dem Mikroskop die Veränderung des Phänotyps kontrolliert. Die Differenzierung wurde über 10 Tage durchgeführt, danach wurden die Zellen für die Versuche verwendet. Die Verarbeitung des Mediums erfolgte nach Herstellerangaben, die vorgeschrieben Inkubationszeit von 14 Tagen wurde aber aufgrund empirischer Versuchsreihen auf zehn Tage verkürzt. Die Zellen hatten meistens nach zehn Tagen eine Konfluenz von $100 \%$ erreicht und starben ab.

\subsubsection{Osteogene Differenzierung}

Die osteogene Differenzierung wurde entsprechend der adipogenen durchgeführt. Nach 24 Std. Inkubationszeit mit DMEM wurde das Nährmedium abgesaugt und die Wells mit $500 \mu \mathrm{l} 10 \%$ PBS gespült. Die Wells wurden daraufhin mit 2,5 ml MSC Osteogenic Differentation Medium (PromoCell, Heidelberg) befüllt und weiter inkubiert. Alle zwei bis drei Tage wurde das Medium gewechselt und ebenfalls die Veränderung des Phänotyps kontrolliert. Die Klone wurden auch hier für 10 Tage mittels Medium differenziert und anschließend für die Versuche verwendet. Nach Herstellerangaben sollte die Differenzierung über drei Wochen laufen; aus oben genannten Gründen wurde deshalb auch hier die Inkubationszeit verkürzt.

\subsubsection{Kontrollpopulation}

Zur Erstellung einer Negativkontrolle wurden die Klone zum selben Zeitpunkt ausgesät wie die Klone, die adipogen und osteogen differenziert werden sollten. Die Anfangskonzentration der Zellen und die Kulturbedingungen wurden wie in Kap. 2.2.1.3 (S. 31) beschrieben durchgeführt. Die Negativkontrollen wurden über 10 Tage mit DMEM kultiviert. 


\subsubsection{Oil-Red-Färbung}

Der Nachweis von lipidhaltigen Vakuolen in adipogen differenzierten Klonen wurde mittels der Oil-Red-Färbung nachgewiesen. Hierbei handelt es sich um einen Azofarbstoff, der die Triacylglyceride der Fettvakuolen intensiv rot anfärbt.

Für die Färbelösung wurde zunächst eine Stammlösung erstellt. Dafür wurden 0,35 g Oil-Red-O-Pulver (Sigma-Aldrich, Steinheim) in $100 \mathrm{ml} 100 \%$ 2-Propanol unter ständigem Rühren über Nacht gelöst. Für die Gebrauchslösung wurden dann $6 \mathrm{ml}$ der Stammlösung mit $4 \mathrm{ml}$ aqua dest. verdünnt und durch einen 0,2 $\mu \mathrm{m}$ Sterilfilter (Filtropur S plus 0.2, Sarstedt, Nümbrecht) filtriert. Die Gebrauchslösung ruhte dann bei Raumtemperatur (RT) über Nacht und konnte danach verwendet werden.

Die Durchführung der Färbung war für die differenzierten Klone und die Negativkontrollen identisch. Für die Färbung wurde das Medium aus den Wells abgesaugt und die Zellen zweimal mit $2 \mathrm{ml} 10 \%$ PBS gewaschen. Die DG wurden mit einer Pinzette aus den Wells entnommen und auf Parafilm (Parafilm ${ }^{\circledR} \mathrm{M}$, Brand, Wertheim) gelegt, dadurch konnten die verwendeten Reagenzien sparsamer und genauer appliziert werden. Die Zellen wurden mit $10 \%$ gepuffertem Formalin für eine Std. bei RT fixiert. Das Formalin wurde abgesaugt und die Zellen zweimal mit destilliertem Wasser (PureLab Ultra, Elga LabWater, Celle) gewaschen. Danach erfolgte die Färbung mittels Oil-Red-Gebrauchslösung für $30 \mathrm{~min}$ bei RT. Das OilRed wurde abgesaugt und die Zellen zweimal mit aqua dest. gewaschen. Nachdem die DG getrocknet waren, wurden sie auf Objektträgern $(76 \times 26 \mathrm{~mm}$, Knittel Glasbearbeitungs $\mathrm{GmbH}$, Braunschweig) mit wässrigem Eindeckmedium (Faramount Aqueous Mounting Medium, DAKO, Hamburg) eingedeckelt. Die Ergebnisse wurden unter dem Mikroskop ausgewertet und fotodokumentarisch festgehalten.

\subsubsection{Alkalische-Phosphatase-Färbung}

Zum Nachweis einer AP-Aktivität wurde ein frisch angesetztes Alkalifarbstoffgemisch verwendet (Sigma-Aldrich, Steinheim), dessen Reagenzien alle im Kit enthalten waren. Bei einer positiven Reaktion ergibt sich ein rosa bis kräftig blauer Farbumschlag im Zytoplasma. Für das Farbstoffgemisch wurden 0,1 ml Natriumnitritlösung $(0,1 \mathrm{~mol} / \mathrm{l})$ mit $0,1 \mathrm{ml}$ FBB-Alkalilösung (Fast Blue BBStandardlösung, $5 \mathrm{mg} / \mathrm{ml}$, in 0,4 mol/l Salzsäure, mit Stabilisatoren) in einem $10 \mathrm{ml}$ Falcon Tube (Sarstedt, Nümbrecht) sorgfältig durch Umdrehen gemischt und die Lösung 2 min bei RT stehen gelassen. Diese Diazoniumsalzlösung wird in 4,5 ml 
aqua dest. verdünnt. Zu der verdünnten Lösung kamen 0,1 ml Naphthol As-BI-AlkaliLösung (Naphthol AS-BI Phosphat, $4 \mathrm{mg} / \mathrm{ml}$, in AMPD-Puffer, $2 \mathrm{~mol} / \mathrm{l}, \mathrm{pH}$ 9,5) und das Farbstoffgemisch wurde erneut durch Umdrehen gemischt.

Die Durchführung der Färbung war für die differenzierten Klone und die Negativkontrollen identisch. Für die Färbung wurde das Medium aus den Wells abgesaugt und die Zellen mit $2 \mathrm{ml} 10 \%$ PBS für 15 min gewaschen. Danach wurden die DG auf Parafilm gelegt und die Zellen mit 0,25\% Triton X-100 (Sigma-Aldrich, Steinheim) für 3 min permeabilisiert. Das Triton X-100 wurde durch drei Waschgänge mit aqua dest. vollständig von den DG entfernt und das Alkalifarbstoffgemisch aufgetragen. Die Einwirkzeit betrug $30 \mathrm{~min}$, dabei wurden die DG lichtgeschützt und bei $37^{\circ} \mathrm{C}$ im Inkubator aufbewahrt. Nach dem Färben wurden die Zellen dreimal mit aqua dest. gespült und 2 min mit Neutral Red (Sigma-Aldrich, Steinheim) bei RT gegengefärbt. Die Zellen wurden danach sol ange mit Leitungswasser gewaschen, bis das Neutral-Red vollständig verschwunden war. Nachdem die DG leicht abgetrocknet waren, wurden sie mit wässrigem Eindeckmedium auf Objektträgern eingedeckelt. Die Ergebnisse wurden wieder fotodokumentarisch festgehalten.

\subsubsection{Immunfluoreszenzzytochemie}

\subsubsection{Zur Methode}

Die Methode dient zum Anfärben bestimmter Zell- oder Gewebestrukturen mittels Antikörpern (AK), die fluoreszierende Farbstoffe tragen. Neben der direkten Methode, bei der der AK gegen ein bestimmtes Antigen direkt an einen Farbstoff gekoppelt ist, gibt es die indirekte Methode. Dabei wird ein Primärantikörper gegen das gesuchte Antigen verwendet, über den dann ein sekundärer binden kann, der mit einem fluoreszierenden Farbstoff konjugiert ist. Für die Immunfluoreszenzhistochemie in dieser Arbeit wurde ausschließlich die indirekte Methode verwendet. Sie diente zum quantitativen Nachweis, ob in den differenzierten Klonen adipogen und osteogen spezifische Proteine expremiert wurden. 


\subsubsection{Primäre Antikörper}

\section{Lipoproteinlipase}

Der AK gegen die LPL ist ein monoklonaler IgG-AK von der Maus und wurde käuflich erworben (Monoclonal to Bovine Lipoprotein Lipase \#BM5512, Acris Antibodies $\mathrm{GmbH}$, Hiddenhausen). Er bindet direkt an das C-terminale Ende des Proteins und ist spezifiziert gegen Rinder, lässt sich aber auch für Reaktionen an menschlichen Zellen verwenden. Der AK wurde mit einer Verdünnung von 1:10 verwendet. Zur Verdünnung diente immer eine $1 \%$ BSA-Lösung (engl. „bovine serum albumin“, Sigma-Aldrich, Steinheim).

\section{PPARY}

Als AK gegen PPARy wurde ein monoklonaler IgG-AK von der Maus verwendet (PPAR Y (E-8): sc-7273, Santa Cruz Biotechnology Inc., Santa Cruz-USA). Er bindet an ein Epitop, das durch die Aminosäuren 480-505 des C-terminalen Endes von PPAR y abgebildet wird. Der AK wurde in einer Verdünnung von 1:50 verwendet.

\section{Osteocalcin}

Hierbei handelt es sich um einen polyklonalen IgG-AK vom Kaninchen und wurde bei der Firma Biotrend erworben (Rabbit Anti Human Osteocalcin, BIOTREND Chemikalien $\mathrm{GmbH}$, Köln). Er wurde mit einer Verdünnung von 1:50 verwendet.

\section{Runx-2}

Für den Nachweis von runx-2 wurde ein monoklonaler IgG-AK von der Maus verwendet und stammt von der Firma Millipore (Anti-RUNX-2, clone AS110, Merck Millipore, Darmstadt). Daneben wurde auch ein polyklonaler IgG-AK vom Hasen benutzt, der von der Firma Santa Cruz stammt (Runx-2 Antibody sc-10758, Santa Cruz Biotechnology Inc., Santa Cruz-USA). Beide AK wurden in einer Konzentration von 1:50 benutzt.

\subsubsection{Sekundäre Antikörper}

Die sekundären Antikörper waren ebenfalls käuflich erworben. Es wurde ein mit FITC (Fluoresceinisothiocyanat) gekoppelter polyklonaler Anti-Maus lgG+lgM-AK (AntiMouse $\lg \mathrm{G}+\lg M(\mathrm{H}+\mathrm{L}), \mathrm{KPL}$, Maryland-USA) verwendet, der durch Anregung mit einer Quecksilberhöchstdrucklampe (HBO-Lampe) ein grünes Licht der Wellenlänge von 520-530 nm emittierte. Er wurde 1:10 verdünnt. Der polyklonale IgG-AntiKaninchen-AK (Anti-Rabbit IgG $(\mathrm{H}+\mathrm{L})$ DyLight $^{\mathrm{TM}} 549$ labeled, KPL, Maryland-USA) 
war an DyLight ${ }^{\text {TM }} 549$ gekoppelt und emittierte Licht der Wellenlänge $568 \mathrm{~nm}$. Der AK lag in einer Verdünnung von 1:200 vor.

\subsubsection{Durchführung}

Die DG mit den Klonen wurden auf Parafilm gelegt und zweimal mit $100 \mu \mathrm{l} 10 \%$ PBS gewaschen. Danach wurden die Zellen mit $100 \mu \mathrm{l} 2 \%$ Paraformaldehyd über 15 min fixiert. Es folgten zwei Waschschritte mit $10 \%$ PBS. Die Permeabilisierung wurde über 10 min mit 0,25\% Triton-X 100 durchgeführt. Das Triton wurde durch Waschen mit $10 \%$ PBS entfernt. Dabei wurde so lange gespült, bis keine Spuren des Tritons mehr sichtbar waren. Zur Reduzierung unspezifischer Bindungsstellen wurde mit $100 \mu \mathrm{l} 1 \%$ BSA-Lösung über 15 min bei RT geblockt. Danach erfolgte der Auftrag der primären AK. Sie wurden, wie oben beschrieben, in den angegebenen Konzentrationen mit $1 \%$ BSA-Lösung gemischt und etwa $50 \mu$ pro DG aufpipettiert. Die DG kamen in eine feuchte Kammer und wurden bei $37^{\circ} \mathrm{C}$ für eine Stunde inkubiert. Für die Feuchtigkeit sorgte ein mit PBS getränktes Flies am Boden der Kammer. Nach der Inkubationszeit wurden die Zellen wieder zweimal mit $10 \%$ PBS gewaschen und danach der sekundäre AK mit einem Volumen von $50 \mu \mathrm{l}$ pro DG aufgetragen. Der sekundäre AK inkubierte für 60 min bei $37^{\circ} \mathrm{C}$ in einer feuchten Kammer. Die Zellen wurden nach der Inkubationszeit ein letztes Mal mit $10 \%$ PBS gewaschen und wurden anschließend mit Vectashield ${ }^{\circledR}$ eingedeckelt $\left(\right.$ Vectashield ${ }^{\circledR}$ Mounting Medium with DAPI, Vector Laboratories, Kalifornien-USA). Mit dem im Eindeckmedium enthaltenen DAPI (4,6-Diamidin-2-phenylindol) konnten auf diese Weise die Zellkerne gut sichtbar gemacht werden. Das DAPI bindet an die DNS und die Zellkerne fluoreszieren bei einer Belichtung mit HBO-Lampen (Quecksilberkurzbogen-Lampen) blau. Die Ergebnisse der Immunfluoreszenzmikroskopie wurden fotodokumentarisch festgehalten und quantitativ ausgewertet. Für die Aufnahmen bei 20-facher Vergrößerung wurde ein spezielles Objektiv verwendet, das bei Fluoreszenz einen stärkeren Kontrast ergibt (EC Plan-Neofluar ${ }^{\circledR}$, Carl Zeiss, Oberkochen).

\subsubsection{Western-Blot}

\subsubsection{Zur Methode}

Der Western-Blot dient zum Nachweis von bestimmten Proteinen in einem Proteingemisch. Das Proteingemisch (z.B. ein Zelllysat) wird zunächst mittels Gelelektrophorese in einer Gelmatrix in verschiedene Proteinbanden aufgetrennt. 
Danach erfolgt das eigentliche Blotting, wobei die Proteinbanden aus dem Gel auf eine feste Membran transferiert werden. Als Trägermaterial wird meist Nitrozellulose oder eine PVDF-Membrane (Polyvinylidenfluorid) verwendet. Durch den Einsatz von spezifischen Antikörpern gegen das gesuchte Protein, kann dieses dann auf der Membran detektiert werden.

Die Auftrennung der Proteine für diese Arbeit erfolgte mittels SDS-PAGE (engl. „sodium dodecyl sulfate polyacrylamide gel electrophoresis"). Für dieses Verfahren wird eine Polyacrylamid-Gelmatrix verwendet, deren Porengröße durch unterschiedliche Konzentration des Monomers variiert werden kann. Ein weiterer Vorteil ist, dass die Gele nur sehr wenig mit Proteinen interagieren und chemisch inert sind. Das enthaltene Natriumdodecylsulfat (SDS) ist ein anionisches Tensid, das bei den Proteinen eine Denaturierung verursacht. Ihre Sekundär- und Tertiärstruktur geht dabei verloren und das SDS lagert sich an die Proteine an, sodass die Eigenladung der Proteine vernachlässigt werden kann. Sie sind durch die Anlagerung gleichmäßig negativ geladen und können so im elektrischen Feld nach ihrer Größe aufgetrennt werden. Dabei wandern kleine Proteine schneller durch das Gel, während größere durch die Poren der Matrix zurückgehalten werden. Mit Hilfe einer Commassie-Färbung kann der Erfolg der Proteinauftrennung kontrolliert werden. Durch das Mitlaufen einer Leiter bekannter Größe können die Banden der Proben einem bestimmten Molekulargewicht zugeordnet werden und die Dicke der Bande entspricht der Menge des Proteins.

Im Anschluss an die Auftrennung erfolgt der Transfer auf die Membran. Dazu kommt das Gel mit der Trägermembran in eine mit Transferpuffer gefüllte Kammer. Durch das Anlegen einer Spannung senkrecht zum Gel wandern die Proteine im elektrischen Feld auf die Trägermembran, wo sie fest haften bleiben. Das Bandenmuster bleibt bei diesem Transfer erhalten. Auf dieser Membran können mit spezifischen Antikörpern die gewünschten Proteine nachgewiesen werden. Dazu wird zunächst ein unkonjugierter Primärantikörper verwendet, der an das Protein bindet. Dieser wird dann mittels Sekundärantikörper nachgewiesen. Dabei handelt es sich um ein Konjugat, da der sek. AK an eine HR-Peroxidase gekoppelt ist, die nach Zugabe eines Substrats eine chemolumineszente Reaktion verursacht. Das emittierte Licht kann dann mittels Röntgenfilm in einer Dunkelkammer detektiert werden. 
In den folgenden Abschnitten werden die Abläufe der SDS-PAGE, des Western-Blots und die Immundetektion entsprechend der verwendeten Protokolle beschrieben.

\subsubsection{Probenaufbereitung}

Die Zellen aus 2D-Flaschenkultur wurden geerntet und bei $200 \mathrm{~g}$ über $10 \mathrm{~min}$ zentrifugiert (centrifuge 5810, Eppendorf, Hamburg). Der Überstand wurde verworfen und das Pellet in $1 \mathrm{ml}$ DMEM resuspendiert und anschließend im Zellometer gezählt. Die Zellsuspension wurde erneut bei $200 \mathrm{~g}$ für $10 \mathrm{~min}$ abzentrifugiert. Zum Zellpellet wurde Lysepuffer und 3 x SDS- Probenpuffer pipettiert. Die Anzahl der Zellen und die zugegebenen Volumina an Lysepuffer und $3 \times$ SDS-Probenpuffer können aus der Tabelle 4 entnommen werden.

\begin{tabular}{|c|c|c|c|}
\hline Klon & Zellzahl & Lysepuffer & 3 x SDS-Puffer \\
\hline IF-8 & $5 \times 10^{5}$ & $+50 \mu \mathrm{l}$ & $+17 \mu \mathrm{l}$ \\
\hline IIB-6 & $7,2 \times 10^{5}$ & $+72 \mu \mathrm{l}$ & $+24 \mu \mathrm{l}$ \\
\hline IID-4 & $5 \times 10^{5}$ & $+50 \mu \mathrm{l}$ & $+17 \mu \mathrm{l}$ \\
\hline
\end{tabular}

Tabelle 4: Probenaufbereitung für SDS-PAGE

Diese Suspension wurde in einem Heizblock (Thermocycler comfort, Eppendorf, Hamburg) für 5 min bei $95^{\circ} \mathrm{C}$ erhitzt, wodurch es zur Denaturierung der Proteine kam. Durch das im Lysepuffer enthaltene $\beta$-Mercaptoethanol kommt es auch zum Aufbruch der Disulfidbrücken innerhalb der Proteine, das die Denaturierung zusätzlich verstärkt. Das Zelllysat wurde beim Erhitzen mehrmals auf- und abpipettiert und jeder Klon wurde mit einer Menge von $2 \times 10^{5}$ Zellen pro Geltasche aufgetragen.

\subsubsection{SDS-PAGE}

Für die Formgebung des Gels wurden zwei Glasplatten verwendet, die vor Benutzung mit $100 \%$ Ethanol gereinigt wurden. Zwischen die Platten, von denen eine einen Spacer besaß, wurde eine Gummidichtung gelegt und die Platten mit Metallklammern aufeinander fixiert. $6 \mathrm{~cm}$ vom unteren Rand wurde mit Filzstift eine Linie gezogen, die den späteren Übergang von Sammel- zu Trenngel markieren 
sollte. Zunächst wurde das $10 \%$ Trenngel nach Protokoll zusammenpipettiert (s. Tab. 5) und gut gemischt.

\begin{tabular}{|ll|ll|}
\hline \multicolumn{3}{|c|}{ Trenngel 10\% } & \multicolumn{2}{c|}{ Sammelgel 5\% } \\
\hline $1,4 \mathrm{ml}$ & Trenngelpuffer & $1,25 \mathrm{ml}$ & Sammelpuffer \\
$55 \mathrm{l}$ & $10 \%$ SDS & $50 \mu \mathrm{l}$ & $10 \%$ SDS \\
$5 \mu$ & TEMED & $5 \mu \mathrm{l}$ & TEMED \\
$1,85 \mathrm{ml}$ & Acrylamid & $0,8 \mu \mathrm{l}$ & Acrylamid \\
$2 \mathrm{ml}$ & $\mathrm{H}_{2} \mathrm{O}$ & $2,7 \mathrm{ml}$ & $\mathrm{H}_{2} \mathrm{O}$ \\
$0,25 \mathrm{ml}$ & $10 \%$ APS & $0,2 \mathrm{ml}$ & $10 \%$ APS \\
\hline
\end{tabular}

Tabelle 5: Zusammensetzung der Gele für SDS-PAGE

Die Polymerisation wurde durch Zugabe von $10 \%$ Ammoniumperoxidsulfat (APS) gestartet und das Gel gleich darauf zwischen die Glasplatten bis zur Markierung gegossen. Um Luftblasen im Gel zu minimieren und einen glatten Übergang zum Sammelgel zu schaffen, wurde das Trenngel mit $100 \%$ Ethanol überschichtet. Nach ca. $10 \mathrm{~min}$ war das Trenngel auspolymerisiert und es konnte das Sammelgel (s. Tab.5) aufgetragen werden. Für die Formgebung der Taschen im Gel wurde vorsichtig ein Kunststoffkamm in das noch flüssige Gel gedrückt. Das PolyacrylamidGel wurde nach der Polymerisation in einen Nachbau der Biometra Elektrophoresekammer gestellt. Dazu mussten Gummidichtung, Kamm und Metallklammern entfernt werden und das Gel vorsichtig in die mit $1 \times$ Laufpuffer gefüllte Kammer gestellt werden. Danach konnten die Proben in die Geltaschen einpipettiert werden. Dazu sollten die Proben noch möglichst heiß sein, da sie so eine geringere Viskosität besitzen und das Einpipettieren erleichtert wird. Um die oben angegebene Zellkonzentration zu erhalten, wurden von dem Zelllysat $27 \mu$ pro Tasche aufgetragen. Zur Auswertung der Proteinbanden wurde eine Leiter (PageRuler ${ }^{\mathrm{TM}}$ Prestained Protein Ladder, Fermentas,GmbH, St. Leon-Roth) mit aufgetragen, ihr Volumen ist mit $4 \mu \mathrm{l}$ herstellerbedingt. Zunächst wurden die Proteine mit einer Stromstärke von $10 \mathrm{~mA}$ (Gleichspannung) an der Trenngelkante gesammelt 
und dann mit $25 \mathrm{~mA}$ aufgetrennt. Die Auftrennung der Proteine war abgeschlossen, wenn die Leiter deutlich über das gesamte Gel gewandert war.

\subsubsection{Coomassie-Brilliant-Blau-Färbung}

Mit der Coomassie-Blau-Färbung wurden die im Gel entstandenen Proteinbanden angefärbt und damit erstmalig sichtbar gemacht. Dazu kam das Gel für 30 min in die Coomassie-Färbelösung, bis das Gel gleichmäßig blau gefärbt war. Zum Entfärben kam es $2 \times$ für 15 min in den Entfärber I und danach in den Entfärber II. Der Entfärber II musste so lange gewechselt werden, bis sich die blauen Proteinbanden deutlich vom klaren Hintergrund absetzten. Danach konnte das Gel am Computer eingescannt werden (Scanjet G4050, Hewlett-Packard GmbH, Böblingen)

\subsubsection{Western-Blot}

Für die Übertragung der Proteine wurde die oben angesprochene PVDF-Membran (Merck Millipore, Darmstadt) verwendet. Diese musste zunächst $15 \mathrm{sec}$ mit $100 \%$ Methanol und anschließend 2 min mit aqua dest. durchtränkt werden. Die Membran, sechs Filterpapiere (Amersham Hyperfilm ECL, GE Healthcare, Buckinghamshire, UK) und die Schwämme der Blotkassette wurden vor Benutzung 15 min in $4{ }^{\circ} \mathrm{C}$ kaltem Transferpuffer eingelegt. Auf der Seite der Kassette, die später die Anodenseite darstellte, wurden nacheinander der Schwamm, drei Filterpapiere, die PVDF-Membran und das Gel aufgelegt, danach folgten wieder drei Filterpapiere und ein Schwamm. Die Kassette wurde danach geschlossen und mit zwei Gummibändern fixiert. So gesichert kam sie in die zur Hälfte mit Transferpuffer gefüllte Kammer, die erst nach dem Einsetzen maximal befüllt werden durfte. Ein Magnetrührstab und ein Kühlwasserdurchlauf sorgten während des Blots für eine gleichmäßige lonenkonzentration bzw. Temperatur in der Kammer. Die Proteine wurden in 90 min bei einer Stromstärke von 350 mA auf die Membran transferiert.

\subsubsection{Immunreaktion auf PVDF-Membran}

Der Western-Blot diente zum Vergleich der Expression von runx-2 und sox-9. An der Dicke der Banden ließ sich ablesen, ob das Expressionsmuster der verschiedenen Klone identisch war oder ob sich Unterschiede ergaben. Zur Detektion wurden die im folgenden Text verwendeten AK verwendet. 


\subsection{Primäre Antikörper}

\section{Runx-2}

Für die Immundetektion wurde ebenfalls der oben beschrieben monoklonale IgG-AK (Anti-RUNX-2, clone AS110, Merck Millipore, Darmstadt) verwendet. Der AK wurde dafür 1:1000 mit $5 \%$ Blocklösung verdünnt. Er detektiert runx-2 mit einer Bande bei 55-57 kDa.

\section{Sox-9}

Als AK gegen den Transkriptionsfaktor sox-9 wurde ein polyklonaler AK vom Kaninchen verwendet (Sox-9 (H-90) sc-20095, Santa Cruz Biotechnology Inc., Santa Cruz-USA). Er wurde mit einer Verdünnung von 1:500 verwendet und detektiert sox9 mit einer Bande bei $65 \mathrm{kDa}$.

\subsection{Sekundäre Antikörper}

\section{Anti-Rabbit}

Zur Detektion des primären runx-2-Antikörpers wurde ein polyklonaler IgG-AK verwendet (Anti-Rabbit-IgG-Peroxidase A0545, Sigma-Aldrich Chemie $\mathrm{GmbH}$, Steinheim). Beide benutzten sekundären AK stammen von der Ziege und wurden mit $5 \%$ Blocklösung verdünnt. Die Verdünnung betrug beim Anti-Rabbit 1:100.000. Dieser AK ist mit einer HR-Peroxidase konjugiert und verursacht nach Zugabe von Substrat eine Chemilumineszenzreaktion, die mit einem Röntgenfilm detektiert werden kann.

\section{Anti-Mouse}

Gegen den sox-9-AK wurde ein polyklonaler IgG-AK (Anti-Mouse-lgG-Peroxidase A9917, Sigma-Aldrich Chemie $\mathrm{GmbH}$, Steinheim) mit einer Verdünnung von 1:40.000 benutzt. Dieser AK ist ebenfalls mit einer HR-Peroxidase konjugiert.

\subsection{Durchführung}

Die PVDF-Membran kam für eine Stunde bei RT in eine Lösung aus $5 \%$ Milchpulver in TBS-T, die dafür frisch angesetzt wurde. Diese Blocklösung verhindert, dass die AK mit unspezifischen Proteinbindungsstellen interagieren. Danach wurde der verdünnte primäre $\mathrm{AK}$ aufgetragen und über Nacht auf einer Wippe bei $4{ }^{\circ} \mathrm{C}$ inkubiert. Am folgenden Tag wurde der AK durch Waschen in TBS-T entfernt, dazu waren fünf Waschgänge zu je 5 min notwendig. Auf die Membran konnten dann die 
verdünnten sekundären AK aufgetragen werden; hier reichte eine Inkubationszeit von einer Stunde bei RT. Das Entfernen der AK erfolgte wieder durch fünfmaliges Waschen mit TBS-T über 5 min. Danach konnte mit Hilfe des Amersham ECL Plus Western Blotting Detection Reagents (GE Healthcare, Buckinghamshire-UK) die Chemilumineszenzreaktion durch die HR-Peroxidase ausgelöst werden. Dazu wurden Lösung $A$ und $B$ in einem Verhältnis von 40:1 gemischt und für 5 min auf der Membran bei RT inkubiert. Für einen Blot reichte ein Volumen von $1025 \mu \mathrm{l}$ Gebrauchslösung. Während der Inkubationszeit sollte der Zutritt von Licht vermieden werden. Danach wurde die Lösung abgesaugt und die Membran zwischen zwei Klarsichtfolien in eine Röntgenfilmkassette getan. Ab hier musste in einer Dunkelkammer unter Rotlicht gearbeitet werden.

Der Röntgenfilm wurde der Membrangröße angepasst, auf die Membran gelegt und die Kassette verschlossen. Die Belichtungszeit konnte vorab nicht genau benannt werden, da sie abhängig von der Proteinmenge ist; sie liegt zwischen einer Minute und einer Stunde. Hier wurde eine Belichtungszeit von 30 min gewählt. Der Film wurde anschließend in Entwickler gelegt, die Reaktion mit Wasser gestoppt und der Film im Fixierbad haltbar gemacht.

Durch die mitgelaufene Leiter konnten die Proteinbande anhand ihres Molekulargewichts bestimmt und aufgrund ihrer Dicke quantifiziert werden. 


\section{Ergebnisse}

Der Gegenstand dieser Arbeit ist die Gegenüberstellung der Replikationrate, Differenzierbarkeit und Proteinausstattung von Klonen einer CPC-Zelllinie aus osteoarthrotisch verändertem Gelenkknorpel des Knies. Zunächst werden die Unterschiede ihrer Morphologie in vitro dargestellt. Für den Vergleich der Replikationsrate der Klone IF-8, IIB-6 und IID-4 werden im Folgenden die Ergebnisse des Proliferationsassays präsentiert und die Darstellung ihrer Differenzierbarkeit, als Zeichen ihrer Multipotenz, in Adipozyten und Osteoblasten, und der Nachweis darüber mittels Oil-Red-Färbung und der AP-Reaktion. Die Darstellung der spezifischen Proteine, der differenzierten Klone, wird mit Hilfe der Immunfluoreszenzhistochemie dargestellt. Abschließend ist durch einen Western- Blot gezeigt wurden, wie stark die Proteinausstattung an runx-2 und sox-9 der Klone ist. Dadurch konnte gezeigt werden, ob die Klone von Natur aus ein chondrogenes oder eher osteogenes Differenzierungspotenzial besitzen. Aufgrund der Daten aus dem Replikationsassay und der Differenzierbarkeit der Klone sollte sich ein Zusammenhang ergeben, ob sich schnell wachsende Zellen besser differenzieren lassen als langsam wachsende bzw. ob sie einen Teil ihrer Differenzierbarkeit einbüßen.

\subsection{Klone in 2D-Flaschenkultur}

Während der Zellkultur unter Standardbedingungen mit DMEM bei $37{ }^{\circ} \mathrm{C}$ und $5 \%$ $\mathrm{CO}_{2}$ wurden Übersichtsaufnahme der Klone gemacht, da sich schon unter normalen Kulturbedingungen Unterschiede im Phänotyp zeigten. Die Aufnahmen wurden 12 Tage nach dem Aussetzen der Zellen in $75-\mathrm{cm}^{2}$-Kulturflaschen gemacht. Die Klone IF-8 und IIB-6 zeigten überwiegend ein spindelartiges Erscheinungsbild, wobei sich die Zellen häufig parallel zueinander ausrichteten (vgl. Abb. 6, 7, S. 47). Der KlonIID-4 war in seiner Morphologie häufig zunächst eher kugelig. Später nahm er dann eine eher längliche Form mit ausgeprägten Zellfortsätzen an und bildete zusammenhängende Netzwerke, die immer wieder freie Felder einschlossen (vgl. Abb. 8, S.47). 


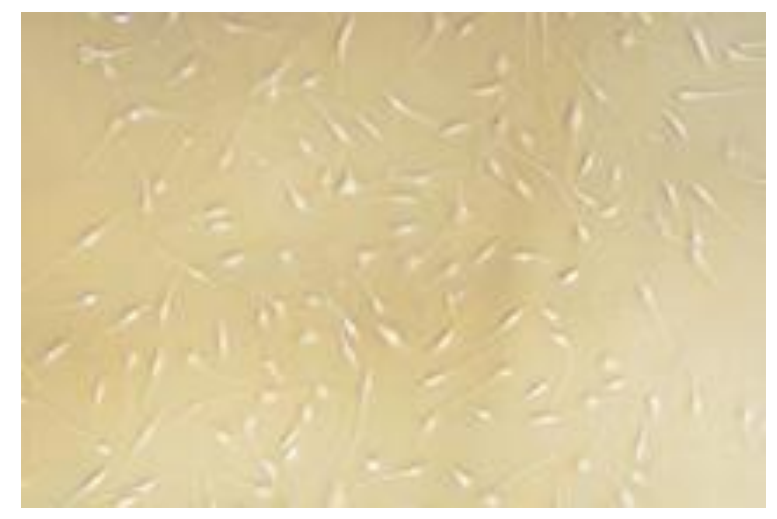

Abbildung 6: Klon-IF-8

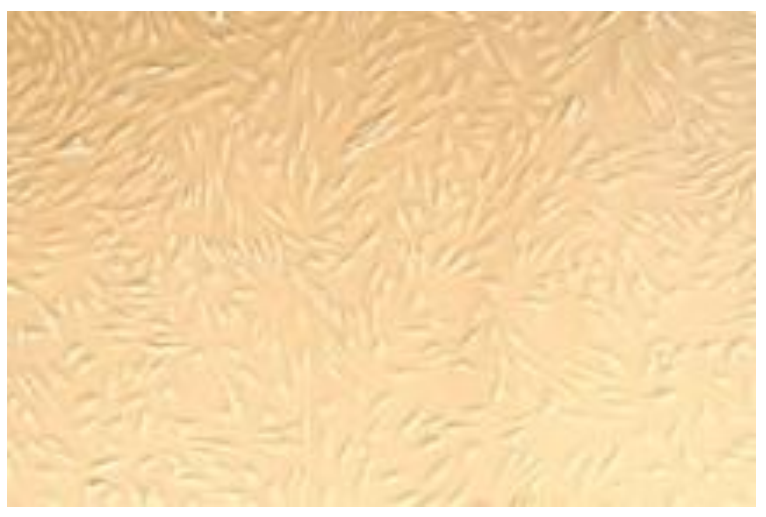

Abbildung 7: Klon-IIB-6

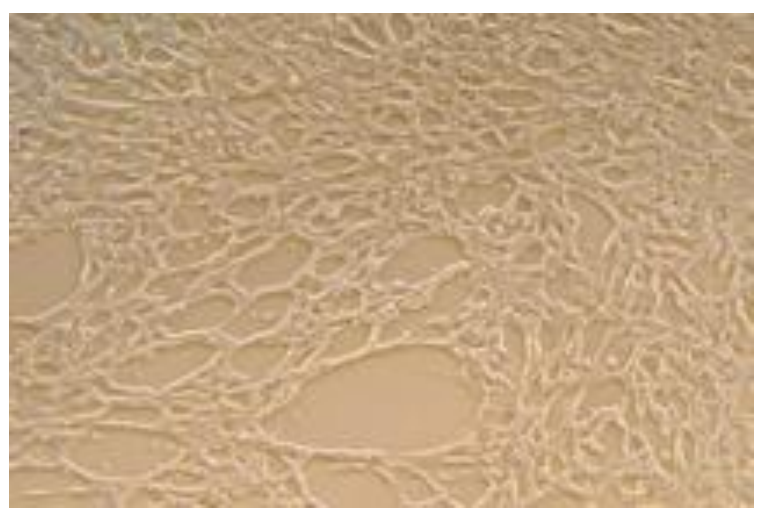

Abbildung 8: Klon-IID-4

\subsection{Ergebnisse des Replikationsassays}

Nach der Auswertung der Replikationsgeschwindigkeit zeigte sich, dass die Klone keine einheitlichen Replikationszyklen besitzen. Beim Klon-IF-8 konnte festgestellt werden, dass sich in zwei von drei Replikationsassays zwischen dem dritten und fünften Tag eine Art Plateauphase einstellte, in der keine Verdoppelung der Zellzahl stattfand, sondern nur eine sehr geringe Vermehrung. Eine weitere Auffälligkeit war der Abfall der Zellzahl während des Versuchs. Beim ersten Test viel die Zahl nach dem vierten Tag auf fast ein Viertel des Vortages ab. Bei den anderen Testreihen kam es jeweils nach dem sechsten Tag zu einem Abfall. Dabei halbierte sich die Zellzahl beim zweiten Test, während sie in der dritten Testreihe nur um 2000 Zellen 
sank. Im Gegensatz zu den anderen Klonen kam die Zellzahl bis zum siebten Tag nie über 100.000, bis auf einen Ausschlag im ersten Test an Tag 4.

Die Klone IIB-6 und IID-4 besaßen eine wesentlich höhere Replikationsrate als IF-8. Während die Zellzahl von IF-8 nur kurzzeitig über 100.000 ging, war bei IIB-6 die Zellzahl bei allen drei Testreihen bereits am vierten Tag deutlich über 100.000 Zellen gewachsen. Beim Klon-IID-4 war das durchschnittlich erst am fünften Tag der Fall. Auch bei der Gesamtzahl der Zellen - nach sieben Tagen - setzte sich Klon-IIB-6 deutlich von den anderen ab. Es wurden bei der zweiten und dritten Testreihe jeweils Zellzahlen über 300.000 erreicht, bei IID-4 lagen die Ergebnisse im Bereich von etwa 200.000 Zellen. Der siebte Tag der ersten Testreihe kann bei allen Klonen nicht mit in die Wertung einfließen, da es an diesem Tag zu Problemen mit dem Zellometer kam.

Durch das Erstellen der Mittelwerte - aus allen drei Testreihen je Klon - wird deutlich, dass die Klone eine deutliche Differenz in der Replikationsgeschwindigkeit besitzen. Während IF-8 und IID-4 bis zum dritten Tag etwa die gleiche Replikationsrate aufwiesen, lag die Zellzahl bei IID-4 am Folgetag schon doppelt so hoch wie bei IF-8. An den weiteren Tagen betrug die Differenz das Drei- bis Vierfache. Der Klon-IIB-6 zeigte die höchste Replikationsrate von allen Klonen, durchgängig vom ersten bis zum siebten Tag. Danach folgte IID-4 und abschließend IF-8 (vgl. Abb. 9, S. 49). 


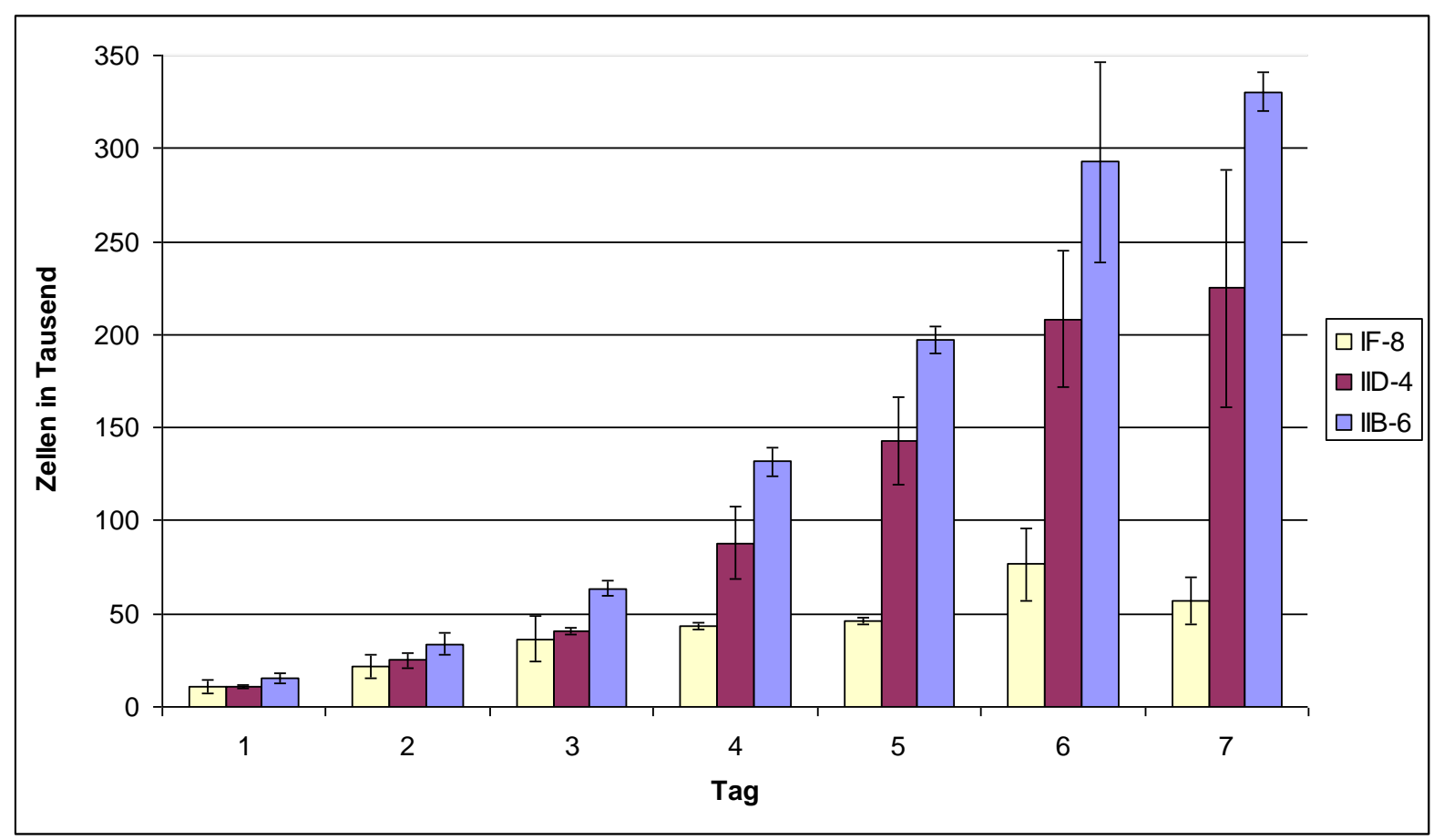

Abbildung 9: Wachstumsdiagramm

\subsection{Ergebnisse der Differenzierung}

Die Zellen wurden in einer Anfangskonzentration von $1 \times 10^{3}$ und $3 \times 10^{3}$ Zellen pro Well ausgesät. Nach Verwendung der Differenzierungsmedien zeigten sich nach sechs Tagen Unterschiede in der Morphologie zwischen beiden Anfangskonzentrationen, die bei den adipogen differenzierten Zellen wesentlich deutlicher ausfielen als bei den osteogen differenzierten.

\subsubsection{Klon-IF-8}

Die Klone im adipogenen Differenzierungsmedium mit einer Anfangskonzentration von $1 \times 10^{3}$ Zellen waren in der Mehrzahl eher spindelförmig mit vereinzelten polymorphen Zellen dazwischen. Die Zellkerne besaßen meistens einen großen, zentral gelegenen Nucleolus (vgl. Abb. 10, S. 50). Die Klone der $3 \times 10^{3}$ Anfangskonzentration waren hingegen überwiegen polymorph und die Nucleoli eher klein und im Zellkern verstreut (vgl. Abb.11, S. 50). Die Zellfortsätze zu den Nachbarzellen waren bei der erhöhten Zelldichte zirkulär ausgeprägt, während die Fortsätze bei der niedrigeren Zelldichten eher an den Zellpolen zu finden waren. 


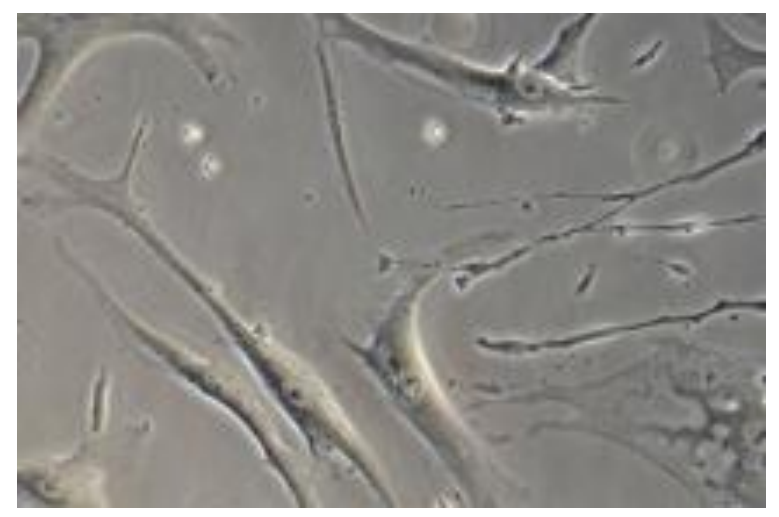

Abbildung 10: Klon-IF-8: 1 x $10^{3}$-adipogen

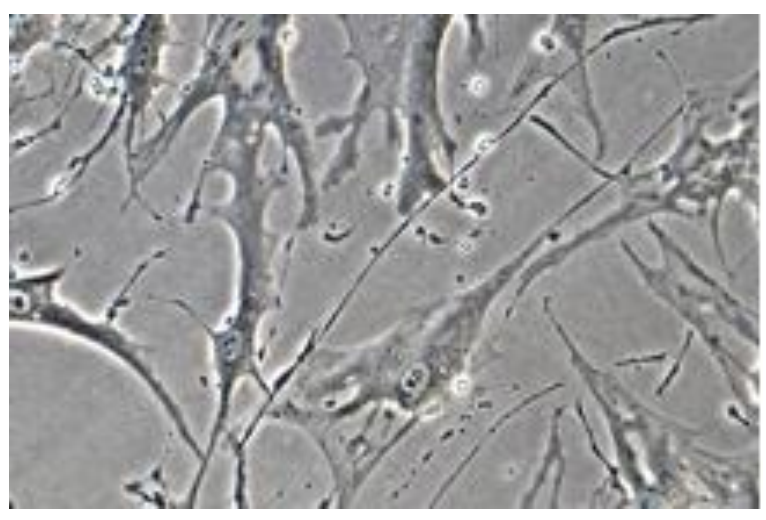

Abbildung 11: Klon-IF-8: 3 × 10³-adipogen

Bei der osteogenen Differenzierung von IF-8 zeigten sich zwischen den verschiedenen Zelldichten keine signifikanten Unterschiede in der Zellmorphologie. Die Zellen flachten bei beiden Gruppen ab und bildeten einen polymorphen Phänotyp mit multiplen Zellfortsätzen zu allen Seiten (vgl. Abb. 12, 13). Bei allen Klonen kam es fast zum gesamten Zelluntergang der $3 \times 10^{3}$ Anfangskonzentrationen.

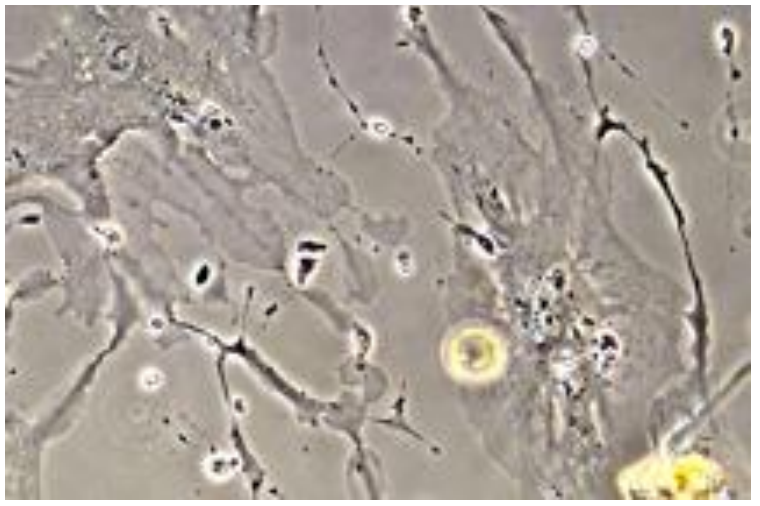

Abbildung 12: Klon-IF-8: $1 \times 10^{3}$-osteogen

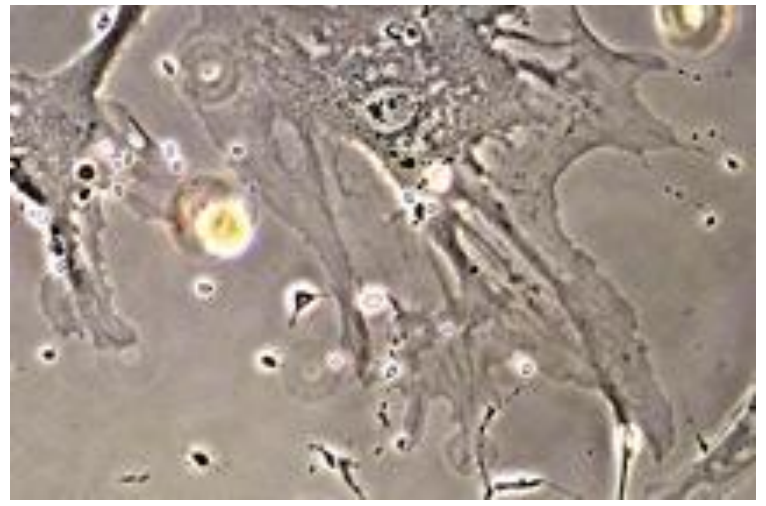

Abbildung 13: Klon-IF-8: 3 × 10³-osteogen

\subsubsection{Klon-IIB-6}

Die adipogen differenzierten Klone mit der Anfangskonzentration von $1 \times 10^{3}$ waren insgesamt etwas kleiner als die Klone aus der dichteren Population. Eine eher längliche Form war bei vielen Zellen noch gut zu erkennen, dazwischen lagen einige wenige polymorphe Zellen mit dünnen Fortsätzen zu Nachbarzellen. Die Zellen besaßen viele kleine Nucleoli, die im Zellkern verteilt lagen (vgl. Abb. 14, S. 51). 
Bei der dichteren Zellpopulation bildeten sich aus einigen spindelförmigen Klonen dreieckige Zellen, die an den Ecken des Dreiecks dünne Fortsätze besaßen (vgl. Abb. 15). Deren Nucleoli waren kleiner und lagen auch zentrierter als bei den anderen Zellformen. Neben den dreieckigen und spindelförmigen Zellen lagen auch Zellen vor, die sehr vielgestaltig waren und dünne Fortsätze zu den Nachbarzellen besaßen.

Bei der osteogenen Differenzierung zeigten sich Unterschiede in der Zellform. Während die dünn ausgesäten Zellen oft eine sternförmige Gestalt annahmen mit sehr langen Fortsätzen zu den Nachbarzellen, besaßen die dicht wachsenden Zellen eine schon sehr osteoblastenähnliche Morphologie (vgl. Abb. 16, 17). Sie waren polymorph und bildeten viele kurze Zellfortsätze zu ihren Nachbarzellen aus, sodass eine geflechtartige Struktur entstand.

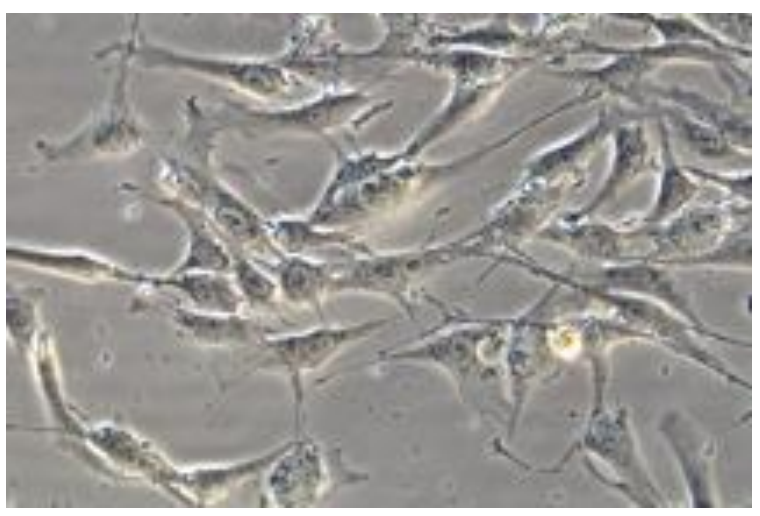

Abbildung 14: Klon-IIB-6: 1 x $10^{3}$-adipogen

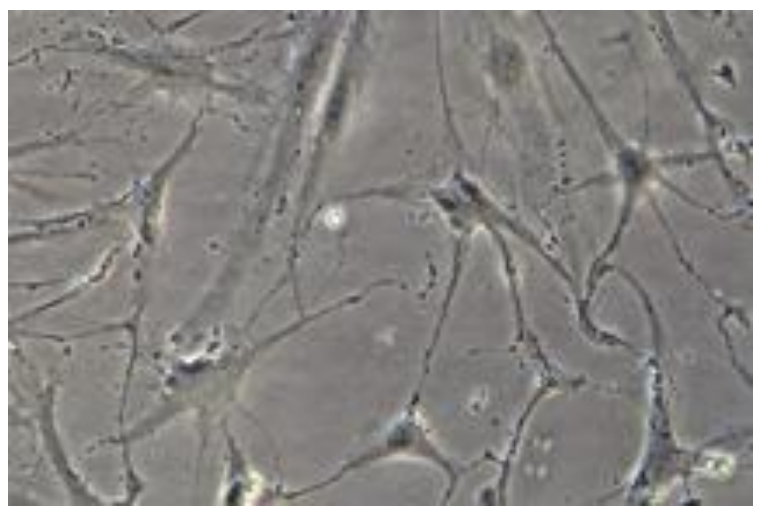

Abbildung 16: Klon-IIB-6: 1 x $10^{3}$-osteogen

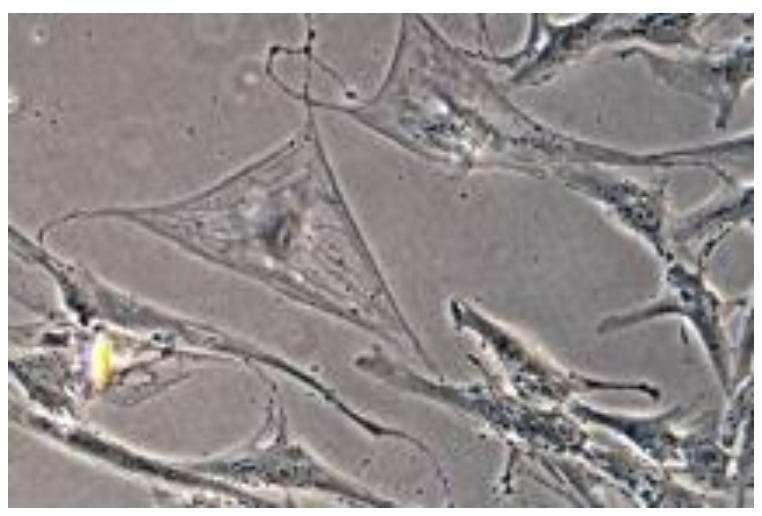

Abbildung 15: Klon-IIB-6: 3 × $10^{3}$-adipogen

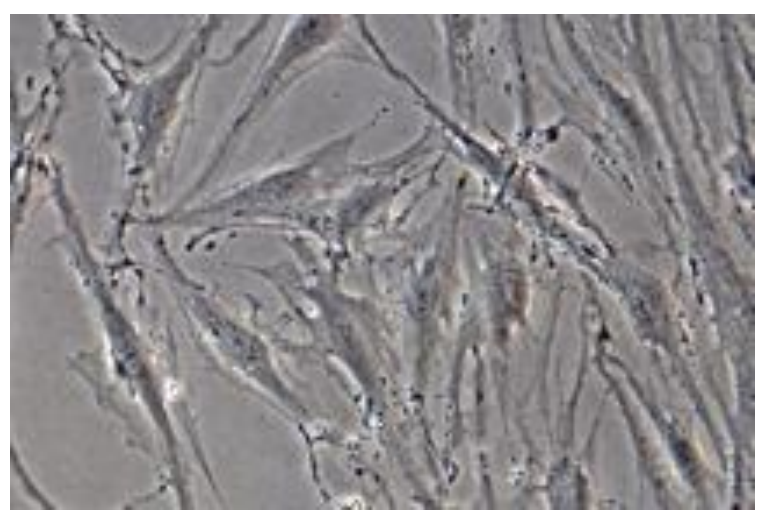

Abbildung 17: Klon-IIB-6: 3 x 10³-osteogen 


\subsubsection{KIon-IID-4}

Der Klon-IID-4 zeigte nach sechs Tagen der adipogenen und osteogenen Differenzierung die signifikantesten Unterschiede im Phänotyp. Die Zellen der $1 \times 10^{3}$ Anfangskonzentration bekamen währen der adipogenen Differenzierung eine kugelige Morphologie mit nur ansatzweise ausgebildeten Zellfortsätzen und einem geringen Zytoplasmaanteil. Die Zellen lagen dabei kolonieartig zusammen (vgl. Abb. 18). Hingegen zeigten die dicht ausgesäten Klone einen polymorphen Phänotyp mit zahlreichen Zellfortsätzen (vgl. Abb. 19). Gegen Ende der Inkubation mit dem Differenzierungsmedium bildeten die Zellen netzartige Strukturen aus, sowie in Kap. 3.1 beschrieben. Dabei blieben auch hier einzelne Bereiche frei.

Bei der osteogenen Differenzierung zeigten sich ebenfalls morphologische Unterschiede. Die Klone mit geringer Konfluenz flachten ab und bildeten einen Phänotyp aus wie er für Osteoblasten üblich ist, allerdings mit wenigen ausgeprägten Zellfortsätzen (vgl. Abb. 20, S. 53). Bei den dicht ausgesäten Zellen bildeten sich zwei Phänotypen; ein kugeliger und ein eher länglicher Zelltyp. Die Zellen bildeten wieder netzartige Strukturen mit freien Flächen aus, wobei häufig der längliche Zelltyp die freien Flächen umsäumte, während der kugelige Zelltyp den Raum zwischen den Freiflächen ausfüllte (vgl. Abb. 21, S. 53).

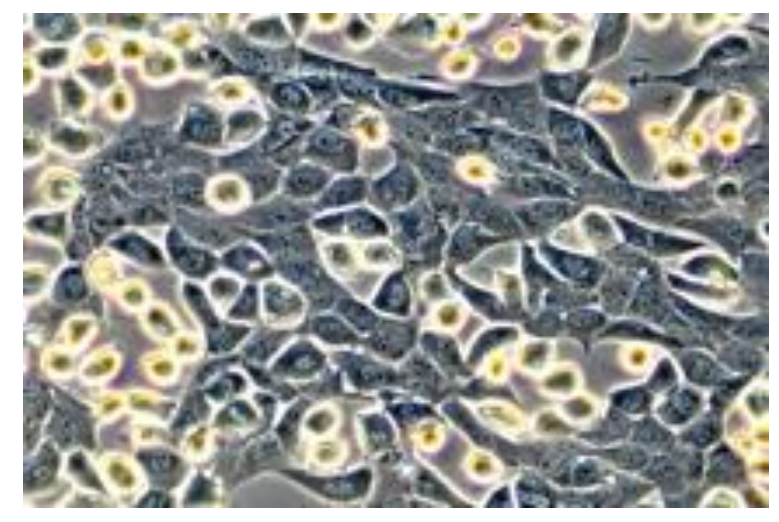

Abbildung 18: Klon-IID-4: 1 x $10^{3}$-adipogen

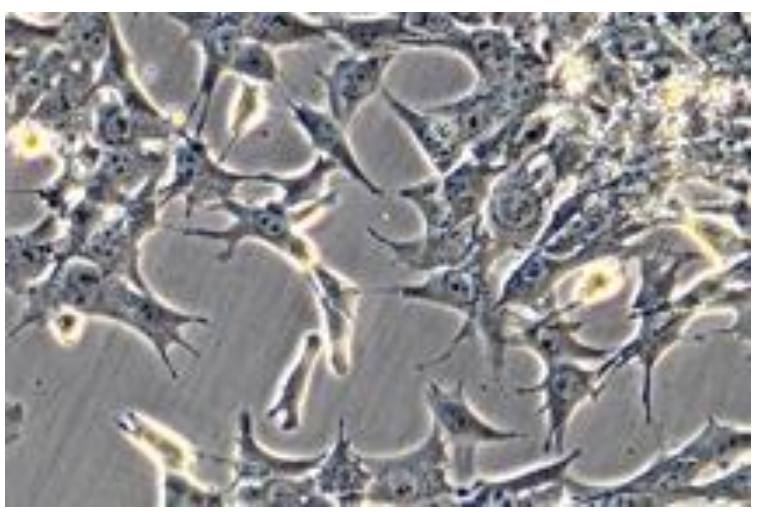

Abbildung 19: Klon-IID-4: 3 × 10³-adipogen 


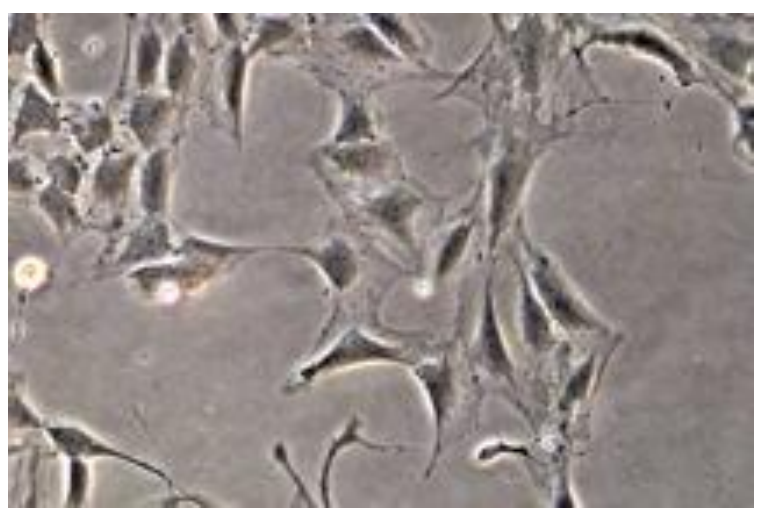

Abbildung 20: Klon-IID-4: 1 x 10³-osteogen

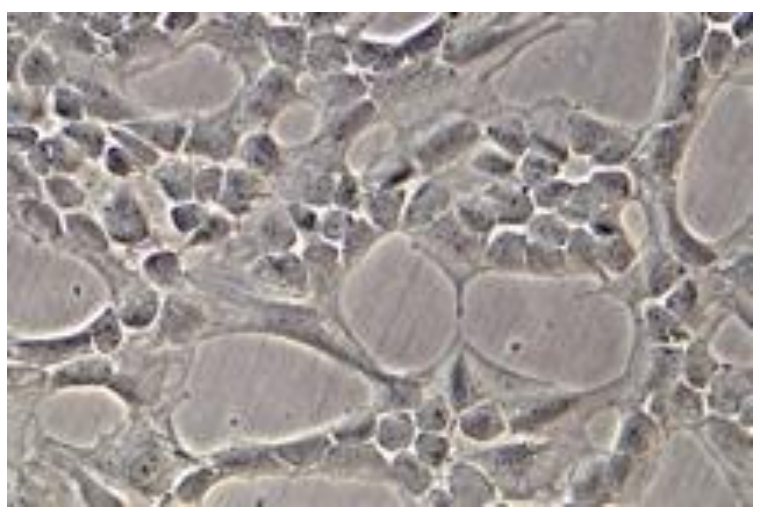

Abbildung 21: Klon-IID-4: 3 × 10 $0^{3}$-osteogen

\subsection{Oil-Red-Färbung}

Nach zehn Tagen der Inkubationszeit mit adipogenem Differenzierungsmedium wurden die gebildeten Fettvakuolen mittels Oil-Red-Färbung nachgewiesen. Zwischen den einzelnen Klonen gab es dabei keine quantitativen Unterschiede in ihrer Differenzierbarkeit. Jede Zelle jedes Klons entwickelte Fettvakuolen, die deutlich im Zytosol an ihrer roten Färbung zu erkennen waren (vgl. Abb. 22 und 24, 26, S. 54).

Zum Nachweis, dass nicht differenzierte Klone keine Fettvakuolen bilden, wurde die Kontrollpopulation nach zehn Tagen Inkubationszeit mit DMEM ebenfalls mit Oil-Red behandelt. Es zeigten sich nach der Farbstoffeinwirkung keinerlei angefärbte Bereiche im Zytosol der Zellen (vgl. Abb. 23 und 25, 27, S. 54).

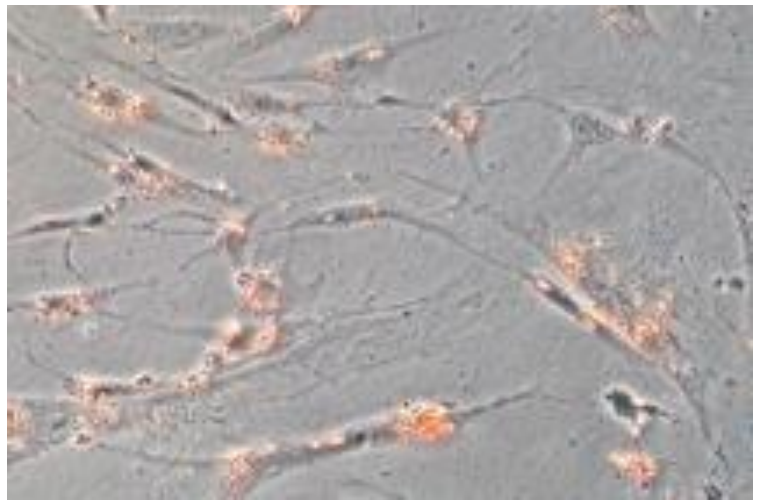

Abbildung 22: Klon-IF-8: Oil-Red

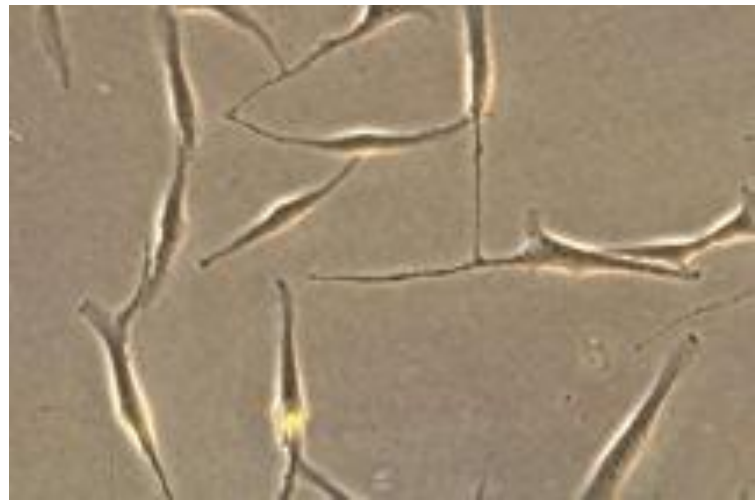

Abbildung 23: Klon-IF-8: Oil-Red-Kontrolle 


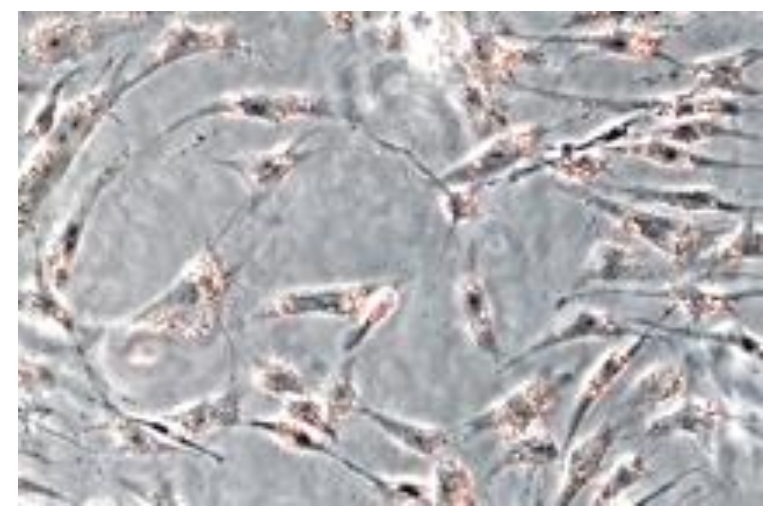

Abbildung 24: Klon-IIB-6: Oil-Red

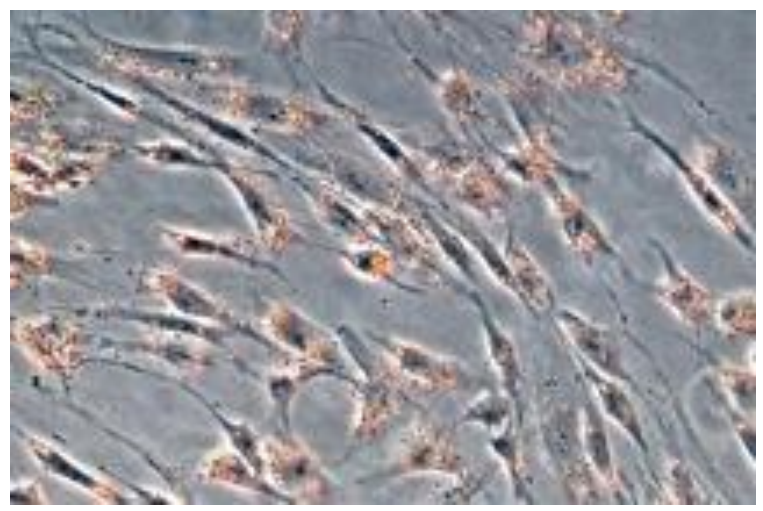

Abbildung 26: Klon-IID-4: Oil-Red

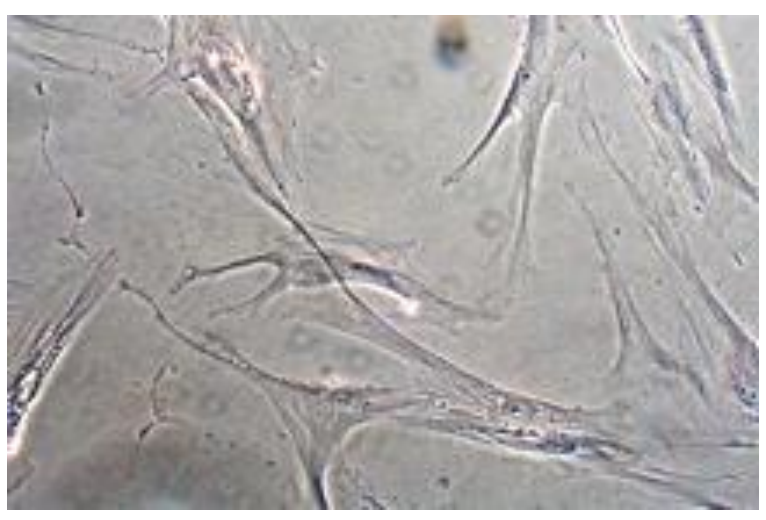

Abbildung 25: Klon-IIB-6: Oil-Red-Kontrolle

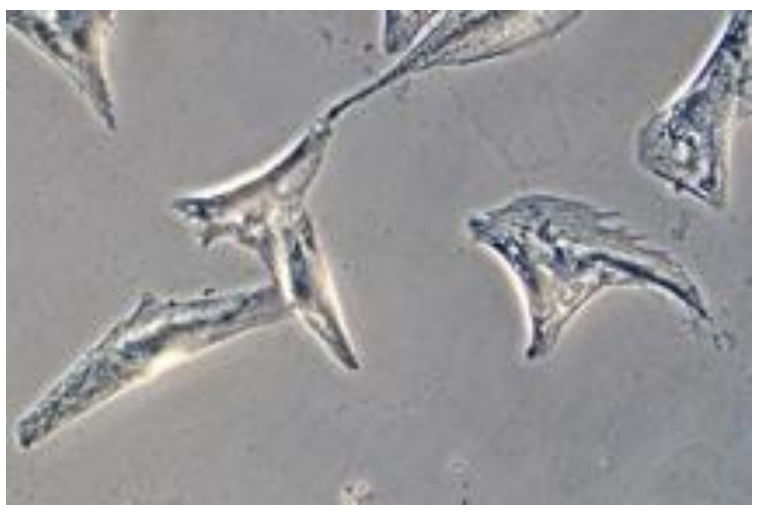

Abbildung 27: Klon-IID-4: Oil-Red-Kontrolle

\subsection{Alkalische-Phosphatase}

Der Nachweis der AP wurde nach zehn Tagen Inkubationszeit mit osteogenem Differenzierungsmedium erstellt. Die Zellen vertrugen insgesamt das osteogene Differenzierungsmedium sehr schlecht. Viele Zellen waren nach den zehn Tagen Inkubationszeit abgestorben, vor allem die dicht ausgesäten Zellpopulationen. Durch eine quantitative Auswertung der besiedelten OT unter dem Mikroskop konnte festgestellt werden, dass bei Klon-IF-8 der größte Verlust an Zellen zu verzeichnen war. Die Unterschiede von IIB-6 und IID-4 waren so marginal, dass sie nicht differenzierbar waren. Bei allen Klonen reagierten nur vereinzelte Zellgruppen auf die Färbung der AP, niemals der gesamte Zellverband. Diese Zellgruppen waren umsäumt von morphologisch identischen Zellen, die aber keine Reaktion auf das Farbstoffgemisch zeigten. Positive Zellen bekamen durch den eingesetzten Farbstoff eine rosa bis intensiv blaue Färbung (vgl. Abb. 28, 30, 32) und konnten dadurch als osteoblastäre Zellen identifiziert werden. Durch die Auswertung der AP-Färbung konnten keine Unterschiede bezüglich der osteogenen Differenzierbarkeit zwischen 
den Klonen festgestellt werden, außer einer erhöhten Mortalität während der Differenzierung bei Klon-IF-8.

Bei der Kontrollpopulation kam es zu keiner Farbänderung in den Zellen (vgl. Abb. $29,31,33)$

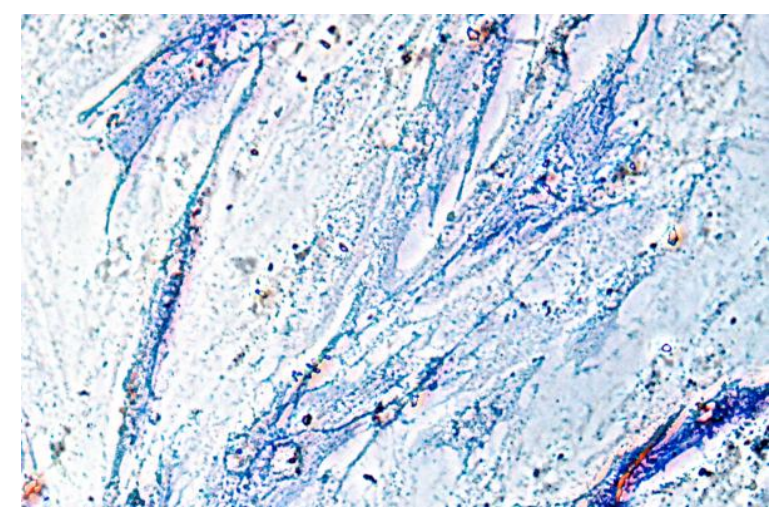

Abbildung 28: Klon-IF-8: AP-Färbung

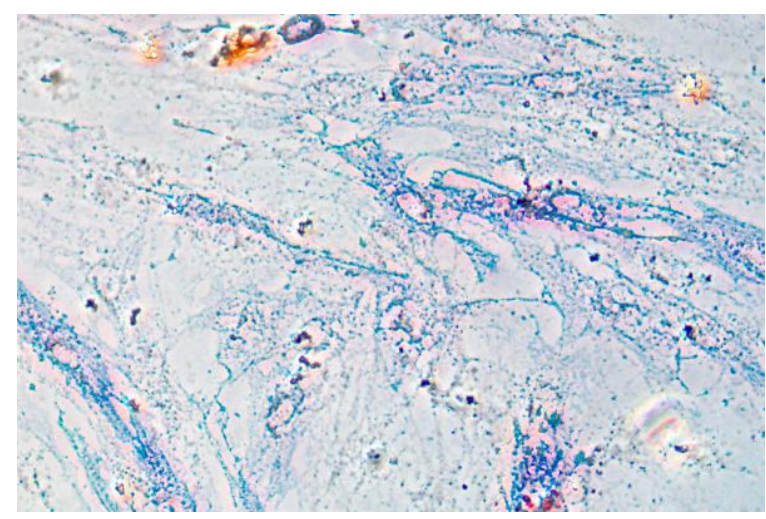

Abbildung 30: Klon-IIB-6: AP-Färbung

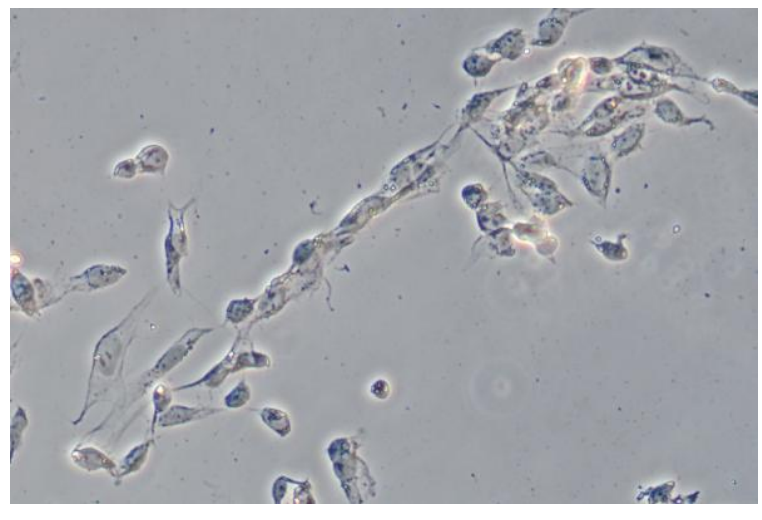

Abbildung 29: Klon-IF-8: AP-Kontrolle

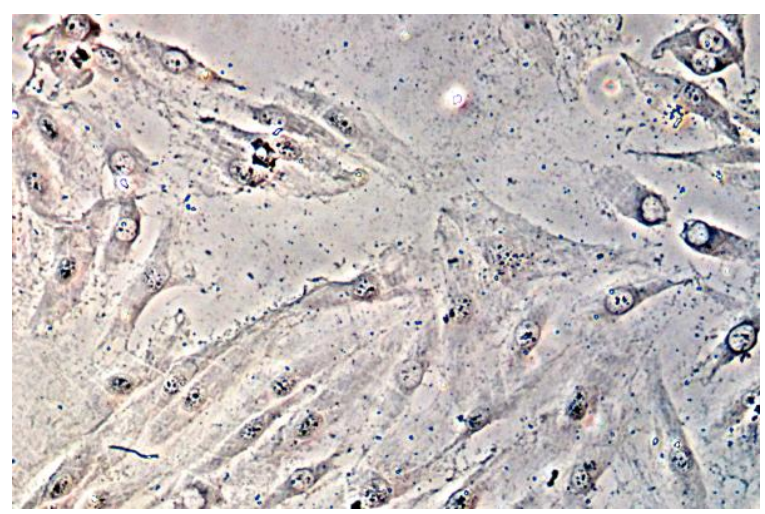

Abbildung 31: Klon-IIB-6: AP-Kontrolle 


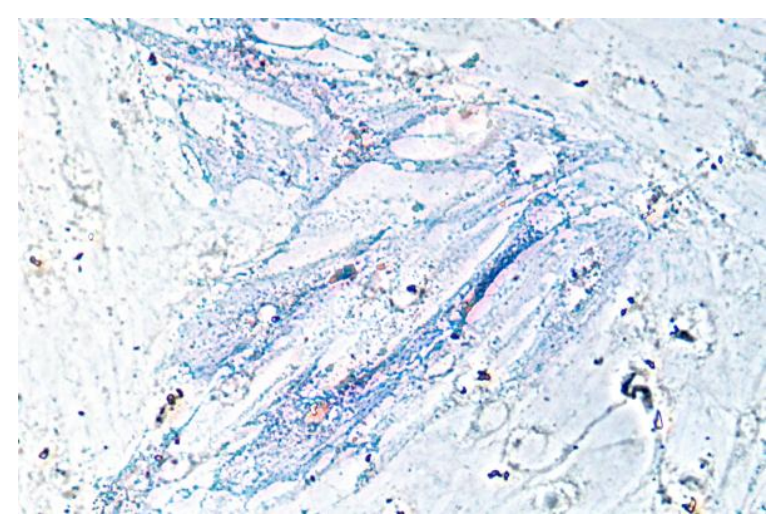

Abbildung 32: Klon-IID-4: AP-Färbung

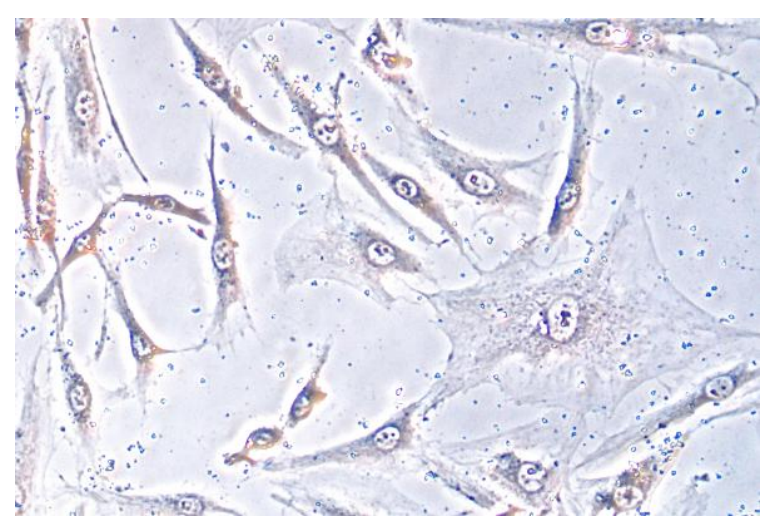

Abbildung 33: Klon-IID-4: AP-Kontrolle

\subsection{Immunfluoreszenzzytochemie}

Mittels der Immunfluoreszenzzytochemie konnte nachgewiesen werden, dass die differenzierten Zellen auch spezifische Proteine exprimierten, die Adipozyten und Osteoblasten chrakterisieren. Dabei zeigten alle adipogen differenzierten Zellen das Vorhandensein der LPL, sowie den als Transkriptionsfaktor wirkenden Rezeptor PPAR $\gamma$, der für die Differenzierung von Adipozyten verantwortlich ist. Bei den osteogen differenzierten Zellen konnte der Nachweis erbracht werden, dass alle Zellen das Protein Osteocalcin exprimierten, das nur im Knochen vorkommt, sowie den Transkriptionsfaktor runx-2, der für die Differenzierung von Osteoblasten zuständig ist. Alle Negativkontrollen zeigten keine Anzeichen einer Fluoreszenz.

Insgesamt ergaben sich keine qualitativen Unterschiede bezüglich der Exprimierung der untersuchten Proteine zwischen den differenzierten Klonen. Alle in Osteoblasten und Adipozyten differenzierten Klone exprimierten die oben angegebenen Proteine bzw. Transkriptionsfaktoren und konnten mittels AK nachgewiesen werden.

In den folgenden Abbildungen 34-57 sind die Ergebnisse der Immunfluoreszenzhistochemie abgebildet. Die Abbildungen sind nach den entsprechenden Klonen sortiert. 


\subsubsection{KIon-IF-8}
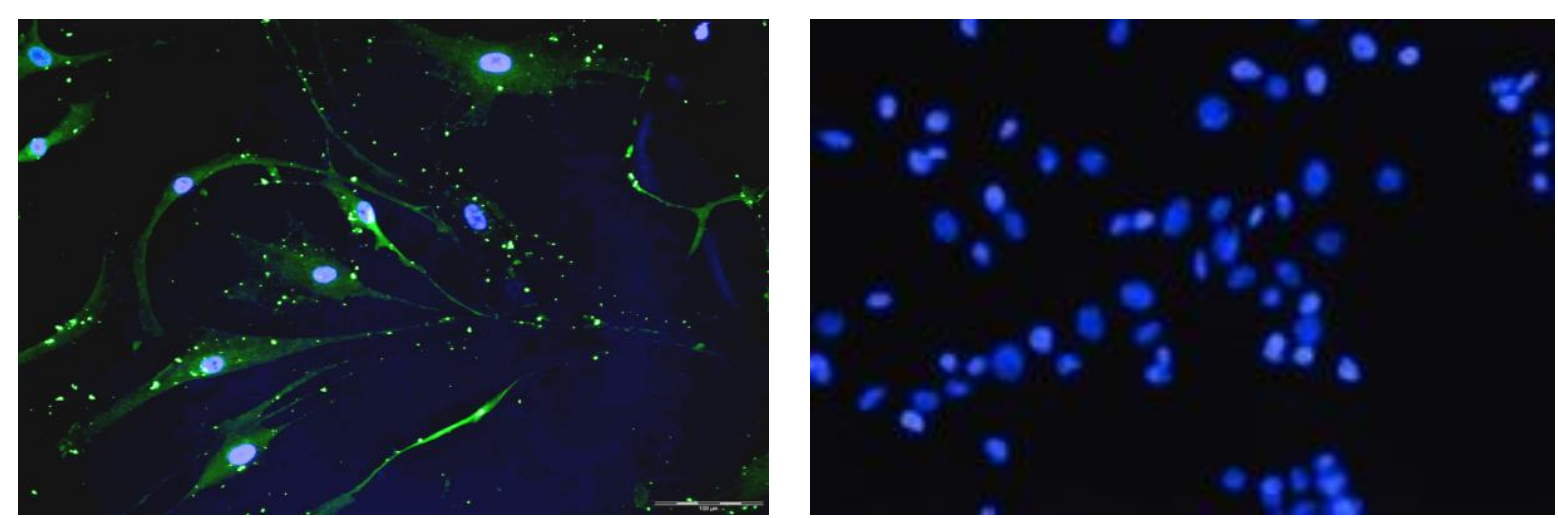

Abbildung 34: IF-8-LPL

Abbildung 35: IF-8-LPL-Kontrolle
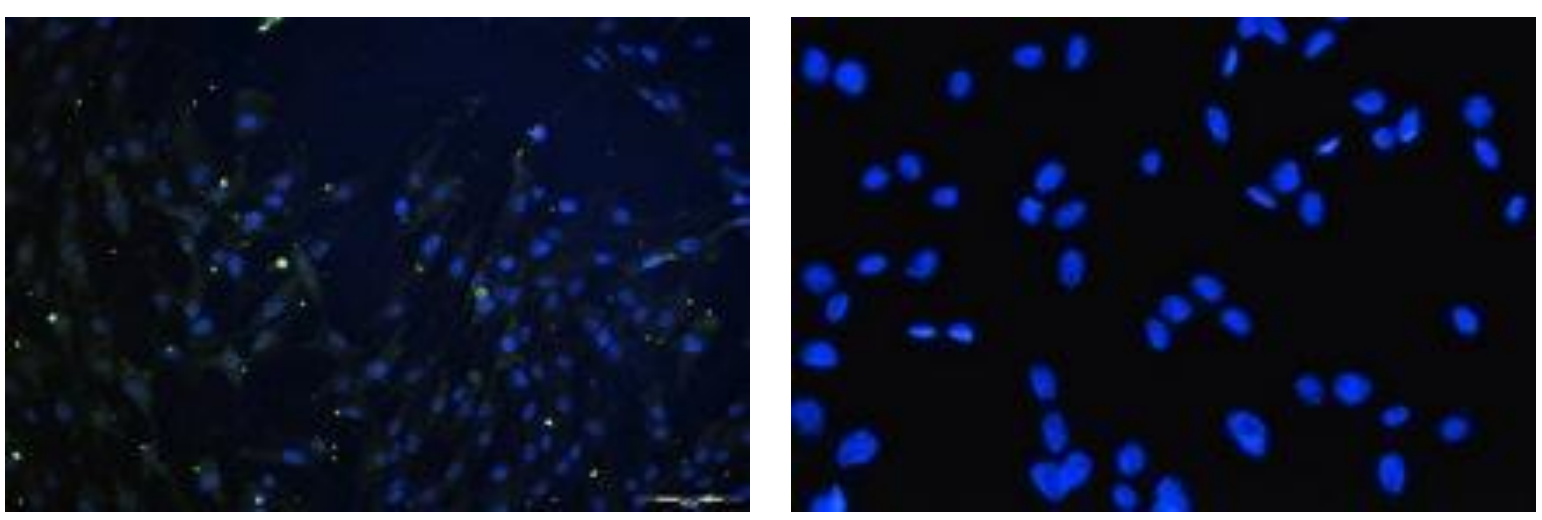

Abbildung 36: IF-8-PPAR $\gamma$

Abbildung 37: IF-8-PPAR $\gamma-$ Kontrolle
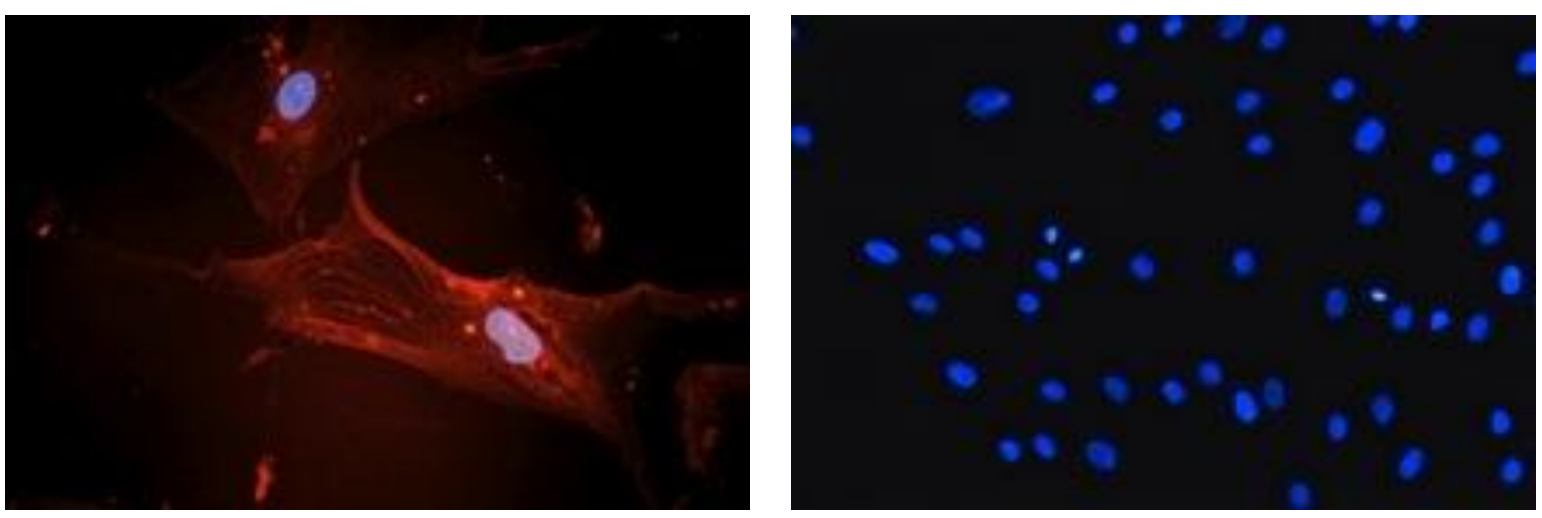

Abbildung 38: IF-8-Osteocalcin

Abbildung 39: IF-8-Osteocalcin-Kontrolle 

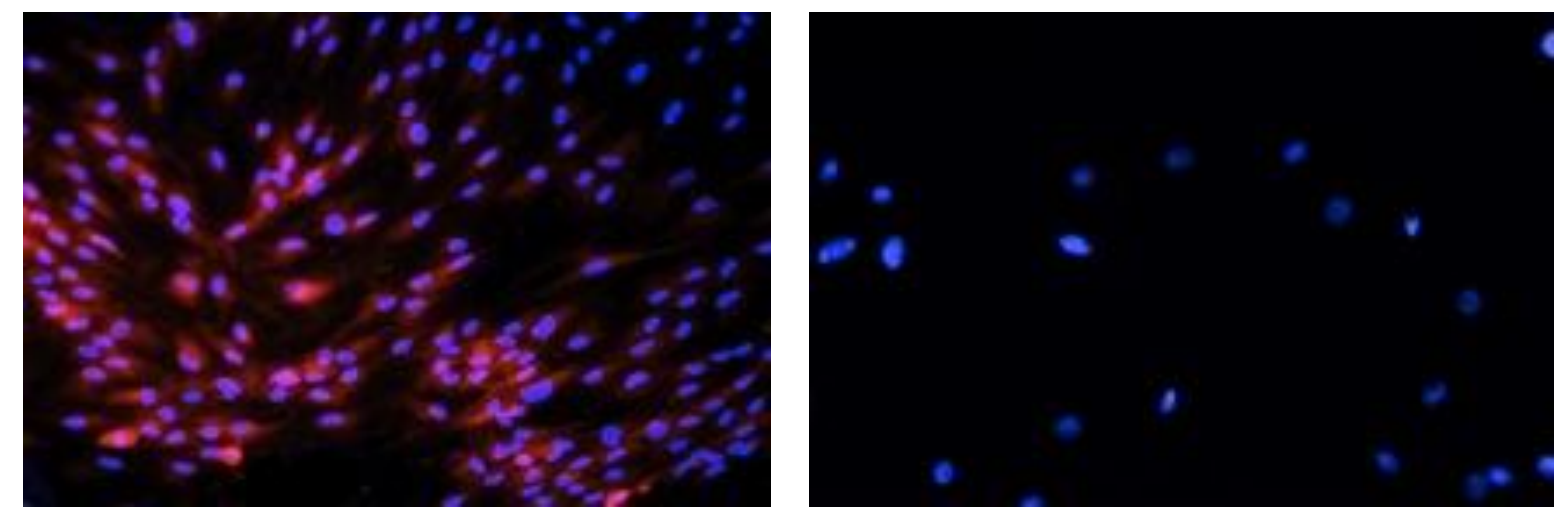

Abbildung 40: IF-8-runx-2

Abbildung 41: IF-8-runx-2-Kontrolle

\subsubsection{KIon-IIB-6}
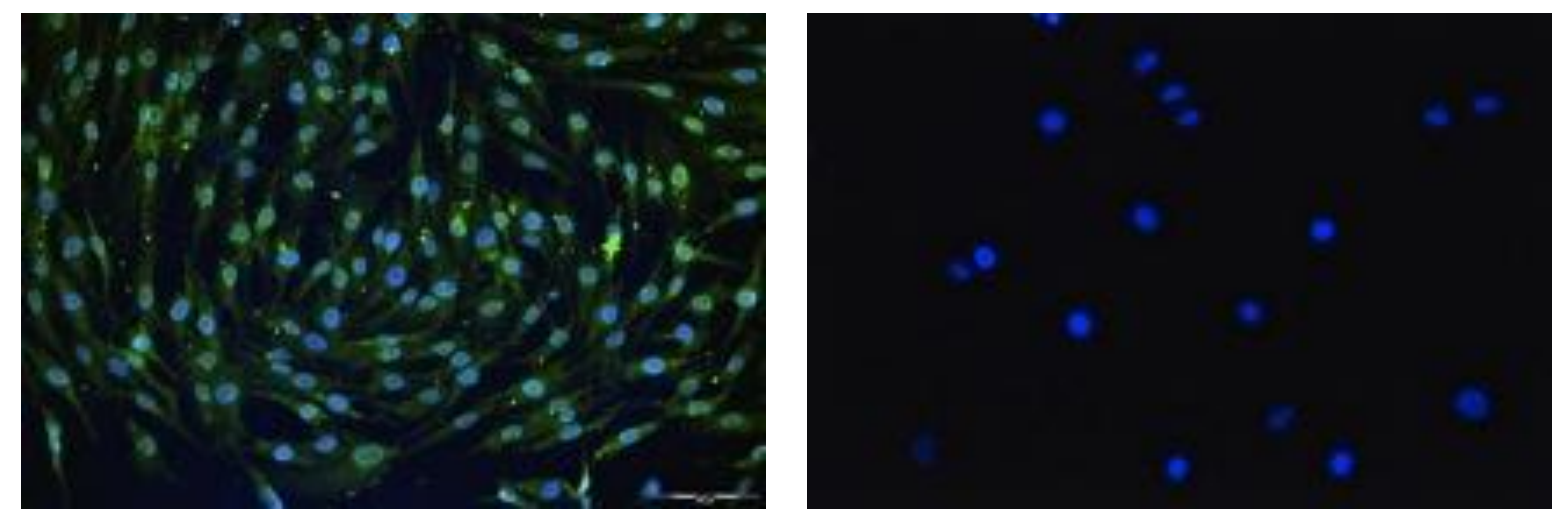

Abbildung 42: IIB-6-LPL

Abbildung 43: IIB-6-LPL-Kontrolle
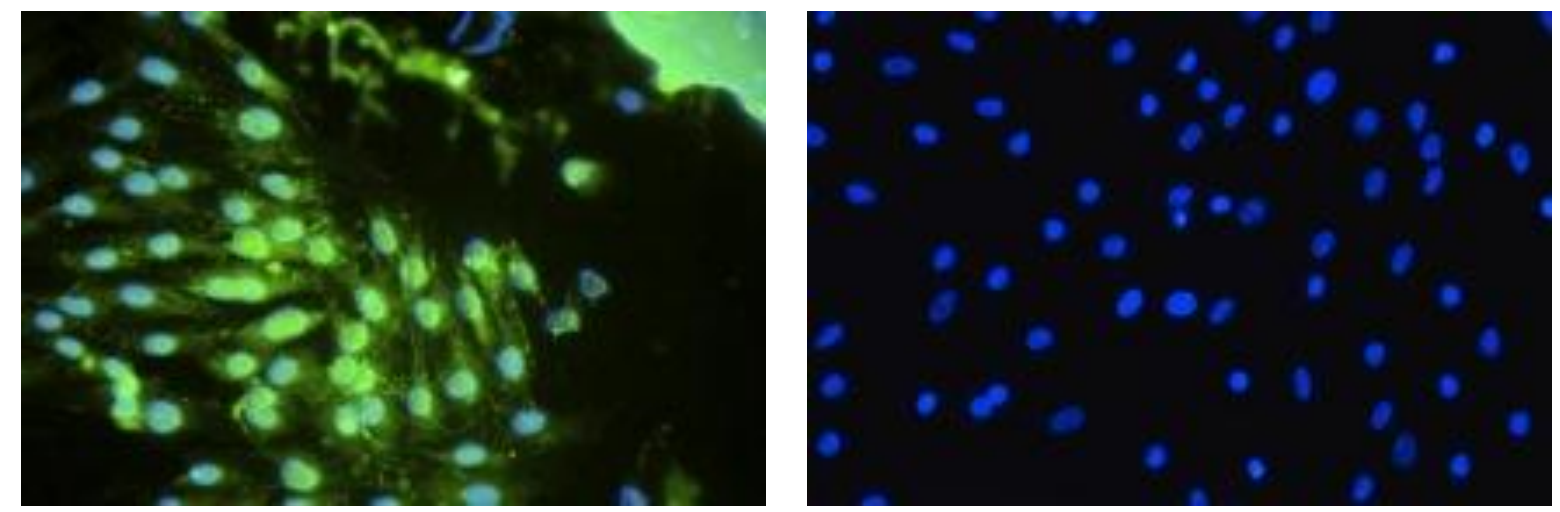

Abbildung 44: IIB-6-PPAR $\gamma$

Abbildung 45: IIB-6-PPAR $\gamma$-Kontrolle 


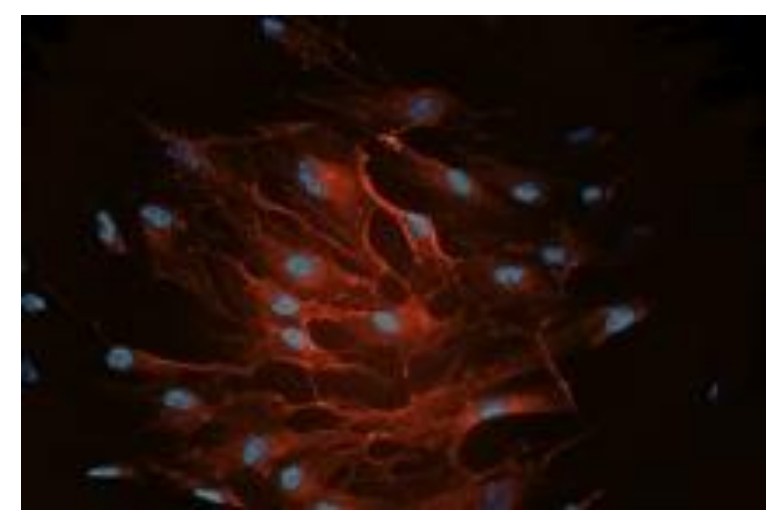

Abbildung 46: IIB-6-Osteocalcin

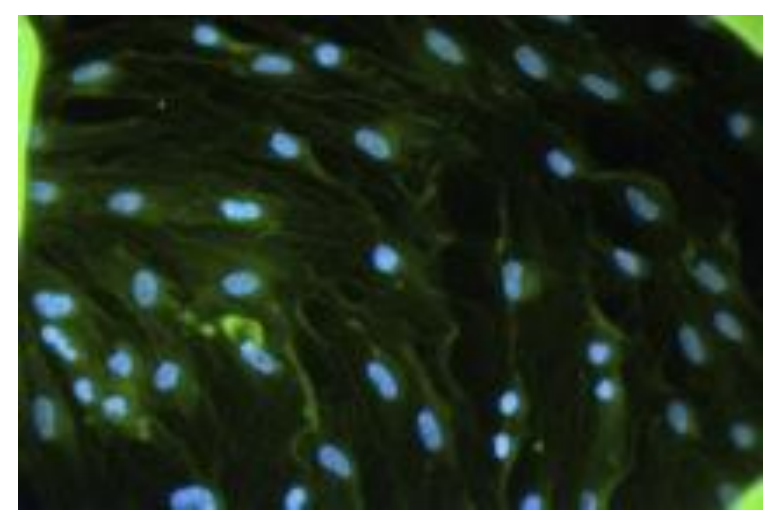

Abbildung 48: IIB-6-runx-2

\subsubsection{Klon-IID-4}

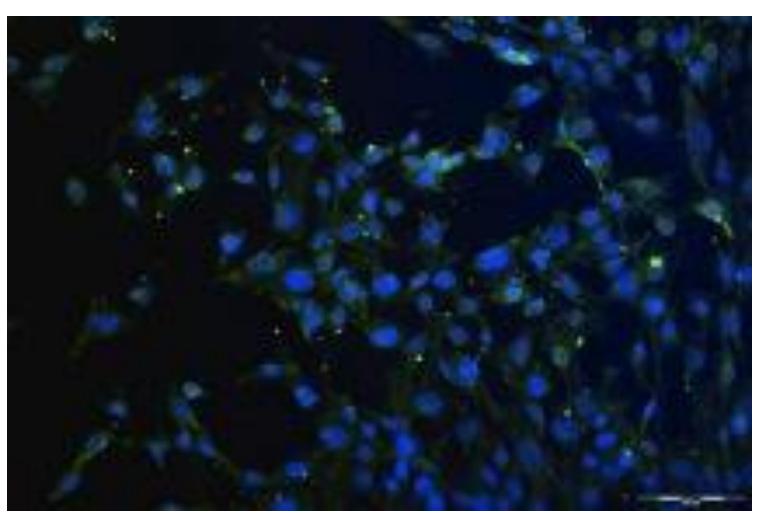

Abbildung 50: IID-4-LPL

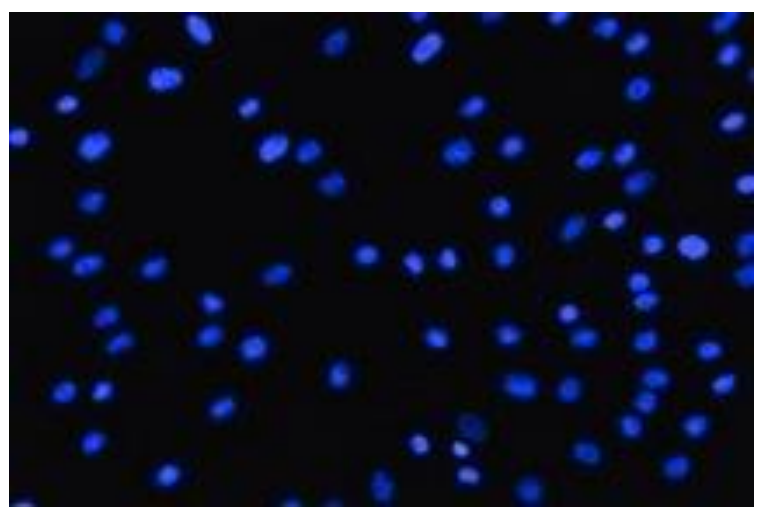

Abbildung 47: IIB-6-Osteocalcin-Kontrolle

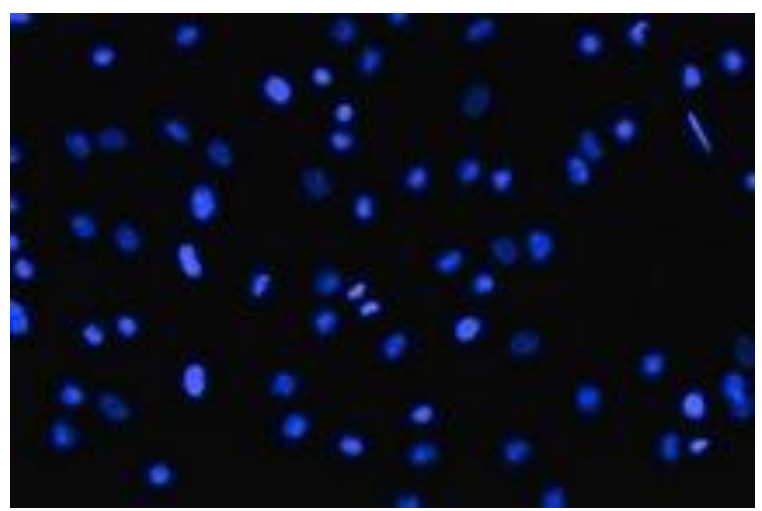

Abbildung 49: IIB-6-runx-2-Kontrolle

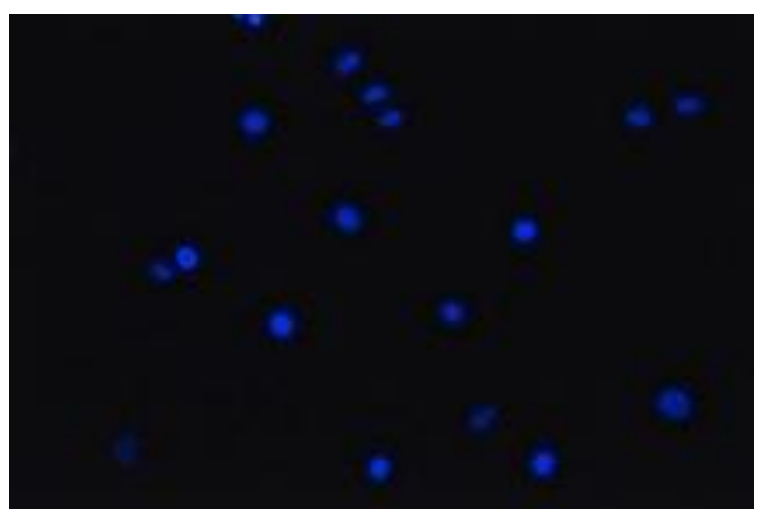

Abbildung 51: IID-4-LPL-Kontrolle 

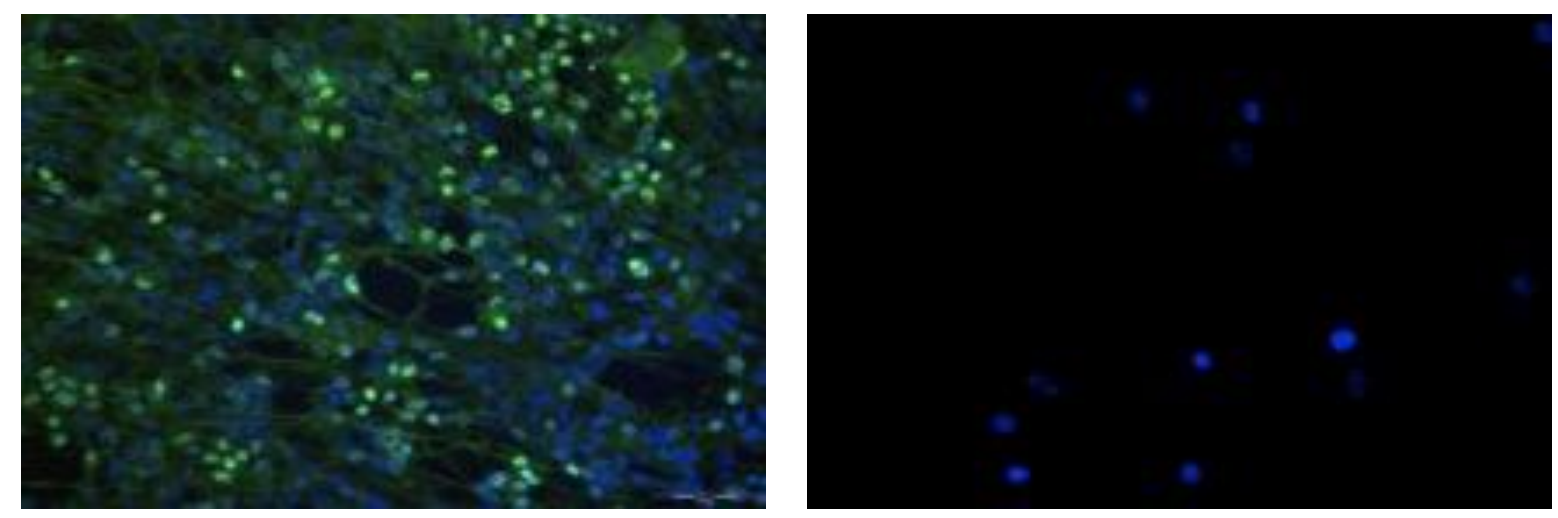

Abbildung 52: IID-4-PPAR $\gamma$

Abbildung 53: IID-4-PPAR $\gamma$-Kontrolle
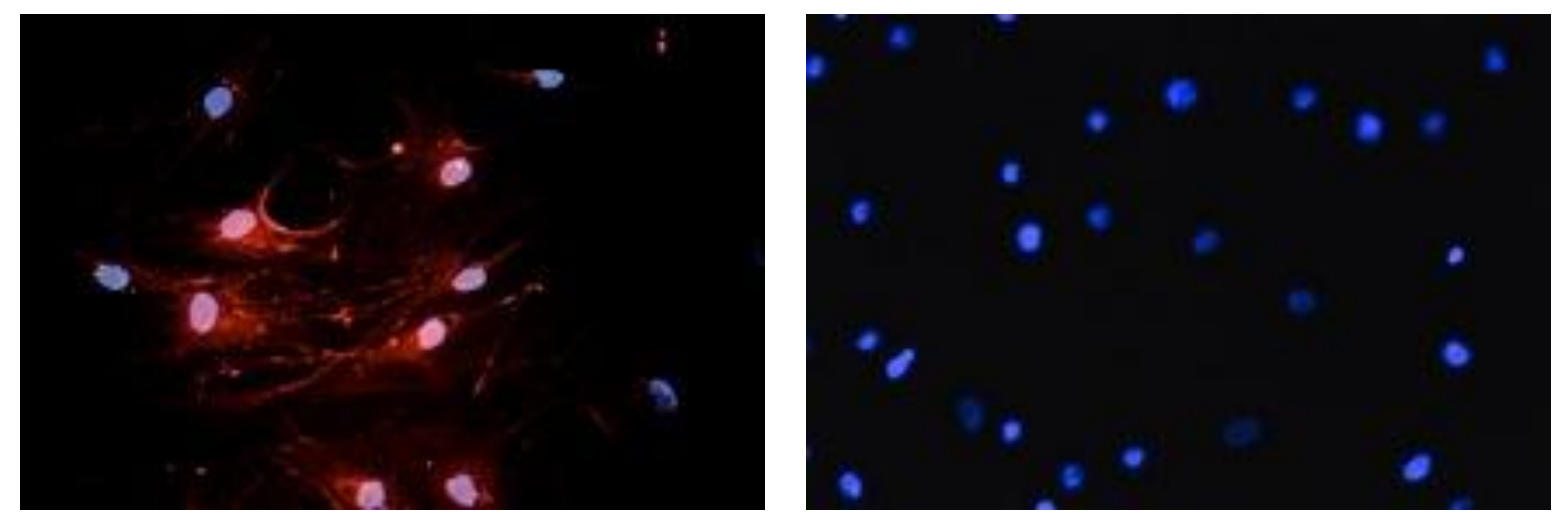

Abbildung 54: IID-4-Osteocalcin

Abbildung 55: IID-4-Osteocalcin-Kontrolle
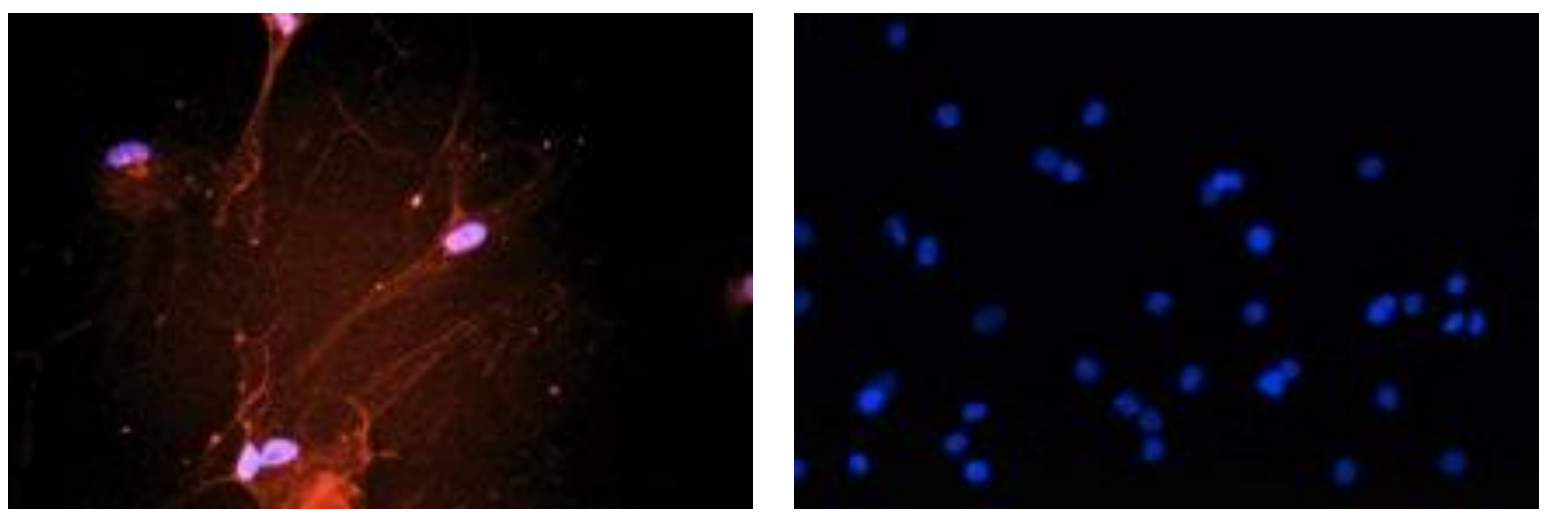

Abbildung 56: IID-4-runx-2

Abbildung 57: IID-4-runx-2-Kontrolle 


\subsection{Western-Blot}

\subsubsection{Runx-2}

Der osteogene Transkriptionsfaktor runx-2 konnte mittels Western-Blot bei allen Klonen aus 2D-Flaschenkultur nachgewiesen werden. Bei jedem Klon stellte sich eine Bande bei ca. $55 \mathrm{kDa}$ dar, das dem Detektionsbereich von runx-2 für den verwendeten AK entsprach (vgl. Abb. 58). Die Auswertung der Banden zeigte, dass die Klone IF-8 und IID-4 eine gegenüber Klon-IIB-6 erhöhte Transkriptionsrate von runx-2 besaßen, da die Banden wesentlich dicker waren. Die dickste Proteinbande für runx-2 ergab sich beim Klon IF-8. Dort war bei ca. 70 kDa eine zusätzliche Bande sichtbar. Solche Banden entstehen allerdings häufig durch glykosylierte oder phosphorylierte Proteinuntergruppen des gesuchten Proteins.

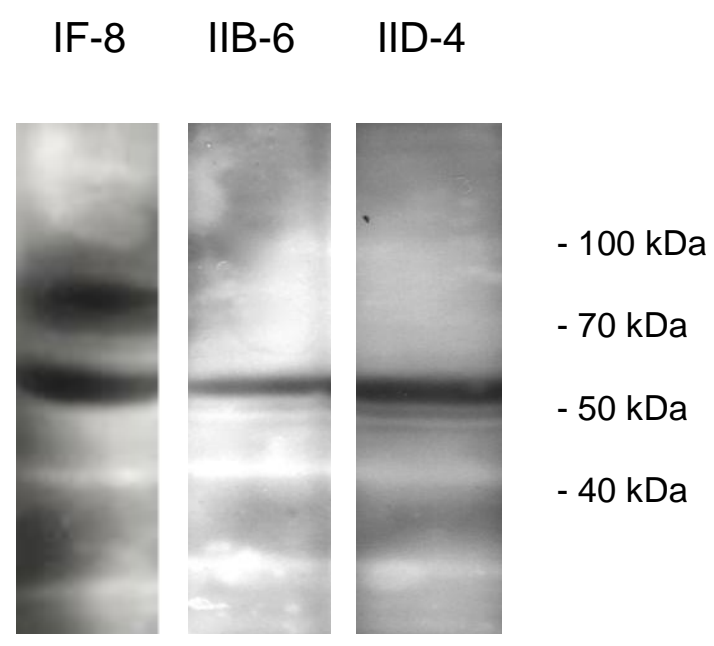

Abbildung 58: Western-Blot: runx-2 (zusammengesetztes Bild)

\subsubsection{Sox-9}

Der Nachweis des chondrogenen Transkriptionsfaktors sox-9 war nicht bei allen Klonen so deutlich wie bei runx-2. Bei den Klonen IIB-6 und IID-4 stellte sich eine gleich stark ausgeprägte Bande bei ca. $65 \mathrm{kDa}$ dar, was mit einem etwa identischen chondrogenen Potenzial dieser Klone zu deuten ist. Beim Klon IF-8 hingegen konnte keine klar definierte Bande bei $65 \mathrm{kDa}$ ausgemacht werden (vgl. Abb. 59, S. 62), 
sondern nur ein leicht verdunkelter Bereich auf dem Röntgenfilm. Das chondrogene Potenzial dieses Klons liegt somit weit unter dem der anderen Klone.

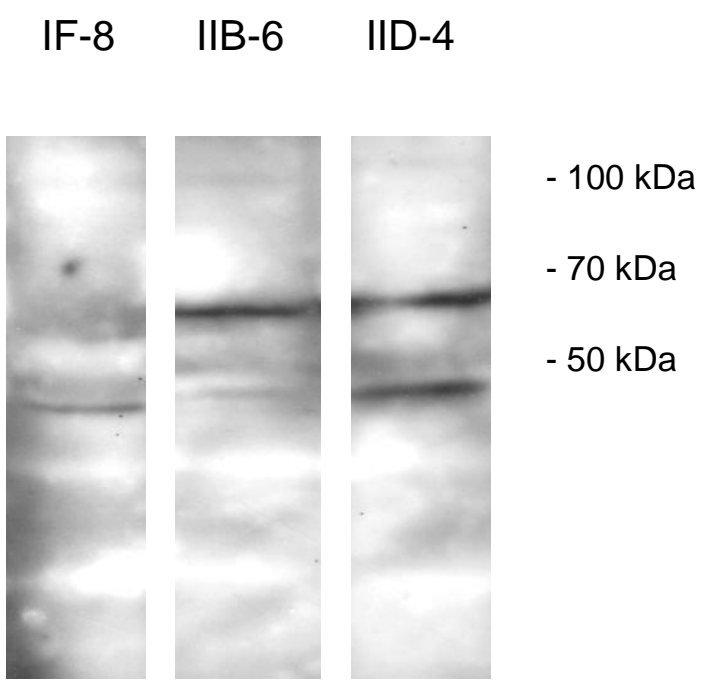

Abbildung 59: Western-Blot: sox-9 (zusammengesetztes Bild)

Neben der vom sox-9-AK detektierten Bande bei ca. $65 \mathrm{kDa}$, stellte sich bei allen Klonen noch eine Bande bei knapp unter 50 kDa dar. Diese Bande besaß bei allen Klonen eine unterschiedliche Ausprägung; sie war bei IID-4 am Stärksten und nahm über IF-8 zu IIB-6 ab. 


\section{Diskussion}

Betrachtet man die schlechte Regenerationsfähigkeit des hyalinen Knorpels der Gelenke und die progradiente Entwicklung der OA bis zum Jahre 2020 (Woolf und Pfleger 2003), dann bleibt die Entwicklung neuer Therapiemaßnahmen für degenerative Gelenkserkrankungen ein wichtiges Feld der aktuellen Forschung. Ein Forschungsschwerpunkt ist momentan die Verwendung und Beeinflussung von ortsansässigen MPCs, die aufgrund ihrer unvollkommenen Ausdifferenzierung eine Möglichkeit bieten könnten, auf molekularbiologischer Ebene Regenerationsprozesse einzuleiten und steuern zu können. Bei der Gonarthrose könnten dabei die von Koelling et al. (2009) beschriebenen migrierenden CPCs eine Form der zellbasierenden Therapie ermöglichen. Sie besitzen alle Eigenschaften von MPCs; sie lassen sich in Adipozyten, Osteoblasten und Chondrozyten differenzieren, sie können weiterhin proliferieren und sie sind klonal.

Beim Aufbau einer homogenen Zellkultur von MPCs ergeben sich allerdings häufig Probleme, da es selbst bei geklonten Zellen innerhalb der Population zu Dedifferenzierungen kommt, unterschiedlichen Replikationsraten und Veränderung ihrer multipotenten Eigenschaften (Barbero et al. 2003). Zellen besitzen auch innerhalb einer Population ein großes Maß an Plastizität (Koestenbauer et al. 2006).

Um die eben genannten Veränderungen bei den migrierenden CPCs zu untersuchen, wurden für diese Arbeit erstmalig Klone einer CPC-Zelllinie miteinander verglichen. Die Hypothese, die dieser Arbeit zugrunde lag war die Vermutung, dass es einen Zusammenhang zwischen Proliferationsrate und Differenzierbarkeit innerhalb einer Zellpopulation gibt. Es könnte möglich sein, dass sich langsam proliferierende Zellen schlechter differenzieren lassen als schnell wachsende, da sie sich eventuell in einem fortgeschrittenen Stadium der Ausdifferenzierung befinden. Für diese Vergleichsstudie wurde ihr Phänotyp in Zellkultur untersucht und ein Proliferationsassay erstellt. Der Nachweis über ihre adipogene und osteogene Differenzierbarkeit erfolgte mittels Oil-Red-Färbung und der AP-Reaktion. Eine Validierung der Differenzierbarkeit wurde durch die Immunfluoreszenzzytochemie erbracht. Das chondrogene und osteogene Grundmuster, wie es bei den CPCs vorkommt, wurde mittels Western-Blot verglichen. 


\subsection{Diskussion zur Methode}

\subsubsection{Proliferationsassay}

Die Auszählung der Zellen beim Proliferationsassay wurde mit dem Cellometer ${ }^{\mathrm{TM}}$ AutoT4 (Nexcolom, Lawrence, USA) durchgeführt. Dabei handelt es sich um ein Hellfeldmikroskop, das zusammen mit einer Software automatisiert die Zelldichte und Zellzahl, sowie lebende und tote Zellen messen kann. Laut Herstellerangaben liegt die Standardabweichung im Durchschnitt bei 5 \%. Auch bei verklumpten Zellen soll die Software einzelne Zellen messen können. Bei diesem Verfahren wird allerdings immer nur die komplette Zellzahl gemessen, neu proliferierte Zellen allein kann das Zellometer nicht bestimmen. Um die Fehlerquote dennoch zu minimieren, wurden die Mittelwerte aus drei Testreihen bestimmt. Ein neueres und sehr viel genaueres Verfahren funktioniert über das Nukleosid 5-Ethynyl-2-desoxyuridin (EdU) (Click IT ${ }^{\circledR}$ EdU Cell Proliferation Assays, Life Technologies ${ }^{\text {TM }} \mathrm{GmbH}$, Darmstadt-DE), das nach der Zellteilung in neu synthetisierte DNS eingebaut wird. Die Zellen, die EdU in ihre DNS inkorporiert haben, können dann mit einem speziellen Farbstoff mittels Durchflusszytometer gemessen werden. Dabei detektiert ein Laserstrahl nur die durch den Farbstoff fluoreszierenden Nukleoside, wodurch die Proliferationsrate genau bestimmt werden kann (Diermeier-Daucher et al. 2009).

\subsubsection{Zelldifferenzierung}

Die Differenzierung von MPCs bzw. MSCs durch Nährmedien ist ein etabliertes Standardverfahren zum Nachweis, dass sich diese Zellen in alle Zelllinien des Mesoderms differenzieren lassen. Schon Owen und Friedenstein zeigten 1988 die Differenzierbarkeit von MSCs aus dem Knochenmark durch die Zugabe bestimmter Wachstumsfaktoren in vitro. Obwohl seitdem immer neue ortsansässige Progenitorzellen in den verschiedenen Geweben identifiziert werden konnten (Dowthwaite et al. 2004, Kruse et al. 2006), die auch über die Zelllinien des Mesoderms hinaus transdifferenziert werden konnten (Kokai et al. 2005), bleibt bis heute die Differenzierung in Adipozyten, Chondrozyten oder Osteoblasten der Goldstandard zum Nachweis der Plastizität von MSCs (Vater et al. 2011). Für die Differenzierung in Adipozyten und Osteozyten der Klone IF-8, IIB-6 und IID-4 wurden kommerziell erworben Differenzierungsmedien der Firma PromoCell verwendet. Über die genaue Zusammensetzung dieser Medien ist nichts weiter bekannt, aber ihre Wirksamkeit ist wissenschaftlich erwiesen (Ramgolam et al. 2011). Bei den 
Zusätzen, die für die Differenzierung benötigt werden, handelt es sich um verschiedene Wachstumsfaktoren, Seren und Zytokine. Bei der adipogenen Differenzierung kommen Nährmedien mit Dexamethason, IBMX (3-Isobutyl-1methylxanthin), Insulin und Indometacin zum Einsatz, die auch Zusätze wie Trijodthyronin, Ascorbinsäure-2-phosphat und FGF-2 (engl. „fibroblast growth factor $2^{\prime \prime)}$ enthalten. Für die osteogene Differenzierung werden klassisch Medien mit Dexamethason, $\beta$-Glycerophosphat und Ascorbinsäure verwendet, denen Zusätze an Vitamin D3, TGF- $\beta$ und BMP beigemengt sind (Vater et al. 2011).

Um morphologische Veränderungen zu untersuchen, wie sie bei Zellen in MonolayerKultur häufig auftreten (Mareddy et al. 2007), wurden die zu differenzierenden Zellen mit zwei verschieden Dichten ausgesät. Es wurden pro Klon jeweils einmal $1 \times 10^{3}$ und $3 \times 10^{3}$ Zellen/Well in Kultur genommen, wodurch ein ausreichender Dichteunterschied gegeben war. Dadurch konnte lichtmikroskopisch ausgewertet werden, ob sich nicht nur zwischen den Klonen, sondern auch innerhalb der Klonpopulation morphologische Unterschiede bei der Differenzierung ergeben. Die Unterschiede wurden nach sechs Tagen Inkubationszeit ausgewertet, da die morphologischen Veränderungen am Größten waren. Die erworbenen Medien wurden in Bezug auf die Inkubationszeit nicht nach Herstellerangaben verwendet. Der Hersteller schreibt für die Adipozyten eine Inkubationszeit von 14 Tagen vor, bei den Osteoblasten drei Wochen. Dies schien für die Klone des CPCs zu lange, da regelmäßig alle Zellen abstarben. Aufgrund mehrerer Versuche wurde eine Inkubationszeit von zehn Tagen für den Differenzierungsnachweis festgelegt, obwohl dabei auch fast alle Zellen der dichteren Populationen abstarben.

Für den Nachweis ihrer adipogenen und osteogenen Differenzierung wurden die Standardverfahren der Oil-Red-Färbung und die AP-Färbung verwendet. Dabei handelt es sich um Nachweisverfahren, die schon während der Differenzierung positiv reagieren und somit frühzeitig eine adipogene bzw. osteogene Differenzierung nachweisen können. Für spätere Phasen der osteogenen Differenzierung wäre auch die Verwendung von Alizarin möglich, einem Farbstoff, der Kalzium rot anfärbt (Vater et al. 2011). 


\subsubsection{Immunfluoreszenzzytochemie}

Zur Validierung der Nachweisverfahren der adipogenen und osteogenen Differenzierung mittels Oil-Red-Färbung und AP-Färbung wurde die Immunfluoreszenzzytochemie angewandt. Durch die Verwendung von Antikörpern gegen spezifische Proteine der Adipozyten und Osteoblasten kann ein sicherer Nachweis erbracht werden, dass die differenzierten Zellen auch als solche funktionieren (Vater et al. 2011). Für die Adipozyten wurden AK gegen PPARY und die LPL verwendet. PPARy ist einer der spezifischen Transkriptionsfaktoren, der die Expression von Genen reguliert, die für die Induktion und Progression der adipogenen Differenzierung verantwortlich sind; dieser Einfluss gilt in vivo und in vitro (Rosen et al. 1999). Neben PPARY spielt auch der Transkriptionsfaktor C/EBP (engl. „CCAAT/enhancer-binding-proteine) bei der adipogenen Differenzierung eine wichtige Rolle und kann als Alternative zum Nachweis verwendet werden (Gregoire et al. 1998). Die LPL katalysiert extrahepatisch die Hydrolyse von Triglyceriden in freie Fettsäuren, die den Adipozyten als Metaboliten zur Verfügung stehen, dadurch eignet sie sich ausgezeichnet als Marker von Fettzellen (Zechner et al. 2000). Für die Osteoblasten wurde ein AK gegen den spezifischen Transkriptionsfaktor runx-2 eingesetzt, da durch inn viele für die Osteosynthese relevanten Gene bzw, deren Promotoren aktiviert werden. Darunter befinden sich die Gensequenzen für Osterix, Kollagen-I-alpha-1, Osteocalcin und BSP (engl. „bone sialoproteine“). (Ducy et al. 1997 und 1999, Lian et al. 2006, Nakashima et al. 2002, Kern et al. 2001, RomeroPrado et al. 2006). Zur Detektion von Osteocalcin wurde in dieser Arbeit ebenfalls ein AK eingesetzt, da es häufig als Standardprotein für den Nachweis der osteogenen Differenzierung eingesetzt wird. Wie bei den Adipozyten gibt es mehrere Proteine, die zum Nachweis mittels AK in Frage kommen. Dabei muss aber unterschieden werden, dass bestimmte Proteine erst im Verlauf der Osteogenese gebildet werden. So können grundsätzlich die AP, Kollagen-1-alpha-1, TGF- $\beta 1$ (engl. „transforming growth factor-beta 1), Osteonectin und BMP-2 frühzeitig nachgewiesen werden, während Osteocalcin und Osteopontin zu den später nachweisbaren Proteinen gehören (Spector et al. 2001, Long 2001, Young 2003, Zhu et al. 2001).

Für die Immunfluoreszenz wurden überwiegen monoklonale AK verwendet. Diese sind, im Gegensatz zu polyklonalen AK, spezifischer gegen das gesuchte Antigen, 
da sie aufgrund ihres Herstellungsverfahrens nur ein bestimmtes Epitop des gesuchten Antigens erkennen. Die polyklonalen AK werden in verschiedenen B-ZellKlonen reproduziert, wodurch es zu verschiedenen Epitopspezifitäten bei gleicher Antigenspezifität kommt. Dadurch kann es bei Versuchen zu Kreuzreaktionen mit unspezifischen Bindungen kommen und das Ergebnis verfälschen (Luttmann et al. 2009). Um unspezifische Bindungen zu verringern, wurden die Zellen für 15 min mit einer $1 \%$ BSA-Lösung behandelt und dadurch die Bindungen geblockt.

Insgesamt wurde bei der Auswahl der AK auch darauf geachtet, dass die zu detektierenden Proteine in dieser Arbeit auch als Nachweis bei den Differenzierungsversuchen der CPCs von Koelling et al. (2009) verwendet wurden. Dadurch können Vergleiche in der Differenzierbarkeit zwischen den Klonen und der Mischpopulation der CPCs herangezogen werden.

\subsubsection{Western-Blot}

Wie von Koelling et al. (2009) beschrieben, besitzen die Mischpopulationen der CPCs chondrogene und osteogene Eigenschaften. Mittels quantitativer real-time RTPCR wurden Chondrozyten, Osteoblasten und die CPCs in Bezug auf ihren mRNA Gehalt an runx-2 und sox-9 miteinander verglichen. Der Vergleich des Expressionslevels von runx-2 und sox-9 der Klone erfolgte im Gegensatz dazu in dieser Arbeit durch einen Western-Blot.

Der quantitative Nachweis von mRNA durch die real-time RT-PCR ist eine sehr exakte Methode und ist heute ein etabliertes und anerkanntes Verfahren in der Genexpressionsanalyse, das die Nutzung von Blots in Zukunft wohl vollkommen ablösen wird. Ihre Vorteile sind die hohe Sensitivität und eine gute Reproduzierbarkeit der Ergebnisse, die aufgrund zahlenbasierender Auswertung immer exakt verglichen werden können (Bustin et al. 2005). Allerdings kommt es bei unsachgemäßem Umgang mit mRNA, Primern und Pufferlösungen schnell zu einer Potenzierung von Fehlern, die die Ergebnisse der RT-PCR verfälschen.

Eine einfachere, aber nicht genauere Methode zum quantitativen Nachweis von Proteinen ist der Western-Blot, der wesentlich länger in der Labormethodik etabliert ist und noch immer als Standardverfahren häufig Anwendung findet. Der WesternBlot ist wenig techniksensibel und einfach in der Durchführung. Die Auswertung der 
Proteinbanden des Blots nach Molekülmasse und Dicke der Proteinbanden erfolgt jedoch durch den subjektiven Eindruck des Betrachters; dadurch sind die Ergebnisse des Blots nicht so genau reproduzierbar wie bei der RT-PCR (Kurien et al. 2011).

Bei den verwendeten AK handelt es sich bei runx-2 um einen monoklonalen, bei sox9 um einen polyklonalen. Wie im Diskussionsteil der Immunfluoreszenzzytochemie beschrieben, besitzt hier der AK gegen runx-2 eine höhere Epitopspezifität als der AK gegen sox-9. Um Kreuzreaktionen zu verringern, wurden unspezifische Bindungsstellen mit einer $5 \%$ Lösung aus Milchpulver in TBS-T geblockt.

\subsection{Diskussion der Ergebnisse}

\subsubsection{Phänotypen}

Während der Inkubation der Klone mit DMEM unter Standardbedingungen in Zellkulturflaschen zeigten sich Unterschiede im Phänotyp. Die Klone IF-8 und IIB-6 zeigten einen fibroblastenartigen Phänotyp, so wie inn Owen und Friedenstein (1988) für die Stammzellen des Knochenmarks definierten und waren damit morphologisch identisch zu den CPCs aus heterogenen Populationen. Beim Klon-IID-4 bildeten sich fast ausschließlich Zellen mit einer kugeligen Morphologie aus, die in einzelnen Gruppen vorlagen, die wiederum durch spindelartige Zellen verbunden waren. Morphologische Variationen wurden in vitro schon mehrfach beobachtet und wurden in der Literatur durch eine Dedifferenzierung der Zellen oder mit einer gesteigerten Zellalterung begründet (Barbero et al. 2003, Mareddy et al. 2007, von der Mark et al. 1977). In Bezug auf die morphologischen Unterschiede bei fortgeschrittener Zellalterung, konnten Prockop et al. (2001) nachweisen, dass MSCs aus dem Knochenmark aus zwei verschiedene Populationen bestehen. Zum Teil sind es schnell wachsende, spindelartige Zelltypen, die auch ein erhöhtes $M a ß$ an Multipotenz aufweisen und die junge Zellpopulation bilden. Zum Anderen sind es flache, großflächige Zellen, die nur noch eine eingeschränkte Differenzierungsfähigkeit besitzen und der älteren Zellgeneration angehören.

Die morphologische Variabilität der Klone setzte sich auch während der Differenzierung zu Adipozyten und Osteoblasten fort, wobei es auch zwischen den unterschiedlich dicht ausgesäten Zellen zu Unterschieden im Aussehen kam. Vater et al. (2011) charakterisierten die adipogene Differenzierung bei klonalen MSCs mit 
dem Übergang von fibroblastenartigen Zellen zu abgeflachten, kugeligen Zellen und die osteogene mit der Transformation in leicht kubische Zellen. Ein Zusammenhang zwischen Morphologie und Zelldichte konnte auch bei diesen MSCs festgestellt werden.

Bei den adipogen differenzierten Klonen der CPCs zeigte sich nach sechs Tagen, dass die dichter wachsenden Zellen im Durchschnitt größer waren und mehrere Zellfortsätze ausbildeten als die Klone in der $1 \times 10^{3}$ Anfangskonzentration. Umso dichter die Zellen ausgesät waren, desto schneller bildete sich ein anderer Phänotyp aus mit multiplen Fortsätzen zu den Nachbarzellen. Bei der Zellpopulation mit geringerer Dichte waren teilweise noch die spindelartigen Formen der undifferenzierten Klone sichtbar, nur dass Zellausläufer nun auch seitlich aus den Zellen austraten. Bei der osteogenen Differenzierung zeigten sich wenige Unterschiede zwischen den Zellmorphologien in Bezug auf die Konfluenz. Bei IF-8 und IIB-6 entwickelten sich die Zellen wie von Vater et al. (2011) beschrieben zu osteoblastenähnlichen Zellen. Beim Klon-IID-4 zeigte sich ein umgekehrtes Bild zur adipogenen Differenzierung. Die Zellen mit erhöhter Konfluenz blieben eher rund, ohne die Ausbildung von Zellfortsätzen, sodass die Zellen ihren Phänotyp der undifferenzierten Klone beibehielten. Die anderen Zellen flachten ab und bildeten wenig ausgeprägte Fortsätze aus. Pittenger et al. (1999) und Murphy et al. (2002) beschreiben eine abnehmende Differenzierbarkeit von älteren MSCs in Chondrozyten und Adipozyten, wobei die Differenzierbarkeit in Osteoblasten meist unverändert bleibt. Es wird angenommen, dass sich aus MSCs osteochondrogene Progenitorzellen entwickeln, die zu Beginn ihrer hierarchischen Entwicklung ein chondrogenes Potenzial besitzen, das im Laufe der Zellalterung in ein osteogenes Potenzial übergeht bzw. es nur eine gemeinsame Vorläuferzelle für Knorpel und Knochen gibt (Muraglia et al. 2000). Auf Basis dieser Vermutung könnte sich auch erklären lassen, warum es bei der osteogenen Differenzierung der CPC-Klone weniger Variationen im Phänotyp gab als bei der adipogenen. Wie Koelling et al. (2009) beschrieben, besitzen die CPCs ein basales Expressionsmuster an chondrogenen und osteogenen Transkriptionsfaktoren, die eine Nähe zu beiden Zelllinien vermuten lässt. Geht man nach den Publikationen von Prockop et al. 2001 und Murphy et al. 2002, dann implizieren untypische Phänotypen von MSCs fortgeschrittene Zellalterung, eine langsamere Proliferationsrate und schlechtere 
multipotente Eigenschaften. Aufgrund des untypischen Phänotyps des Klons-IID-4, müsste dieser am weitesten in der Zellalterung fortgeschritten sein.

\subsubsection{Proliferationsassay und Differenzierungsnachweis}

Barbero et al. (2003) beschrieben eine klonale Population von dedifferenzierten Chondrozyten aus humanen Gelenken, die auf ihre Multipotenz getestet werden sollten. Dabei viel auf, dass sich die Proliferationsraten zwischen den Klonen teils um das Doppelte unterschieden und dass sich nicht alle Klone osteogen, chondrogen oder adipogen differenzieren ließen. Manche Zellen besaßen gar keine Multipotenz oder redifferenzierten sich nur in Chondrozyten. Es gab bei dieser Studie keinen Klon, der schnell proliferierte und dabei tripotent war, diese Klone lagen eher bei einer mittleren bis langsameren Proliferationsrate. Auffällig war aber die Häufung, dass sich schnell proliferende Klone oft nur in Chondrozyten differenzieren ließen und langsam wachsende überproportional häufig nur in Adipozyten und Osteoblasten. Bei den Klonen der CPCs gab es ebenfalls starke Abweichungen in der Proliferationsgeschwindigkeit. Von IF-8 ausgehend gab es zu Klon-IIB-6 eine fast dreimal so schnelle Teilungsrate innerhalb von sieben Tagen. Auch Klon-IID-4 besitzt noch eine doppelt so schnelle Proliferationsgeschwindigkeit wie IF-8. Wie oben erwähnt, ist die Abnahme der Proliferationsgeschwindigkeit ein Indiz für die Seneszenz der Zelle und geht mit einer herabgesetzten chondrogenen und adipogenen Differenzierung einher (Prockop et al. 2001). Demnach hätte sich IF-8 besser osteogen differenzieren lassen müssen und schlechter bzw. gar nicht adipogen. Die Auswertungen der Oil-Red-O- und AP-Färbung sowie der Immunfluoreszenz zeigten aber keinerlei Unterschiede zwischen den Klonen. Auch die Auswertungen der Kontrollpopulationen zeigten keine positiven Zellen. Insgesamt zeigen die Klone das gleiche Differenzierungspotenzial wie die heterogene CPCPopulation. Eine chondrogene Differenzierung der Klone muss an dieser Stelle noch erfolgen, um eventuelle Veränderungen der chondrogenen Zelllinie zu untersuchen. In dieser Arbeit wurde ein eventuelles chondrogenes und osteogenes Expressionsmuster mittels Western-Blot untersucht.

\subsubsection{Western-Blot}

Betrachtet man die Ergebnisse des Western-Blots und des Proliferationsassays auf dem Hintergrund des Differenzierungsmodells von Muraglia et al. (2000), dann 
lassen sich die Klone deutlich nach ihrem Alter charakterisieren, bzw. kann eine Aussage über ihre osteochondrogene Plastizität gemacht werden. Das Modell beschreibt, dass es keine getrennten MPCs für Knorpel und Knochen gebe, sondern chondrogene MPCs die Progenitorzellen beider Gewebe seien. Der Nachweis des osteogenen Transkriptionsfaktors runx-2 zeigte eine quantitative Zunahme der Proteinbandendicke über den schnell proliferierenden Klon-IIB-6 bis hin zu dem langsam proliferierenden Klon-IF-8. Dadurch konnte nachgewiesen werden, dass IF8 das höchste osteogene Potenzial der Klone besitzt. Andersherum verhält es sich bei der Auswertung des chondrogenen Potenzials durch den Nachweis von sox-9. Hier konnte bei IF-8 nicht eindeutig eine Bande identifiziert werden, während die Proteinbanden über IID-4 und IIB-6 an Dicke zunahmen. Es zeigt, dass das chondrogene Potenzial von IF-8 unterhalb der Detektionsgrenze des Western-Blots liegt bzw. der Klon kein chondrogenes Potenzial mehr besitzt. Zusammenfassend ergibt sich daraus, dass es bei denn CPCs einen Zusammenhang zwischen Proliferationsgeschwindigkeit und des osteochondrogenen Potenzials gibt. Schnell proliferierende CPCs sind eher chondrogen, langsame eher osteogen.

\subsubsection{Charakteristika migrierender CPCs}

Wie Koelling et al. (2009) beschrieben hatten, besitzen die migrierenden CPCs, trotz ihres osteochondrogenen Expressionsmusters, multipotente Eigenschaften und konnten durch Stammzellmarker auch als Stammzellen identifizert werden. Allerdings ist die Herkunft dieser Zellen unklar und ebenfalls, ob innerhalb einer klonalen CPCPopulation die Differenzierungsfähigkeit, Proliferation und das osteochondrogene Potenzial identisch sind, da immer wieder Unterschiede zwischen heterogenen und klonalen Zellpopulationen in der Literatur beschrieben wurden.

Mit dieser Arbeit konnte nachgewiesen werden, dass die multipotenten Eigenschaften der CPCs auch innerhalb einer klonalen Population weiterhin bestehen und es zwischen innen keine quantitativen Unterschiede bezüglich ihrer Differenzierungsfähigkeiten in Adipozyten und Osteoblasten in vitro gibt. Die chondrogene Differenzierung zeigten Koelling et al. in der 2009 veröffentlichten Publikation. Diese Differenzierungsfähigkeiten sind unter anderem Anzeichen für Stammzellen aus dem Knochenmark (Caplan 1991). Pittenger et al. (1999) konnte auch an klonalen Stammzellpopulationen des Knochenmarks nachweisen, dass diese sich in mesenchymale Zelllinien differenzieren lassen. Allerdings zeigte sich im 
Gegensatz zur Mischpopulation, wie ebenfalls von Muraglia et al. (2000) nachgewiesen, dass klonale Zelllinien nicht mehr das gleiche multipotente Potenzial besaßen. Osteogen waren die Klone immer, aber die chondrogene und adipogene Differenzierbarkeit war bei einigen Klonen nicht mehr vorhanden. Bei den klonalen CPCs tauchte dieser Unterschied nicht auf, da die adipogene Differenzierbarkeit eindeutig nachgewiesen werden konnte. Hierbei muss aber auch erwähnt werden, dass mit dem Vergleich von drei Klonen einer Population eine vergleichsweise kleine Versuchsreihe gewählt wurde und die Ergebnisse bei einer größeren Kontrollgruppe variieren könnten.

Bezieht man das hierachische Entwicklungsmodell von Koestenbauer et al. (2006) mit ein, könnte angenommen werden, dass sich Zelllinien innerhalb einer CPCPopulation in verschiedenen Differenzierungsphase befinden, die den Übergang multipotenter MSCs zu tri- oder bipotenten Progenitorzellen darstellen. Dies würde erklären, weshalb die CPCs noch adipogene Potenz besitzen, aber in ihrer Entwicklung durch extrinsische Faktoren im Knorpel beeinflusst werden und ein vermehrt basales osteochondrogenes Expressionsmuster besitzen. Murphy et al. (2002) und Pittenger et al. (1999) konnten nachweisen, dass MSCs zunächst ihre adipogene Potenz verlieren und im Folgenden nur noch osteochondrogene bzw. nur noch osteogene Zellen sind. Dieser Verlust an Differenzierbarkeit geht mit einer verlangsamten Proliferationsrate einher und steht im Zusammenhang mit einer fortgeschrittenen Zellalterung bzw. einem fortgeschrittenen Differenzierungsstadium (Prockop et al. 2001). Durch die Auswertung der osteogenen und chondrogenen Transkriptionsfaktoren der klonalen CPCs, in Bezug zu ihren Proliferationsraten, konnte in dieser Arbeit ebenfalls gezeigt werden, dass schnell proliferierende Klone eher ein chondrogenes Potenzial besitzen und langsam proliferierende eher ein osteogenes. Hier zeigte sich der Vorteil des Western-Blots, da sich exakt ein Zusammenhang zwischen Proliferationsgeschwindigkeit und der Bandendicke von sox-9 und runx-2 nachweisen ließ. Somit konnte im Gegensatz zu anderen Publikationen, in denen die osteogene und chondrogene Differenzierbarkeit dichotom ausgewertet wurde, gezeigt werden, dass eine Abnahme der Proliferationsgeschwindigkeit schon mit herabgesetzter Expression von sox-9 einhergeht und chondrogene Eigenschaften nicht erst gänzlich fehlen müssen. Koelling et al. (2009) zeigten, dass bei einem Knockdown von runx-2 der Transkriptionsfaktor sox-9 stärker exprimiert wurde und damit das chondrogene Potenzial. In diesem Bezug sollte 
untersucht werden, ob die Proliferationsrate nach einem Knockdown von runx-2 ebenfalls ansteigt. Das wäre ein weiterer Beweis dafür, dass Proliferationsgeschwindigkeit und osteochondrogenes Potenzial bei den CPCs im Zusammenhang stehen. Dabei muss berücksichtigt werden, dass es sich bei den CPCs um Zellen handelt, die im Reparaturgewebe der späten Gonarthrose zu finden sind und nicht direkt im Knochenmark. Das bedeutet, dass das Expressionsmuster der CPCs durch intrinsische und extrinsische Faktoren im Knorpel gesteuert wird (Caplan 1991), sie aber dennoch ein adipogenes Differenzierungspotenzial besitzen. Dadurch könnte anzunehmen sein, dass ihre Entwicklungsbahn im Knochenmark beginnt und sie in die defekten Knorpelanteile migrieren, um sich erst dort in chondrogene Progenitoren zu differenzieren. In diesem Zusammenhang sollte in Zukunft auch untersucht werden, inwieweit Parallelen zwischen der enchondralen Ossifikation, der sekundären Knochenheilung und den Reparaturmechanismen der fortgeschrittenen $\mathrm{OA}$ zu finden sind, da bei der sekundären Knochenheilung ebenfalls chondrogene und osteogene MSCs, Angiogenese und Knorpelbildung eine Rolle spielen (Takahata et al. 2012, Xiao et al. 2010).

Da die CPCs überwiegend Kollagen I bilden anstatt das im Knorpel vorkommende Kollagen II (Koelling et al. 2009), müssen für Stammzelltherapien zur Knorpelregenaration bei fortgeschrittener Gonarthrose noch viele Kenntnisse über die CPCs gewonnen werden. Für die Entwicklung von Therapieansätzen konnte jedoch mit dieser Arbeit gezeigt werden, dass die Heterogenität der CPCs in Bezug auf ihr osteochondrogenes Potenzial und die damit verbundene Veränderung der Proliferationsgeschwindigkeit in Zukunft mit berücksichtigt werden müssen. 


\section{Zusammenfassung}

Die progrediente, muskuloskelettale Erkrankung Ostheoarthrose wird aufgrund der immer älter werdenden Weltbevölkerung im Jahre 2020 einer der häufigsten Invaliditätsgründe sein. Koelling et al. beschrieb 2009 eine migrierende, chondrogene Progenitorzelllinie (CPC) im Reparaturgewebe der fortgeschrittenen Gonarthrose des Menschen, die Stammzelleigenschaften besitzt. Sie sind multipotent, klonal und besitzen ein osteochondrogenes Expressionsmuster, wodurch sie sich für neue Behandlungsmöglichkeiten bei der Ostheoarthrosetherapie eignen könnten.

In dieser Arbeit wurden in vitro drei Klone einer humanen CPC-Population aus osteoarthrotisch verändertem Knorpel hinsichtlich ihrer multipotenten Eigenschaften, Proliferationsgeschwindigkeit und unterschiedlicher Phänotypen gegenübergestellt, da sich bei anderen Stammzellinien Zusammenhänge zwischen diesen Eigenschaften zeigen, die mit fortgeschrittener Ausdifferenzierung der Stammzellen begründet wird.

Die drei Klone IF-8, IIB-6 und IID-4 wurden 12 Tage unter Standardbedingungen in 2D-Flaschenkultur gehalten und anschließend ihr normaler Phänotyp ausgewertet. Dabei zeigte sich, dass IF-8 und IIB-6 eher einen fibroblastenartigen Phänotyp ausbildeten, während sich bei IID-4 erst kugelige Zellen bildeten, die später teils in eine längliche Form übergingen. Die fibroblastenartige Form entsprach der von CPCs aus heterogenen Kulturen, wohingegen der Phänotyp von IID-4 auf Dedifferenzierung oder fortgeschrittenere Differenzierung schließen ließ. Die Klone für die Differenzierungsversuche wurden mit zwei verschiedenen Zelldichten ausgesät, um auch eventuelle Einflüsse der Zelldichte mit in die Untersuchung einzubeziehen. Es wurde pro Well einmal die Anfangskonzentration von 1000 Zellen gewählt und einmal 3000 Zellen pro Well. Nach sechs Tagen wurden morphologische Veränderungen unter dem Mikroskop ausgewertet. Die Differenzierung in Adipozyten und Osteoblasten erfolgte insgesamt über zehn Tage mit anschließendem Differenzierungsnachweis mittels Oil-Red-Färbung von Adipozyten, bzw. der AlkalischenPhosphatase-Reaktion der Osteoblasten. Es wurde zusätzlich mit der Immunfluoreszenzzytochemie kontrolliert, ob in den differenzierten Zellen auch spezifische Proteine exprimiert wurden und sich zwischen den Klonen ein quantitativer Unterschied ergibt, der auf einen veränderten Differenzierungsgrad der Klone schließen konnte. Für die Adipozyten wurden Antikörper gegen die 
Lipoproteinlipase und PPARY gewählt, bei den Osteoblasten kamen Antikörper gegen Osteocalcin und den osteogenen Transkriptionsfaktor runx-2 zum Einsatz. Allen Differenzierungsversuchen wurden jeweils Kontrollgruppen gegenübergestellt. Die Ergebnisse zeigten morphologische Unterschiede zwischen den Klonen und den verschiedenen Zelldichten, die bei der osteogenen Differenzierung nicht so stark ausgeprägt waren wie bei der adipogenen. Der Klon-IID-4 zeigte auch hier die am Stärksten ausgeprägtesten morphologischen Unterschiede zwischen den Zellen selber und der verschiedenen Dichtegrade. Die quantitative Auswertung mittels OilRed und Alkalischer-Phosphatase, bzw. die Ergebnisse der Immunzytochemie ergaben hingegen keine Abweichungen zwischen den Klonen und keine Veränderung in Abhängigkeit zur Zelldichte. Dadurch konnte gezeigt werden, dass bei den CPCs ein veränderter Phänotyp kein Hinweis auf eine fortgeschrittene Zellalterung und verminderte Differenzierbarkeit ist. Auch die Zelldichte nimmt auf die Differenzierung in andere Zellinien keinen positiven oder negativen Einfluss. Deutliche Unterschiede zwischen den Klonen zeigten sich hinsichtlich ihrer Proliferationsgeschwindigkeit und ihres osteochondrogenen Grundmusters. Für das Proliferationsassay wurden über den Zeitraum von sieben Tagen die Zellzahlen gemessen. Dabei wurde festgestellt, dass sich Klon-IF-8 am langsamsten teilte, danach folgte IID-4 und am Ende IIB-6. Im Zusammenhang mit dem Western-Blot, bei dem der osteogene Transkriptionsfaktor runx-2 und der chondrogene Transkriptionsfaktor sox-9 miteinander verglichen wurden, konnte eine Beziehung zwischen Proliferationsgeschwindigkeit und der Ausprägung der Trans- kriptionsfaktoren festgestellt werden. Mit Abnahme der Proliferationsgeschwindigkeit nimmt die Expression von runx-2 zu, während die Expression von sox-9 abnimmt. Dadurch konnte nachgewiesen werden, dass die CPCs mit abnehmender Zellteilung in einen vermehrt osteogenen Zustand übergehen und ihren osteochondrogenen Charakter verlieren. Dieser Übergang hat jedoch keinen Einfluss auf ihre multipotenten Eigenschaften. Mit den Ergebnissen konnte gezeigt werden, dass sich CPCs, ähnlich wie andere Progenitorzellen auch, in ihrer Entwicklung weiter ausdifferenzieren und sich dadurch innerhalb einer Population verschiedene Entwicklungszustände ergeben, die eine genauere Charakterisierung der CPCs weiter erschweren. 


\section{Literaturverzeichnis}

Ahmed TA, Hincke MT (2010):

Strategies for articular cartilage lesion repair and functional restoration. Tissue Eng Part B Rev $\underline{16}$ (3), 305-29

Aigner T, McKenna L (2002):

Molecular pathology and pathobiology of osteoarthritic cartilage. Cell Mol Life Sci $\underline{59}$ (1), 5-18

Alliot-Licht B, Bluteau G, Magne D, Lopez-Cazaux S, Lieubeau B, Daculsi G, Guicheux J (2005):

Dexamethasone stimulates differentiation of odontoblast-like cells in human dental pulp cultures. Cell Tissue Res $\underline{321}$ (3), 391-400

Alonso L, Fuchs E (2003):

Stem cells in the skin: waste not, Wnt not. Genes Dev 17 (10), 1189-200

Alsalameh S, Amin R, Gemba T, Lotz M (2004):

Identification of mesenchymal progenitor cells in normal and osteoarthritic human articular cartilage. Arthritis Rheum $\underline{50}$ (5), 1522-32

Altman R, Asch E, Bloch D, Bole G, Borenstein D, Brandt K, Christy W, Cooke TD, Greenwald R, Hochberg M, et al. (1986):

Development of criteria for the classification and reporting of osteoarthritis. Classification of osteoarthritis of the knee. Diagnostic and Therapeutic Criteria Committee of the American Rheumatism Association. Arthritis Rheum $\underline{29}$ (8), 103949

Aydelotte MB, Michal LE, Reid DR, Schumacher BL (1996):

Chondrocytes from the articular surface and deep zones express different, but stable phentoypes in alginate gel culture. Trans Orthop Res Soc 21, 317

Barbero A, Ploegert S, Heberer M, Martin I (2003):

Plasticity of clonal populations of dedifferentiated adult human articular chondrocytes. Arthritis Rheum $\underline{48}$ (5), 1315-25 
Bartlett W, Skinner JA, Gooding CR, Carrington RW, Flanagan AM, Briggs TW, Bentley G (2005):

Autologous chondrocyte implantation versus matrix-induced autologous chondrocyte implantation for osteochondral defects of the knee: a prospective, randomised study. J Bone Joint Surg Br 87 (5), 640-5

\section{Benya PD, Shaffer JD (1982):}

Dedifferentiated chondrocytes reexpress the differentiated collagen phenotype when cultured in agarose gels. Cell $\underline{30}$ (1), 215-24

\section{Benya PD, Padilla SR, Nimni ME (1978):}

Independent regulation of collagen types by chondrocytes during the loss of differentiated function in culture. Cell $\underline{15}$ (4), 1313-21

\section{Bianco P (2011):}

Bone and the hematopoietic niche: a tale of two stem cells. Blood 117 (20), 5281-8

Bianco P, Costantini M, Dearden LC, Bonucci E (1988):

Alkaline phosphatase positive precursors of adipocytes in the human bone marrow. $\mathrm{Br} \mathrm{J}$ Haematol $\underline{68}$ (4), 401-3

\section{Bianco P, Robey PG, Simmons PJ (2008):}

Mesenchymal stem cells: revisiting history, concepts, and assays. Cell Stem Cell $\underline{2}$ (4), 313-9

\section{Bonfanti P, Barrandon Y, Cossu G (2012):}

'Hearts and bones': the ups and downs of 'plasticity' in stem cell biology. EMBO Mol Med 4 (5), 353-361

\section{Bruder SP, Fink DJ, Caplan Al (1994):}

Mesenchymal stem cells in bone development, bone repair, and skeletal regeneration therapy. J Cell Biochem $\underline{56}$ (3), 283-94

\section{Brunt KR, Weisel RD, Li RK (2012):}

Stem cells and regenerative medicine - future perspectives. Can J Physiol Pharmacol $\underline{90}$ (3), 327-35 


\section{Buckwalter JA, Hunziker EB, Rosenberg LC (1988):}

Articular cartilage: Composition and structure; in: Injury and Repair of the Musculoskeletal Soft Tissues, 1. Auflage; hrsg. v. Woo SL, Buckwalter JA; American Academy of Orthopaedic Surgeons, Park Ridge/IL 1988, 405-425

Buckwalter JA, Mankin HJ, Grodzinsky AJ (2005):

Articular cartilage and osteoarthritis. Instr Course Lect $\underline{54}, 465-480$

\section{Burton PM (2008):}

Insights from diploblasts; the evolution of mesoderm and muscle. J Exp Zool B Mol Dev Evol $\underline{310}$ (1), 5-14

\section{Bustin SA, Benes V, Nolan T, Pfaffl MW (2005):}

Quantitative real-time RT-PCR--a perspective. J Mol Endocrinol $\underline{34}$ (3), 597-601

\section{Caplan Al (1991):}

Mesenchymal stem cells. J Orthop Res $\underline{9}$ (5), 641-50

Caplan Al (2007):

Adult mesenchymal stem cells for tissue engineering versus regenerative medicine. J Cell Physiol $\underline{213}$ (2), 341-7

Collett GD, Canfield AE (2005):

Angiogenesis and pericytes in the initiation of ectopic calcification. Circ Res $\underline{96}$ (9), 930-8

Colter DC, Class R, DiGirolamo CM, Prockop DJ (2000):

Rapid expansion of recycling stem cells in cultures of plastic-adherent cells from human bone marrow. Proc Natl Acad Sci U S A 97 (7), 3213-8

Crisan M, Yap S, Casteilla L, Chen CW, Corselli M, Park TS, Andriolo G, Sun B, Zheng B, Zhang L et al. (2008):

A perivascular origin for mesenchymal stem cells in multiple human organs. Cell Stem Cell $\underline{3}$ (3), 301-13

da Silva Meirelles L, Chagastelles PC, Nardi NB (2006):

Mesenchymal stem cells reside in virtually all post-natal organs and tissues. $\mathrm{J}$ Cell Sci $\underline{119}$ (11), 2204-13 
Diermeier-Daucher S, Clarke ST, Hill D, Vollmann-Zwerenz A, Bradford JA, Brockhoff G (2009):

Cell type specific applicability of 5-ethynyl-2'-desoxyuridine (EdU) for dynamic proliferation assessment in flow cytometry. Cytometry A $\underline{75}$ (6), 535-46

D'Ippolito G, Diabira S, Howard GA, Menei P, Roos BA, Schiller PC (2004):

Marrow-isolated adult multilineage inducible (MIAMI) cells, a unique population of postnatal young and old human cells with extensive expansion and differentiation potential. J Cell Sci 117 (14), 2971-81

Dowthwaite GP, Bishop JC, Redman SN, Khan IM, Rooney P, Evans DJ, Haughton L, Bayram Z, Boyer S, Thomson B, Wolfe MS, Archer CW (2004):

The surface of articular cartilage contains a progenitor cell population. J Cell Sci $\underline{117}$ (6), 889-97

Drost AC, Weng S, Feil G, Schäfer J, Baumann S, Kanz L, Sievert KD, Stenzl A, Möhle R (2009):

In vitro myogenic differentiation of human bone marrow-derived mesenchymal stem cells as a potential treatment for urethral sphincter muscle repair. Ann N Y Acad Sci $\underline{1176}, 135-43$

Ducy P, Zhang R, Geoffroy V, Ridall AL, Karsenty G (1997):

Osf2/Cbfa1: a transcriptional activator of osteoblast differentiation. Cell 89 (5), 747-54

Ducy P, Starbuck M, Priemel M, Shen J, Pinero G, Geoffroy V, Amling M, Karsenty G (1999):

A Cbfa1-dependent genetic pathway controls bone formation beyond embryonic development. Genes Dev $\underline{13}$ (8), 1025-36

Egloff C, Hügle T, Valderrabano V (2012):

Biomechanics and pathomechanisms of osteoarthritis. Swiss Med Wkly 142, w13583

Evans MJ, Kaufman MH (1981):

Establishment in culture of pluripotential cells from mouse embryos. Nature $\underline{292}$ (5819), 154-6 
Farrington-Rock C, Crofts NJ, Doherty MJ, Ashton BA, Griffin-Jones C, Canfield AE (2004):

Chondrogenic and adipogenic potential of microvascular pericytes. Circulation $\underline{110}$ (15), 2226-32

\section{Felson DT (1990):}

Epidemiology of the rheumatic diseases. Curr Opin Rheumatol $\underline{2}$ (2), 301-8

Felson DT (2004):

An update on the pathogenesis and epidemiology of osteoarthritis. Radiol Clin North Am $\underline{42}(1), 1-9$

Felson DT (2006):

Clinical practice. Osteoarthritis of the knee. N Engl J Med $\underline{354}$ (8), 841-8

Fickert S, Fiedler J, Brenner RE (2004):

Identification of subpopulations with characteristics of mesenchymal progenitor cells from human osteoarthritic cartilage using triple staining for cell surface markers. Arthritis Res Ther $\underline{6}$ (5), 422-32

\section{Flouzat-Lachaniette $\mathrm{CH}$ (2012):}

At-risk situations for knee osteoarthritis. Rev Prat $\underline{62}$ (5), 630-4

French AJ, Adams CA, Anderson LS, Kitchen JR, Hughes MR, Wood SH (2008):

Development of human cloned blastocysts following somatic cell nuclear transfer with adult fibroblasts. Stem Cells $\underline{26}$ (2), 485-93

\section{Friedenstein AJ (1980):}

Stromal mechanisms of bone marrow: cloning in vitro and retransplantation in vivo. Haematol Blood Transfus $\underline{25}, 19-29$

Friedenstein AJ, Piatetzky-Shapiro II, Petrakova KV (1966):

Osteogenesis in transplants of bone marrow cells. J Embryol Exp Morphol $\underline{16}$ (3), $381-90$

Friedenstein AJ, Chailakhjan RK, Vasiliev AV (1970):

Formation of clone in monolayer of bone marrow cultures. Bull Exp Biolog Med 2, 9496 


\section{Friedenstein AJ, Chailakhyan RK, Gerasimov UV (1987):}

Bone marrow osteogenic stem cells: in vitro cultivation and transplantation in diffusion chambers. Cell Tissue Kinet $\underline{20}$ (3), 263-72

Friedenstein AJ, Petrakova KV, Kurolesova Al, Frolova GP (1968):

Heterotopic of bone marrow. Analysis of precursor cells for osteogenic and hematopoietic tissues. Transplantation $\underline{6}$ (2), 230-247

Friedenstein AJ, Deriglasova UF, Kulagina NN, Panasuk AF, Rudakowa SF, Luriá EA, Ruadkow IA (1974):

Precursors for fibroblasts in different populations of hematopoietic cells as detected by the in vitro colony assay method. Exp Hematol $\underline{2}$ (2), 83-92

Fuchs E, Tumbar T, Guasch G (2004):

Socializing with the neighbors: stem cells and their niche. Cell 116 (6), 769-78

Goldberg VM (2012):

Stem Cells in Osteoarthritis. HSS J $\underline{8}$ (1), 59-61

Goldring MB, Goldring SR (2006):

Clinical aspects, pathology and pathophysiology of osteoarthritis. J Musculoskelet Neuronal Interact $\underline{6}$ (4), 376-8

Goldring MB, Goldring SR (2007):

Osteoarthritis. J Cell Physiol $\underline{213}$ (3), 626-34

Gong Z, Calkins G, Cheng EC, Krause D, Niklason LE (2009):

Influence of culture medium on smooth muscle cell differentiation from human bone marrow-derived mesenchymal stem cells. Tissue Eng Part A 15 (2), 319-30

Gregoire FM, Smas CM, Sul HS (1998):

Understanding adipocyte differentiation. Physiol Rev $\underline{78}$ (3), 783-809

Gronthos S, Franklin DM, Leddy HA, Robey PG, Storms RW, Gimble JM (2001) Surface protein characterization of human adipose tissue-derived stromal cells. J Cell Physiol $\underline{189}$ (1), 54-63 
Hamel MB, Toth M, Legedza A, Rosen MP (2008):

Joint replacement surgery in elderly patients with severe osteoarthritis of the hip or knee: decision making, postoperative recovery, and clinical outcomes. Arch Intern Med $\underline{168}$ (13), 1430-40

Hidaka C, Goldring MB (2008):

Regulatory Mechanisms of Chondrogenesis and Implications for Understanding Articular Cartilage Homeostasis. Curr Rheumatol Rev 4 (3), 136-147

Ho AD, Wagner W (2007):

The beauty of asymmetry: asymmetric divisions and self-renewal in the haematopoietic system. Curr Opin Hematol 14 (4), 330-6

Hoemann CD, Lafantaisie-Favreau CH, Lascau-Coman V, Chen G, GuzmánMorales J (2012):

The cartilage-bone interface. J Knee Surg 25 (2), 85-97

Horton WE Jr, Bennion P, Yang L (2006):

Cellular, molecular, and matrix changes in cartilage during aging and osteoarthritis. $J$ Musculoskelet Neuronal Interact $\underline{6}$ (4), 379-81

Jackson KA, Mi T, Goodell MA (1999):

Hematopoietic potential of stem cells isolated from murine skeletal muscle. Proc Natl Acad Sci U S A $\underline{96}$ (25), 14482-6

Kern B, Shen J, Starbuck M, Karsenty G (2001):

Cbfa1 contributes to the osteoblast-specific expression of type I collagen genes. J Biol Chem $\underline{276}$ (10), 7101-7

Knoblich JA (2001):

Asymmetric cell division during animal development. Nat Rev Mol Cell Biol $\underline{2}$ (1), 11 20

Koelling S, Miosge N. (2009):

Stem cell therapy for cartilage regeneration in osteoarthritis. Expert Opin Biol Ther. $\underline{9}$ (11), 1399-405 
Koelling S, Kruegel J, Irmer M, Path JR, Sadowski B, Miro X, Miosge N (2009): Migratory chondrogenic progenitor cells from repair tissue during the later stages of human osteoarthritis. Cell Stem Cell 4 (4), 324-35

Koestenbauer S, Zech NH, Dohr G (2006):

Trans-Differenzierung von adulten Stammzellen - Ist eine Veränderung in Richtung naiverer Zellen möglich? J Reproduktionsmed Endokrinol $\underline{3}$ (5), 324-30

Kokai LE, Rubin JP, Marra KG (2005):

The potential of adipose-derived adult stem cells as a source of neuronal progenitor cells. Plast Reconstr Surg 116 (5), 1453-60

Kruse C, Kajahn J, Petschnik AE, Maass A, Klink E, Rapoport DH, Wedel T (2006):

Adult pancreatic stem/progenitor cells spontaneously differentiate in vitro into multiple cell lineages and form teratoma-like structures. Ann Anat $\underline{188}$ (6), 503-17

Kuettner KE (1992):

Biochemistry of articular cartilage in health and disease. Clin Biochem $\underline{25}$ (3), 155163.

Kurien BT, Dorri Y, Dillon S, Dsouza A, Scofield RH (2011):

An overview of Western blotting for determining antibody specificities for immunohistochemistry. Methods Mol Biol $\underline{717}, 55-67$

Lee CC, Kim KD (2012):

Stem cell microenvironment as a potential therapeutic target. Regen Med $\underline{7}$ (1), 3-5

Lepperdinger G (2011):

Inflammation and mesenchymal stem cell aging. Curr Opin Immunol $\underline{23}$ (4), 518-24

Lian JB, Stein GS, Javed A, van Wijnen AJ, Stein JL, Montecino M, Hassan $M Q$, Gaur T, Lengner CJ, Young DW (2006):

Networks and hubs for the transcriptional control of osteoblastogenesis. Rev Endocr Metab Disord $\underline{Z}$ (1-2), 1-16 


\section{Long MW (2001):}

Osteogenesis and bone-marrow-derived cells. Blood Cells Mol Dis $\underline{27}$ (3), 677-90

\section{Luttmann W, Bratke K, Küpper M, Myrtek D:}

Der Experimentator: Immunologie. 3. Auflage; ${ }^{\circledR}$ Spektrum Akademischer Verlag, Heidelberg 2009

Mackay AM, Beck SC, Murphy JM, Barry FP, Chichester CO, Pittenger MF (1998):

Chondrogenic differentiation of cultured human mesenchymal stem cells from marrow. Tissue Eng 4 (4), 415-28

Mafi S, Hindocha S, Mafi R, Griffin M, Khan WS (2011):

Adult mesenchymal stem cells and cell surface characterization - a systematic review of the literature. Open Orthop J $\underline{5}$ (2-M4), 253-260

\section{Mankin HJ, Dorfman H, Lippiello L, Zarins A (1971):}

Biochemical and metabolic abnormalities in articular cartilage from osteo-arthritic human hips. II. Correlation of morphology with biochemical and metabolic data. J Bone Joint Surg Am $\underline{53}$ (3), 523-37

\section{Mareddy S, Crawford R, Brooke G, Xiao Y (2007):}

Clonal isolation and characterization of bone marrow stromal cells from patients with osteoarthritis. Tissue Eng $\underline{13}$ (4), 819-29

\section{Martin GR (1981):}

Isolation of a pluripotent cell line from early mouse embryos cultured in medium conditioned by teratocarcinoma stem cells. Proc. Natl. Acad. Sci. U.S.A. $\underline{78}$ (12), 7634-7638

Méndez-Ferrer S, Michurina TV, Ferraro F, Mazloom AR, Macarthur BD, Lira SA, Scadden DT, Ma'ayan A, Enikolopov GN, Frenette PS (2010):

Mesenchymal and haematopoietic stem cells form a unique bone marrow niche. Nature $\underline{466}$ (7308), 829-34

\section{Miosge N, Hartmann M, Maelicke C, Herken R (2004):}

Expression of collagen type I and type II in consecutive stages of human osteoarthritis. Histochem Cell Biol 122 (3), 229-36 


\section{Muhammad H, Schminke B, Miosge N (2013):}

Current concepts in stem cell therapy for articular cartilage repair. Expert Opin Biol Ther $\underline{13}$ (4), 541-8

\section{Muir H (1995):}

The chondrocyte, architect of cartilage. Biomechanics, structure, function and molecular biology of cartilage matrix macromolecules. Bioessays 17 (12), 1039-48

\section{Muraglia A, Cancedda R, Quarto R (2000):}

Clonal mesenchymal progenitors from human bone marrow differentiate in vitro according to a hierarchical model. J Cell Sci $\underline{113}$ ( Pt 7), 1161-6

\section{Murphy JM, Dixon K, Beck S, Fabian D, Feldman A, Barry F (2002):}

Reduced chondrogenic and adipogenic activity of mesenchymal stem cells from patients with advanced osteoarthritis. Arthritis Rheum $\underline{46}$ (3), 704-13

Nakashima K, Zhou X, Kunkel G, Zhang Z, Deng JM, Behringer RR, de Crombrugghe $B$ (2002):

The novel zinc finger-containing transcription factor osterix is required for osteoblast differentiation and bone formation. Cell $\underline{108}$ (1), 17-29

Oswald J, Boxberger S, Jørgensen B, Feldmann S, Ehninger G, Bornhäuser M, Werner C (2004):

Mesenchymal stem cells can be differentiated into endothelial cells in vitro. Stem Cells $\underline{22}$ (3), 377-84

\section{Owen M, Friedenstein AJ (1988):}

Stromal stem cells: marrow-derived osteogenic precursors. Ciba Found Symp 136, $42-60$

Pittenger MF, Mackay AM, Beck SC, Jaiswal RK, Douglas R, Mosca JD, Moorman MA, Simonetti DW, Craig S, Marshak DR (1999):

Multilineage potential of adult human mesenchymal stem cells. Science $\underline{284}$ (5411), $143-7$

\section{Polesskaya A, Seale P, Rudnicki MA (2003):}

Wnt signaling induces the myogenic specification of resident CD45+ adult stem cells during muscle regeneration. Cell $\underline{113}$ (7), 841-52 
Poole AR (1999):

An introduction to the pathophysiology of osteoarthritis. Front Biosci $\underline{4}, 662-670$

Poole AR, Kojima T, Yasuda T, Mwale F, Kobayashi M, Laverty S (2001):

Composition and structure of articular cartilage: a template for tissue repair. Clin Orthop Relat Res 391, 26-33

\section{Poole CA, Ayad S, Gilbert RT (1992):}

Chondrons from articular cartilage. V. Immunohistochemical evaluation of type VI collagen organisation in isolated chondrons by light, confocal and electron microscopy. J Cell Sci $\underline{103}$ (4), 1101-10

Pritzker KP, Gay S, Jimenez SA, Ostergaard K, Pelletier JP, Revell PA, Salter D, van den Berg WB (2006):

Osteoarthritis cartilage histopathology: grading and staging. Osteoarthritis Cartilage 14 (1), 13-29

Prockop DJ, Sekiya I, Colter DC (2001):

Isolation and characterization of rapidly selfrenewing stem cells from cultures of human marrow stromal cells. Cytotherapy $\underline{3}$ (5), 393-396

Ramgolam K, Lauriol J, Lalou C, Lauden L, Michel L, de la Grange P, Khatib AM, Aoudjit F, Charron D, Alcaide-Loridan C, Al-Daccak R (2011):

Melanoma spheroids grown under neural crest cell conditions are highly plastic migratory/invasive tumor cellsendowed with immunomodulator function. PLoS One $\underline{6}$ (4), e18784

Reya T, Duncan AW, Ailles L, Domen J, Scherer DC, Willert K, Hintz L, Nusse R, Weissman IL (2003):

A role for Wnt signalling in self-renewal of haematopoietic stem cells. Nature $\underline{423}$ (6938), 409-14

Reyes M, Lund T, Lenvik T, Aguiar D, Koodie L, Verfaillie CM (2001):

Purification and ex vivo expansion of postnatal human marrow mesodermal progenitor cells. Blood $\underline{98}$ (9), 2615-25 
Romero-Prado M, Blázquez C, Rodríguez-Navas C, Muñoz J, Guerrero I, Delgado-Baeza E, García-Ruiz JP (2006):

Functional characterization of human mesenchymal stem cells that maintain osteochondral fates. J Cell Biochem $\underline{98}$ (6), 1457-70

Rosen ED, Sarraf P, Troy AE, Bradwin G, Moore K, Milstone DS, Spiegelman BM, Mortensen RM (1999):

PPAR gamma is required for the differentiation of adipose tissue in vivo and in vitro. Mol Cell $\underline{4}(4), 611-7$

Rudert M, Wirth CJ (1998):

Knorpelregeneration und Knorpelersatz. Orthopäde $2 \underline{7}$ (5), 309-321

Sacchetti B, Funari A, Michienzi S, Di Cesare S, Piersanti S, Saggio I, Tagliafico E, Ferrari S, Robey PG, Riminucci M et al. (2007):

Self-renewing osteoprogenitors in bone marrow sinusoids can organize a hematopoietic microenvironment. Cell 131 (2), 324-36

Sandell LJ, Aigner T (2001):

Articular cartilage and changes in arthritis. An introduction: cell biology of osteoarthritis. Arthritis Res $\underline{3}$ (2), 107-13)

Schaefer DJ, Klemt C, Zhang XH, Stark GB (2000):

Tissue Engineering mit mesenchymalen Stammzellen zur Knorpel- und Knochenneubildung. Der Chirurg $\underline{71}$ (9), 1001-1008

Shamblott MJ, Axelman J, Wang S, Bugg EM, Littlefield JW, Donovan PJ, Blumenthal PD, Huggins GR, Gearhart JD (1998):

Derivation of pluripotent stem cells from cultured human primordial germ cells. Proc Natl Acad Sci U S A $\underline{95}$ (23), 13726-31

Song J, Kiel MJ, Wang Z, Wang J, Taichman RS, Morrison SJ, Krebsbach PH (2010):

An in vivo model to study and manipulate the hematopoietic stem cell niche. Blood $\underline{115}$ (13), 2592-600 
Spector JA, Luchs JS, Mehrara BJ, Greenwald JA, Smith LP, Longaker MT (2001):

Expression of bone morphogenetic proteins during membranous bone healing. Plast Reconstr Surg 107 (1), 124-34

Sun HB (2010):

Mechanical loading, cartilage degradation, and arthritis. Ann N Y Acad Sci 1211, 3750

Takahashi K, Tanabe K, Ohnuki M, Narita M, Ichisaka T, Tomoda K, Yamanaka S (2007):

Induction of pluripotent stem cells from adult human fibroblasts by defined factors. Cell $\underline{131}$ (5), 861-72

Takahata M, Awad HA, O'Keefe RJ, Bukata SV, Schwarz EM (2012):

Endogenous tissue engineering: PTH therapy for skeletal repair. Cell Tissue Res $\underline{347}$ (3), 545-52

\section{Tavassoli M (1976):}

Ultrastructural development of bone marrow adipose cell. Acta Anat 94 (1): S. 65-77

Terada N, Hamazaki T, Oka M, Hoki M, Mastalerz DM, Nakano Y, Meyer EM, Morel L, Petersen BE, Scott EW (2002):

Bone marrow cells adopt the phenotype of other cells by spontaneous cell fusion. Nature $\underline{416}$ (6880), 542-5

Tesche F, Miosge N (2005):

New aspects of the pathogenesis of osteoarthritis: the role of fibroblast-like chondrocytes in late stages of the disease. Histol Histopathol $\underline{20}$ (1), 329-37

Thomson JA, Itskovitz-Eldor J, Shapiro SS, Waknitz MA, Swiergiel JJ, Marshall VS, Jones JM (1998):

Embryonic stem cell lines derived from human blastocysts. Science 282 (5391), $1145-1147$

Umlauf D, Frank S, Pap T, Bertrand J (2010):

Cartilage biology, pathology, and repair. Cell Mol Life Sci $\underline{67}$ (24), 4197-211 
Vater C, Kasten P, Stiehler M (2011):

Culture media for the differentiation of mesenchymal stromal cells. Acta Biomater $\underline{7}$ (2), 463-77

von der Mark K, Gauss V, von der Mark H, Müller P (1977):

Relationship between cell shape and type of collagen synthesised as chondrocytes lose their cartilage phenotype in culture. Nature $\underline{267}$ (5611), 531-2

Weiss L (1976):

The hematopoietic microenvironment of the bone marrow: an ultrastructural study of the stroma in rats. Anat Rec $\underline{186}$ (2), 161-84

Willert K, Brown JD, Danenberg E, Duncan AW, Weissman IL, Reya T, Yates JR 3rd, Nusse R (2003):

Wnt proteins are lipid-modified and can act as stem cell growth factors. Nature $\underline{423}$ (6938), 448-52

Woolf AD, Pfleger B (2003):

Burden of major musculoskeletal conditions. Bull World Health Organ $\underline{81}$ (9), 646-56

www.doktor-schubert.net/2011/die-blutbildung (29. Juli 2011):

Schema der Hämatopoese. Modifizierte und übersetzte Version. Im Original von A.Rad auf Wikimedia Commons unter CC-SA-3.0 veröffentlicht.

Ying QL, Nichols J, Evans EP, Smith AG (2002):

Changing potency by spontaneous fusion. Nature $\underline{416}$ (6880), 545-8

Young MF (2003):

Bone matrix proteins: their function, regulation, and relationship to osteoporosis. Osteoporos Int $\underline{14}$ (3), 35-42

\section{Zechner R, Strauss J, Frank S, Wagner E, Hofmann W, Kratky D, Hiden M, Levak-Frank S (2000):}

The role of lipoprotein lipase in adipose tissue development and metabolism. Int $\mathrm{J}$ Obes Relat Metab Disord $\underline{24}$ (4), 53-6 
Zhang J, Niu C, Ye L, Huang H, He X, Tong WG, Ross J, Haug J, Johnson T, Feng JQ et al. (2003):

Identification of the haematopoietic stem cell niche and control of the niche size. Nature $\underline{425}$ (6960), 836-41

Zhu JX, Sasano Y, Takahashi I, Mizoguchi I, Kagayama M (2001):

Temporal and spatial gene expression of major bone extracellular matrix molecules during embryonic mandibular osteogenesis in rats. Histochem J $\underline{33}$ (1), 25-35 


\section{Danksagung}

Ich danke Prof. Dr. med. Nicolai Miosge für die Idee zu dieser Arbeit und die gute Betreuung. Ein besonderer Dank richtet sich auch an Christa Bode, die mir bei Problemen im Labor immer sehr hilfsbereit zur Seite stand. 